\title{
Top 40 questions in coupled human and natural systems (CHANS) research
}

\author{
$\underline{\text { Daniel Boyd Kramer }}^{1}, \underline{\text { Joel Hartter }}^{2}, \underline{\text { Angela E. Boag }}^{2}, \underline{\text { Meha Jain }}^{3}, \underline{\text { Kara Stevens }}^{4}, \underline{\text { Kimberly A. Nicholas }}^{5}, \underline{\text { William J. Mc Connell }}^{6}$
} and Jianguo $\mathrm{Liu}^{7}$

\begin{abstract}
Understanding and managing coupled human and natural systems (CHANS) is a central challenge of the 21st century, but more focus is needed to pursue the most important questions within this vast field given limited research capacity and funding. We present 40 important questions for CHANS research, identified through a two-part crowdsourcing exercise within the CHANS community. We solicited members of the International Network of Research on Coupled Human and Natural Systems (CHANS-Net) to submit up to three questions that they considered transformative, receiving 540 questions from 207 respondents. After editing for clarity and consistency, we asked the network's members to each evaluate a random subset of 20 questions in importance on a scale from 1 (least important) to 7 (extremely important). Questions on land use and agriculture topped the list, with a median importance ranking of 5.7, followed by questions of scale, climate change and energy, sustainability and development, adaptation and resilience, in addition to seven other categories. We identified 40 questions with a median importance of 6.0 or above, which we highlight as the current view of researchers active in the field as research questions to pursue in order to maximize impact on understanding and managing coupled human and natural systems for achieving sustainable development goals and addressing emerging global challenges.
\end{abstract}

Key Words: coupled human and natural systems; horizon scan; human-environment systems; social-ecological systems; sustainability science; top questions

\section{INTRODUCTION}

Coupled human and natural systems (CHANS) are integrated systems where humans and nature interact, e.g., social-ecological systems (SES) or human-environment systems (Liu et al. 2007a). CHANS research is broadly integrative and interdisciplinary across the social and natural sciences and seeks to understand the complexity of human-nature interactions at the heart of many contemporary problems and society's elusive pursuit of sustainability (Turner et al. 2003a). CHANS research is a response to scientific silos, reductionism, and determinism (Michener et al. 2001), a recognition of the reciprocal interactions between human and natural systems that often result in surprise due to thresholds, nonlinearities, lag effects, path dependence, and emergent phenomena across temporal, spatial, and organizational scales (Liu et al. 2007b). This perspective promises insights not easily found using more traditional, less integrative approaches.

A number of analytical features characterize CHANS research. For example, Liu et al. (2007a) note four similarities in a review of six CHANS research projects: (1) attention to feedbacks between CHANS; (2) interdisciplinary research teams; (3) use of methodological tools from diverse disciplines; and (4) longitudinal data collection. Carter et al. (2014) argue for the analytical utility of CHANS research perspectives and in particular awareness of reciprocal relationships and cross-scale interactions in understanding human-wildlife interactions in China and Nepal. Similarly, Seto et al. (2012) introduce urban land teleconnections as an improved analytical approach to understand the processes of urbanization, land change, and their linkages, arguing for more holistic and spatially integrative analyses of what are often treated as distinct knowledge domains. As a final example, Reynolds et al. (2007) advocate for a more synthetic scientific framework to understand and sustainably maintain environmental, economic, and cultural systems of global drylands, emphasizing the coupled nature of such systems, the importance of slow variables and thresholds in driving system dynamics, cross-scale interactions, and the need to maintain local ecological knowledge; each a familiar theme in CHANS research.

Recognizing the complexity of today's sustainability problems and the potential for CHANS perspectives to offer unique insights, increasing investment by scholars, institutions, and funders demonstrates the growing interest in CHANS research. Since the 1972 United Nations Stockholm Conference on the Human Environment placed sustainable development on the global agenda, CHANS research, as indicated by the number of published peer-reviewed articles, has grown substantially (Fig. 1). Published research related to CHANS accelerated concurrently with two major institutional investments in Sweden and the U.S. In 2006, the Swedish Foundation for Strategic Environmental Research (MISTRA) funded the Stockholm Resilience Centre, a leader in research on social-ecological systems. In 2007, the U.S. National Science Foundation (NSF) created the Dynamics of Coupled Natural and Human Systems $(\mathrm{CNH})$ program to fund new interdisciplinary research as a successor to NSF's program on Bio-Complexity in the Environment (Baerwald et al. 2016). Many other countries, regions, and international partnerships have made institutional investments in CHANS-related research (Fig. 2).

Although the importance of CHANS perspectives and research is increasingly recognized (Mooney et al. 2013, Liu et al. 2015), there has not yet been an assessment of the most important CHANS research questions as identified by scholars and

\footnotetext{
${ }^{1}$ Michigan State University, James Madison College and Department of Fisheries \& Wildlife, ${ }^{2}$ Environmental Studies Program, University of Colorado, Boulder, ${ }^{3}$ School of Natural Resources and Environment, University of Michigan, ${ }^{4}$ National Oceanic and Atmospheric Administration, ${ }^{5}$ Lund University Centre for Sustainability Studies, ${ }^{6}$ Center for Global Change and Earth Observations, Michigan State University, ${ }^{7}$ Michigan State University, Center for Systems Integration and Sustainability, Department of Fisheries \& Wildlife
} 
practitioners. Such efforts have recently been undertaken in diverse fields including agriculture (Pretty et al. 2010), paleoecology (Seddon et al. 2014), and biodiversity conservation (Sutherland et al. 2015) and are potentially useful in prioritizing research and directing policy. Here we present such an assessment for CHANS research. We did this by conducting a two-part crowdsourcing exercise within the CHANS community, soliciting members of the International Network of Research on Coupled Human and Natural Systems (CHANS-Net) to submit and then evaluate questions that would "have the biggest impact on understanding and managing coupled human and natural systems" (Appendix 1). Members of CHANS-Net self-identify as active in and familiar with the CHANS field with many having pursued and procured funding for CHANS research, and thus these results may be used to (1) identify the most pressing problems related to CHANS, (2) prioritize CHANS research, and (3) help direct scarce funding and policy attention.

Fig. 1. Number of published CHANS articles per year per 100,000 articles on Web of Science based on search of titles, keywords, and abstracts for (1) CHANS: coupled, human, and nature, systems within five words of each other, and (2) Socioecological systems; socio, ecological OR environment, and systems within five words of each other.

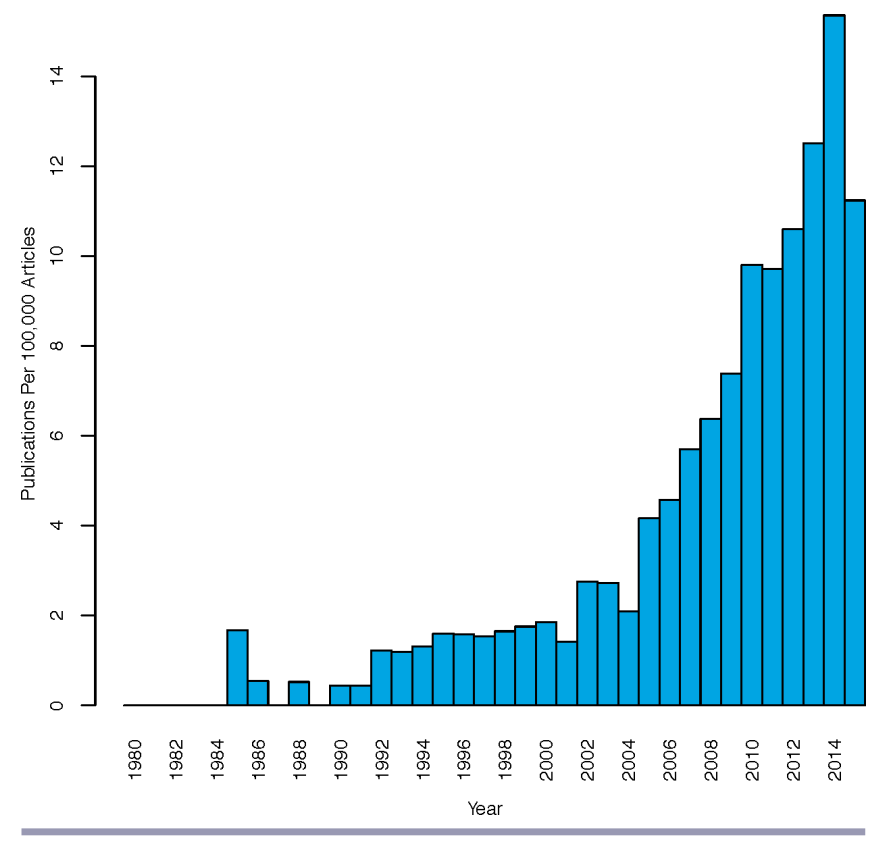

\section{METHODS}

Collecting candidate questions

To first identify and then rank the top questions for CHANS research, we conducted a two-part voluntary, unpaid online survey of the members of CHANS-Net, a U.S. based organization. Membership in CHANS-Net is also voluntary, having been initiated in 2009 by Principal Investigators (PIs) and co-Principal Investigators (co-PIs) of grants from the NSF CNH program and thereafter growing to include members with little or no connection to the CNH Program from many countries. CHANS-Net has organized and sponsored dozens of symposia, workshops, and conference sessions to advance the CHANS community and facilitate communication and collaborations among community members (Liu et al. 2016).

In the first survey (Appendix 1), begun 1 July 2013 and hereafter referred to as the question collection survey, we asked members to submit up to three important questions related to CHANS research. After two reminders, the question collection survey closed on 1 August 2013. We also asked respondents to report whether or not they have been a PI or co-PI on NSF CNH grants, and if so on how many. We asked respondents their primary occupational sector, whether they consider their work strongly inter- or multidisciplinary, which NSF-identified discipline they consider their primary field (National Science Foundation 2013), age, sex, primary nationality, and country of employment.

We received responses from 207 individuals from a member list of 1173 , for a response rate of $17.6 \%$. Four of the coauthors independently determined for each of the 540 questions received (Appendix 2) whether they should be kept, rewritten, or eliminated. Responses were eliminated because they were single words, short phrases, or statements, i.e., rather than questions, or their intent was unclear. Assessments of the submitted questions were discussed among four coauthors until a consensus was reached. Redundant questions were then combined, leaving a final list of 321 distinct questions (Appendix 3) that were lightly edited for spelling, grammar, and clarity.

We undertook a similar process to group questions into 12 categories, working independently and then working toward consensus among all coauthors. The categories were not revealed to respondents of the second survey so as to avoid the possibility of the categories biasing their evaluation.

\section{Evaluating candidate questions}

We developed a second online survey for CHANS-Net members (Appendix 4), hereafter referred to as the question evaluation survey, to evaluate the importance of the final list of 321 questions. Similar to the question collection survey, participation was voluntary with no compensation offered. On 30 June 2015 , we sent the question evaluation survey to the CHANS-Net email distribution list, which by then had grown to 1373 members. While 481 people began the second survey ( $35 \%$ response rate), 352 people completed it including providing question evaluations (26\% response rate). Of the 352 completing the question evaluation survey, 99 had also completed the question collection survey.

The question evaluation survey was developed in Qualtrics, administered through the University of Colorado, Boulder (Qualtrics Labs, Inc., version 12018, Provo, Utah, USA). Because we deemed it too onerous a task for a single participant to evaluate the full question pool $(n=321)$, each participant was presented with 20 randomly selected questions. The Qualtrics randomization algorithm evenly presents the questions for assessment across all surveys started. Therefore, the number of times a question was scored by those who completed a survey (352) followed a normal distribution, ranging from a minimum of 14 to a maximum of 26, with a median of 22 (Appendix 2). Respondents were asked to assess the importance of the questions they saw on a Likert scale from 1 (Not at all Important), to 7 (Extremely Important) and also had the option of not scoring 
Fig. 2. Selected examples of major institutional and research milestones in CHANS research drawn largely from a special journal issue on CHANS, SES, and global change research history (Baerwald et al. 2016, Leemans 2016, Mooney 2016, Pittman et al. 2016, Reid and Mooney 2016). Institutional developments are designated above the timeline. The top 10 cited peer-reviewed papers in CHANS research using the search criteria from Figure 1 are below the timeline.

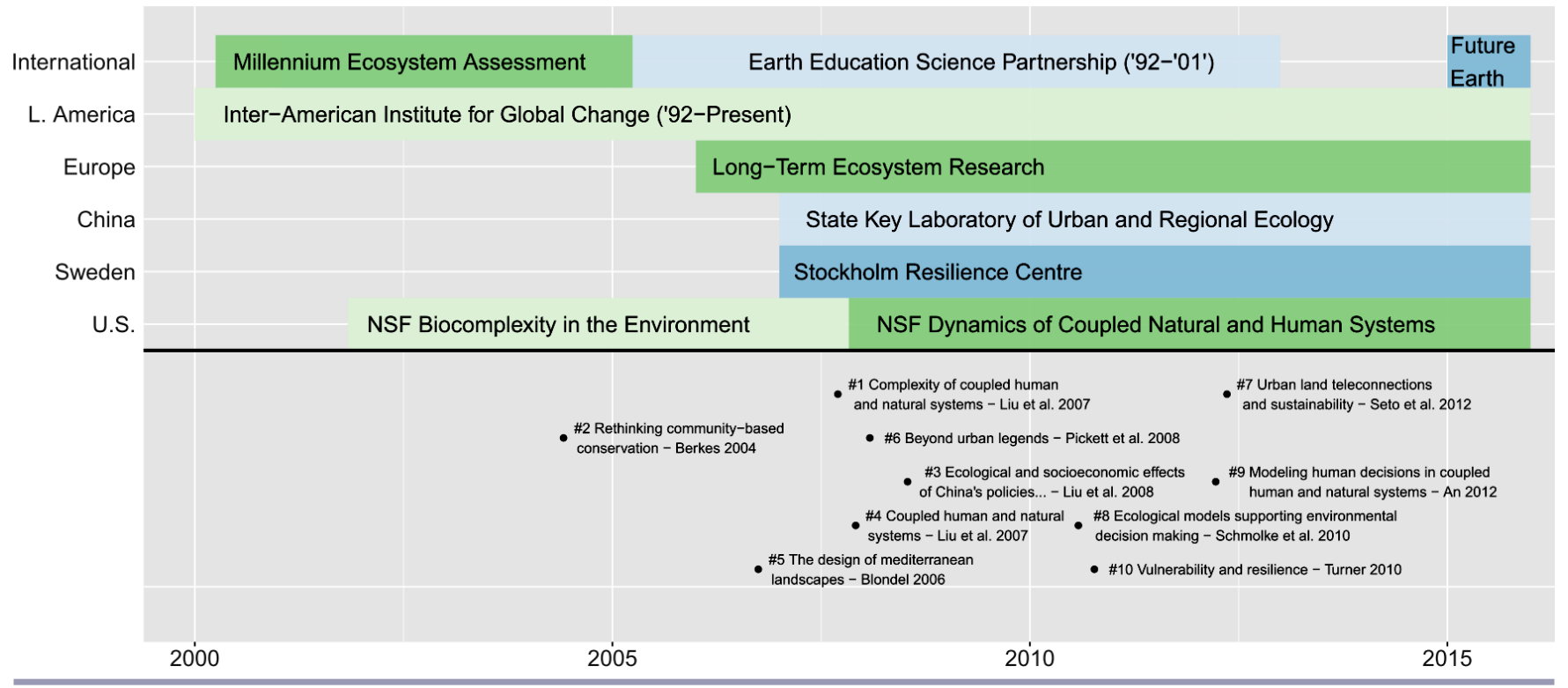

questions, e.g., if they did not find the question clear. We sent four reminders and closed the question evaluation survey on 18 August 2015.

Prior to our analysis, we decided, admittedly arbitrarily, to present the 40 most highly ranked questions. We ordered all questions across categories by mean Likert score and identified the final set of 40 questions by first selecting a subset of questions with mean scores greater than 6.0 (44 questions) and then choosing the top 40 questions of this subset according to minimum score variance, i.e., prioritizing those questions with highest agreement around a high score. Although we recognize the problems related to using the mean as a measure of central tendency for Likert data, we, nevertheless, have done so to distill focus on a tractable number of questions from a large and diverse pool, e.g., to narrow from the 191 questions with a median of 6.0 including all of the top 40 questions we identified. For readers wanting to categorize or order questions in different ways, Appendix 2 lists all questions as well as their categories, number of evaluations, mean, median, variance, and the number of responses for each Likert category. Below, we present the 12 categories of questions in decreasing order of mean question score by category. The listing of questions within categories follows no particular order.

\section{RESULTS}

\section{Survey results}

The mean Likert score across all questions was 5.45 based on a seven-point scale with 170 questions scored at or above the mean and 151 below. The minimum mean question score was 3.75 , and the maximum was 6.36 . Forty-four questions $(14 \%)$ were rated 6.0 or above and 275 questions (86\%) 5.0 or above (Fig. 3).
Fig. 3. Distribution of Likert score across all 321 questions important for coupled human and natural systems research, as rated by 352 question evaluators in the CHANS-Net research group.

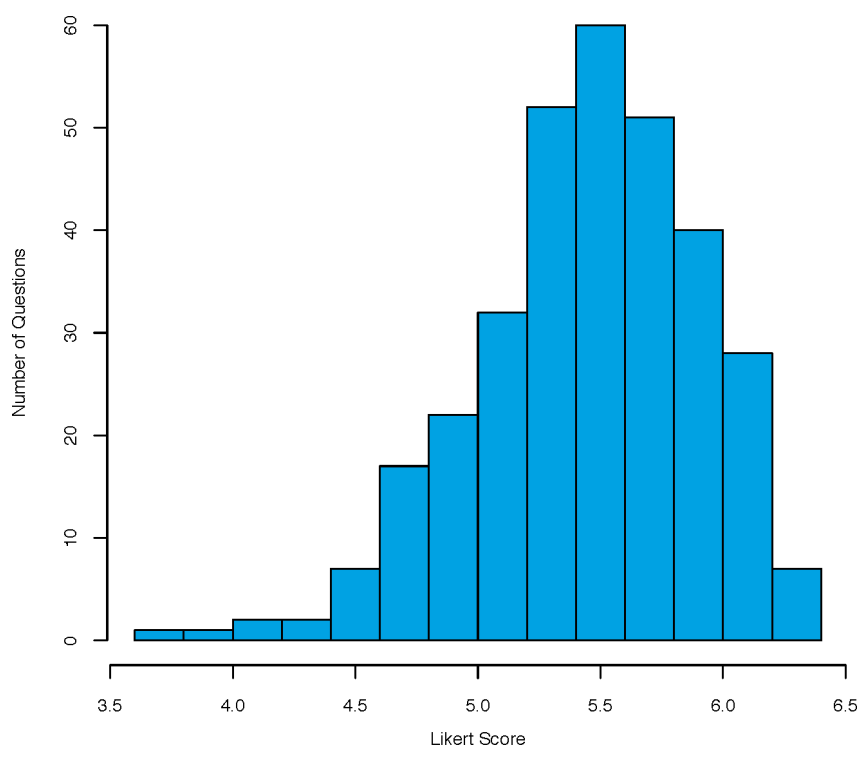

The majority $(61 \%)$ of respondents to the question collection survey, i.e., question originators, shown in blue in Fig. 4, had never been a PI or co-PI on a NSF CNH grant while $39 \%$ of respondents were a PI or co-PI on at least one. Thirty-eight percent of respondents were female. The mean year of birth of respondents 
was 1969. A majority of respondents were North Americans $(76 \%)$ with only $24 \%$ nationals of countries in Africa, AsiaPacific, the Middle East, and South America. An overwhelming percentage of respondents were academics (87\%), who noted their NSF-supported discipline in the broad categories of the social sciences $(46 \%)$, life sciences $(37 \%)$, geosciences $(15 \%)$, and either engineering or computer information and systems engineering (3\%). Nearly all respondents $(94 \%)$ considered their work strongly inter- or multidisciplinary, a distinguishing feature of CHANS research. These percentages were very similar to those from the question evaluation survey (Fig. 4).

Fig. 4. Descriptive statistics on CHANS-Net members who participated in our two surveys to (1) submit important questions (question originators, $\mathrm{N}=207$ ) and (2) to evaluate a subset of 20 of the final 321 questions for their importance (question evaluators, $\mathrm{N}=352$ ).
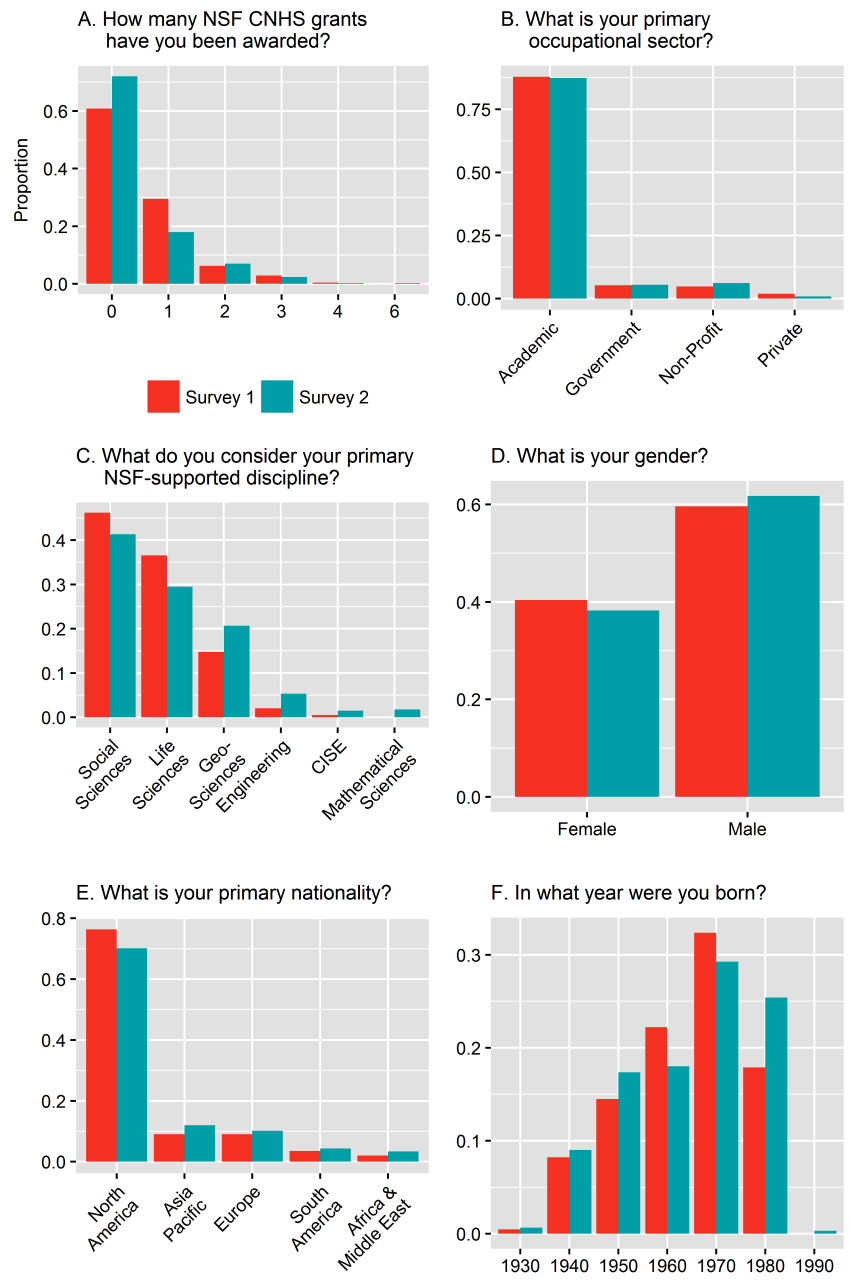

\section{Word cloud analysis}

We present an overview of the 321 questions evaluated, based on the aggregate score given to each word summed across all questions (Fig. 5). In addition to the words indicating CHANS ("human," "natural," "environmental," "systems," "coupled"), we see an emphasis on "change" and key topics like "climate" and "models."
Fig. 5. A word cloud showing the 50 most highly ranked words in the final set of 321 questions sent to the CHANS community for evaluation. The size of each word is weighted by the rank given questions containing that word, aggregated over all questions, disregarding common question words (e.g., how, what).

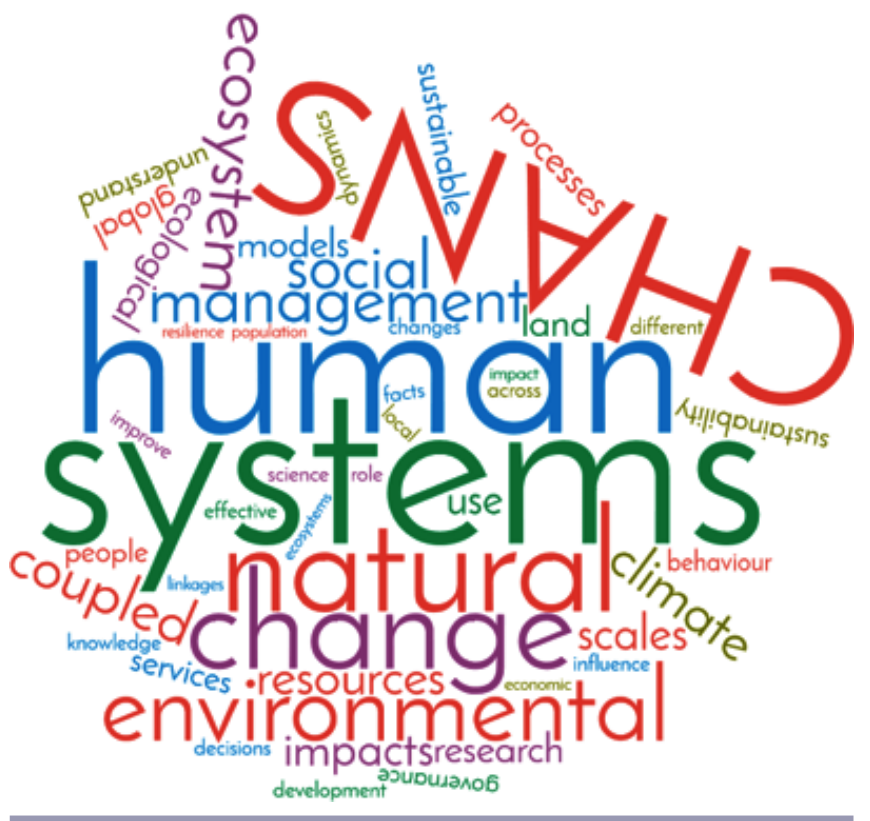

To ascertain if there were any differences in score given to questions within each category, we first calculated the mean score given to each of the 321 questions. We then ranked each category by the median score of these mean values for each question. Among our 12 categories, questions concerning "Land Use \& Agriculture" had the highest median score and questions concerning "Methods" the lowest (Fig. 6).

\section{Top 40 questions by category}

Below, we present the 40 questions ranked most important based on results of the question evaluation survey in order of category importance (Fig. 6), beginning with a short overview of each category.

\section{Land use and agriculture}

Respondents found the most important questions to be those examining the trade-offs inherent in the use of land to produce food and the associated demands on water, energy, and the environment (Foley et al. 2005). Land-use change is a key process underlying the food, water, and energy nexus, a growing research area (FAO 2014, Future Earth 2015, NSF 2015) with each component noted in the five questions below.

- How will climate and other global environmental changes, e.g., water availability, affect agricultural systems in different areas of the world?

- How can we control climate change with demands of increasing food production and increasing energy use?

- What are the environmental and social impacts and underpinnings of a sustainable and just food system? 
- How is the global economy affecting land-use change at regional and finer scales, and how does this land change impact natural systems?

- What characterizes sustainable land-use systems and how can we transition to such systems?

Fig. 6. Ranked categories by median question score from highest to lowest based on 321 final questions. The dark, center line represents the median. The upper and lower edges of the box represent the 25 th and 75 th percentiles, respectively. Dotted lines denote the minimum and maximum values (excluding outliers), and dots indicate outlier questions that are 1.5 times greater than or less than the upper or lower quartile respectively.

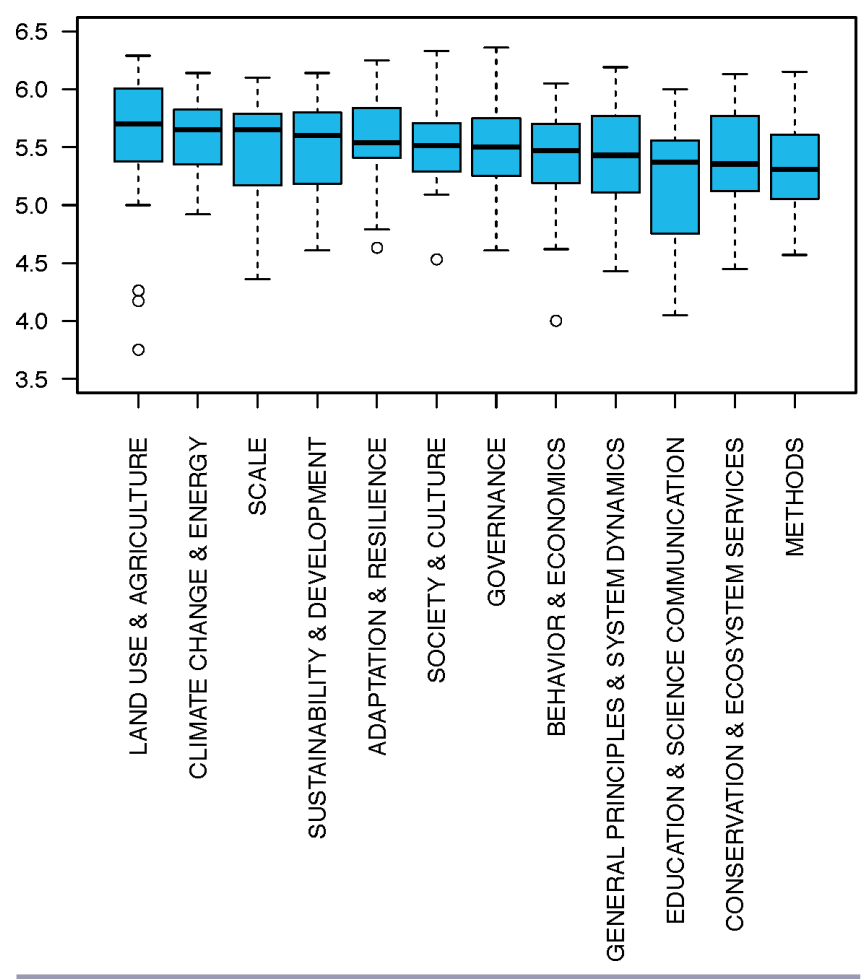

Scale

Human and natural systems and their interactions are complex and heterogeneous. The degree to which this heterogeneity is expressed depends on scale (Pickett and Cadenasso 1995). Understanding processes, causes, effects, and various mitigating factors of human and natural systems across spatial, temporal, and organizational scales is a distinguishing feature of CHANS research. Although the need is apparent, research spanning various scales is itself complex and challenging. Respondents scored two questions highly in this category, one methodological and the other conceptual.

- How can scientists best integrate data, methods, and research designs across multiple spatial and temporal scales?

- What is the role of spatial scale in understanding the coupling between natural and human systems?
Climate change

Climate change introduces great uncertainty and complexity into our modest understanding of CHANS. The effects of climate change are profound for components of both natural and human systems: resource-based livelihoods, ecosystem services, biodiversity, water, energy, and land use (IPCC 2014a). Although exposure to the effects of climate change is universal, the response of human and natural systems is variable because of differences in climate sensitivity, vulnerability, and adaptive capacity (Smit and Wandel 2006, Dawson et al. 2011, IPCC 2014b). The first question in this category provides an example of the CHANS research community's interest in complex, iterative feedbacks. While also suggestive of the potential for climate change to disrupt CHANS, the second question is more specifically focused on natural resource-based livelihoods.

- What are the human consequences of anthropogenic climate change, and how will those human consequences further shape coupled human and natural systems?

- How do we address the complex interlinkages between rural livelihoods and natural resource use in the face of climate variability?

\section{Sustainability and development}

The global agenda for sustainable development is summarized by 17 sustainable development goals (SDGs) and 169 associated targets, released September 2015 (UNDP 2015). Understanding pathways and processes of development is critical to attaining environmental, social, and economic sustainability and addressing these SDGs. The three questions below depict the dualdirectionality of cause and effect between development and environment in CHANS.

- What other global environmental changes besides climate change pose threats to sustainability?

- What alternative pathways of development are available that have a lesser impact on ecosystems and the biosphere?

- How do we couple environmental sustainability with social and economic sustainability?

\section{Adaptation and resilience}

As noted above, global change drivers such as climate change have the potential to disrupt CHANS. Resilience, or "the capacity of a social-ecological system to absorb or withstand perturbations and other stressors such that the system remains within the same regime, essentially maintaining its structure and functions" (Resilience Alliance 2016), depends greatly on the abilities of natural and human systems to adapt. A better understanding of CHANS creates opportunities and insights to assess vulnerability and improve adaptive capacity (Turner et al. 2003b). The questions below ask how we might improve the resilience of both human and natural systems amid the currents of global change.

- How can water management be improved to decrease scarcity, increase security, and make the system less vulnerable?

- How is ecosystem resilience changing with changes in climate, land use, and land cover? 
- How do humans increase their capacity for adaptation to global environmental change?

- How can we best use the reciprocal nature of CHANS to support resilience?

\section{Society and culture}

Along with natural systems, human systems are an important component of the CHANS framework, but they are challenging to understand, model, predict, and integrate into broader conceptual understandings because of the many competing and often conflicting theories on human behavior and societal interactions (Janssen et al. 2015). The questions below position humans as both drivers of environmental change and respondents to these changes.

- How will human population patterns change with ongoing changes in availability of water?

- What are the social drivers at multiple scales of complex CHANS?

- How can we reintegrate humans into our conceptualization and management of "natural" systems?

- What are appropriate and effective methods to bring stakeholders together to address environmental issues?

\section{Governance}

The questions regarding governance suggest a mismatch between CHANS and those regulatory or management systems affecting them (Biermann et al. 2012), reflecting a concern that spatial and temporal processes of natural systems may not be well-integrated with the spatial, e.g., jurisdictions, and temporal, e.g., election cycles, processes of governance. In addition, many systems of governance, e.g., command-and-control, are ill-suited to managing the uncertainties and complex interactions of CHANS (Holling and Meffe 1996). The five questions below ask not only how governance affects CHANS, but how governance can become better at interacting with often complex, uncertain, and variable CHANS.

- How do policies influence human-nature interactions?

- How can social systems and natural life sciences be integrated to better inform each other to make wise use decisions?

- What pathways of governance can work with complexity, feedbacks, and adaptive management?

- How can we design natural resource management approaches that reflect and work with biophysical variability (in time and space)?

- How can resource management practices better integrate ecological resiliency and anticipate disturbance?

\section{Behavior and economics}

Understanding human behavior and decision making is critical to understanding the interactions between human and natural systems. CHANS researchers seek representative models of human behavior and decision making, especially models providing insights into decision making under uncertainty (NSF DMUU 2016). Reflecting maturation in related disciplines, CHANS research seems to be moving beyond rational actor models to utilize insights from behavioral economics, psychology, e.g., prospect theory, sociology, e.g., social networks, and other disciplines. Methodologically, more complex models of decision making lend themselves to agent-based models, a common methodological framework in CHANS research (An 2012). The two questions below suggest a need for better models of human decision-making in the face of uncertainty and as a driver of environmental change.

- How does uncertainty of CHANS affect human decision making?

- What are the drivers of human decision making regarding land-use/land-cover change and natural resources?

General principles and system dynamics

A common theme in CHANS research is that an understanding of feedbacks, thresholds, surprises, nonlinearities, and emergent phenomena, while complicating prediction, is critical to achieving sustainability. The questions below suggest a broad endeavor to identify and understand general principles of complex system dynamics within and across CHANS.

- How do economic and institutional factors interact at multiple scales to influence local conditions?

- How can we understand causation in complex coupled systems?

- How do changes in the environment feedback on individuals, groups, and institutions?

- What characterizes and can we predict tipping points or thresholds in CHANS?

\section{Education and science communication}

Scientists often lament a perceived poor understanding of science, natural systems, natural processes, and anthropogenic influence among the public and policy makers (Weber and Stern 2011). This concern, perhaps owing to the complexities and uncertainties of CHANS, is evident in the two questions below.

- How can the public be educated on the link between extreme events and long-term changes in coupled human and natural systems?

- How can we ensure that interdisciplinary projects that include nonacademic stakeholders become the norm rather than the exception (especially in sustainability science)?

Conservation and ecosystem services

Increasingly, conservation science has attempted to account for the role of people in the conservation of biodiversity from community-based conservation (Berkes 2004) to people-friendly conservation (Marvier and Kareiva 2014) to conservation in working landscapes (Phalan et al. 2011). Similarly, perhaps no other paradigm shift in conservation science in the past 30 years 
eclipses the anthropocentric, ecosystem services framework in importance and influence, reflecting a research agenda that seeks to understand the linkages between ecosystem structure, function, and services with human benefits and values (Potschin and Haines-Young 2011). In addition to offering a bleak assessment of the world's ecosystems, the Millennium Ecosystem Service Assessment (MEA 2005) added conceptual clarity to the linkages between natural and human systems and argued the importance of holistic ecosystem management for long-term sustainability. Not without its critics (e.g., Norgaard 2010), the concept of ecosystem services, the subject of each of the three questions below, fits well within the CHANS perspective because of its explicit linking of human and natural systems.

- What are the linkages between ecosystem services and human well-being?

- How can sustainable ecosystems that are resilient to change and provide ecosystem services for humans be built or managed?

- How can we measure and account for ecosystem services in decisions and connect this to policy-making agendas?

\section{Methods in CHANS research}

A great challenge in CHANS research is to develop analytical methods that effectively capture the interactions between human and natural systems across temporal, spatial, and organizational scales. Challenges include the integration of disparate kinds of data, e.g., biophysical/social, quantitative/qualitative, and analytical representations of complex ecological, e.g., climate change, and social processes, e.g., social learning. Each of the questions below pertains to the representation of complex social or ecological processes in CHANS models.

- How can we incorporate behavior, tipping points, emergent properties, and regime shifts, especially for ecosystem function and social organizations, in CHANS models?

- How can we better represent social systems and processes in CHANS models?

- How can we best represent human decisions, behavior, and human-built elements of natural systems in coupled process models?

- How can we design social-ecological research that is relevant to the social communities affected by ecosystem processes?

\section{DISCUSSION}

The fields of conservation biology (Sutherland et al. 2013, 2014, 2015), agricultural science (Pretty et al. 2010), marine biology (Parsons et al. 2014), plant ecology (Grierson et al. 2011), and others (Seddon et al. 2014) have generated similar "top questions" to focus each community's research efforts, spark discussion, and build stronger links between research and policy. Reviewing these efforts, we find similarities to the top questions identified here as well as some distinctions.

Similar to results from horizon-scanning efforts in plant ecology and marine biology, we identified effective methods of public engagement or education as a concern in our top questions (Grierson et al. 2011, Parsons et al. 2014). Horizon scans in plant ecology, conservation biology, and agriculture identified a top question focused on the challenge of feeding billions in an environmentally sustainable and socially just way, noted in our top questions as well (Sutherland et al. 2009, Pretty et al. 2010, Grierson et al. 2011). Furthermore, there was much overlap with other disciplines around resilience, such as studying how ecosystem resilience is changing and how we can build or maintain resilient systems (Sutherland et al. 2009, Pretty et al. 2010, Seddon et al. 2014). Finally, interdisciplinarity, a hallmark of CHANS research and identified in the CHANS top questions, was also the focus of top questions from similar reviews in marine conservation and agricultural science, identifying a need for more learning and collaboration across disciplines (Pretty et al. 2010, Parsons et al. 2014).

The set of 40 top CHANS questions presented here are unique relative to similar such question identification exercises in the environment-related sciences in the prevalence of those emphasizing how humans would be affected by and adapt to global environmental change, how human population patterns will change with water availability, and how ecosystem services affect human well-being. This demonstrates a distinguishing aspect of CHANS research, feedbacks in which humans influence natural systems but are also affected by them (Liu et al. 2007a).

\section{Limitations}

Any endeavor seeking to identify or rank the most important research questions in a research field is fraught with methodological and conceptual difficulties. This is true of our efforts as well. Our results are based on questions submitted and evaluated by members of a self-selected set of respondents from among members of CHANS-Net, a self-selected network of CHANS researchers. Although the characteristics of respondents to both surveys were very similar, suggesting some correspondence with the underlying CHANS-Net population, CHANS-Net does not collect this information from its members, and therefore we were unable to assess representativeness. Therefore, respondents, a majority of which were male, North American, employed in academia, and identified with the social sciences, life sciences, and geosciences may not be representative of CHANS-Net members nor the broader CHANS community. Thus, caution is warranted in inferring that our results are representative of the views of the undoubtedly more extensive, more diverse, and more global CHANS community. Furthermore, with regard to the question evaluation survey, it is likely that CHANS-Net respondents, despite a great majority of them characterizing their work as inter- or multidisciplinary, were evaluating questions outside their primary field of expertise potentially affecting their evaluations because of bias or unfamiliarity.

Conceptually, we acknowledge that the questions reviewed here represent the current views of CHANS-Net members. The task of generating truly innovative, transformative, future-orientated questions is difficult. Innovation and imagination are rarely products of consensus. Similarly, emerging issues may be relatively unknown among the community. For example, there seems to be increasing research interest in telecoupling, socioeconomic and environmental interactions between distant CHANS through international trade, migration, knowledge dissemination, technology transfer, and payments for ecosystem 
services (e.g. Liu et al. 2013, Gasparri et al. 2016, Hulina et al. 2017). Telecoupling, however, was not mentioned in our top 40 questions. Still, despite these difficulties, our efforts to identify the top CHANS-related research questions represent a first assessment of the views of the CHANS community, a worthwhile endeavor we hope continues periodically with increased attention to the limitations of such exercises and exploration of other methods to identify important questions.

\section{CONCLUSION}

We hope the 40 research questions presented in this paper are a useful contribution to researchers, funders, and policy makers in identifying current research ideas and directions, targeting funding investments, and identifying policy needs related to understanding and managing CHANS. As noted above, the CHANS perspective is in part a response to the increased complexity, interconnectedness, and potential for rapid and unexpected change in the world. As such, CHANS research is challenging, requiring scientists to move beyond scientific silos; to collaborate with those adopting different methods, perspectives, and terminology; and to maintain careful and detailed examination of localized phenomena while considering broader temporal, spatial, and organizational scales. These challenges, reflected in the questions presented here and discussed in depth elsewhere (Gershon 2000, Rylance 2015, Van Noorden 2015, Brown et al. 2016), are part of a larger effort to retool and to rethink our approach to meet the goal of sustainability on an increasingly complex and connected planet.

Responses to this article can be read online at: http://www.ecologyandsociety.org/issues/responses. php/9429

\section{Acknowledgments:}

The authors thank CHANS-Net for providing access to their member list as well as CHANS-Net members for their participation in the crowd-sourcing exercise described above. This collaboration was begun at a CHANS working group in 2012, where KAN and $M J$ were CHANS Fellows, part of the International Network of Research on Coupled Human and Natural Systems, which is sponsored by the National Science Foundation and coordinated by the Center for Systems Integration and Sustainability at Michigan State University. We thank Theo Aalders for assistance with Figure 4.

\section{LITERATURE CITED}

An, L. 2012. Modeling human decisions in coupled human and natural systems: review of agent-based models. Ecological Modelling 229:25-36. http://dx.doi.org/10.1016/j.ecolmodel.2011.07.010

Baerwald, T. J., P. L. Firth, and S. L. Ruth. 2016. The dynamics of coupled natural and human systems program at the U.S. National Science Foundation: lessons learned in interdisciplinary funding program development and management. Current Opinion in Environmental Sustainability 19:123-133. http://dx.doi. org/10.1016/j.cosust.2016.02.001
Berkes, F. 2004. Rethinking community-based conservation. Conservation Biology 18(3):621-630. http://dx.doi.org/10.1111/ j.1523-1739.2004.00077.x

Biermann, F., K. Abbott, S. Andresen, K. Bäckstrand, S. Bernstein, M. M. Betsill, H. Bulkeley, B. Cashore, J. Clapp, C. Folke, A. Gupta, J. Gupta, P. M. Haas, A. Jordan, N. Kanie, T. Kluvánková-Oravská, L. Lebel, D. Liverman, J. Meadowcroft, R. B. Mitchell, P. Newell, S. Oberthür, L. Olsson, P. Pattberg, R. Sánchez-Rodríguez, H. Schroeder, A. Underdal, S. C. Vieira, C. Vogel, O. R. Young, A. Brock, and R. Zondervan. 2012. Navigating the Anthropocene: improving earth system governance. Science 335(6074):1306-1307. http://dx.doi.org/10.1126/ science. 1217255

Blondel, J. 2006. The 'design' of Mediterranean landscapes: a millennial story of humans and ecological systems during the historic period. Human Ecology 34(5):713-729. http://dx.doi. org/10.1007/s10745-006-9030-4

Brown, R., A. Deletic, and T. H. F. Wong. 2016. How to catalyse collaboration. Nature 525:7-9.

Carter, N. H., A. Viña, V. Hull, W. J. McConnell, W. Axinn, D. Ghimire, and J. Liu. 2014. Coupled human and natural systems approach to wildlife research and conservation. Ecology and Society 19(3):43. http://dx.doi.org/10.5751/es-06881-190343

Dawson, T. P., S. T. Jackson, J. I. House, I. C. Prentice, and G. M. Mace. 2011. Beyond predictions: biodiversity conservation in a changing climate. Science 332(6025):53-58. http://dx.doi. org/10.1126/science. 1200303

Foley, J. A., R. Defries, G. P. Asner, C. Barford, G. Bonan, S. R. Carpenter, F. S. Chapin, M. T. Coe, G. C. Daily, H. K. Gibbs, J. H. Helkowski, T. Holloway, E. A. Howard, C. J. Kucharik, C. Monfreda, J. A. Patz, I. C. Prentice, N. Ramankutty, and P. K. Snyder. 2005. Global consequences of land use. Science 309 (5734):570-574. http://dx.doi.org/10.1126/science.1111772

Food and Agriculture Organization of the United Nations (FAO). 2014. The water, energy, and food nexus: a new approach in support of food security and sustainable agriculture. FAO, Rome, Italy.

Future Earth. 2015. Future Earth 2025 Vision. Future Earth, Paris, France.

Gasparri, N. I., T. Kuemmerle, P. Meyfroidt, Y. le Polain de Waroux, and H. Kreft. 2016. The emerging soybean production frontier in Southern Africa: conservation challenges and the role of south-south telecouplings. Conservation Letters 9(1):21-31. http://dx.doi.org/10.1111/conl.12173

Gershon, D. 2000. Pushing the frontiers of interdisciplinary research: an idea whose time has come. Nature 404(6775):313-315. http://dx.doi.org/10.1038/35005213

Grierson, C. S., S. R. Barnes, M. W. Chase, M. Clarke, D. Grierson, K. J. Edwards, G. J. Jellis, J. D. Jones, S. Knapp, G. Oldroyd, G. Poppy, P. Temple, R. Williams, and R. Bastow. 2011. One hundred important questions facing plant science research. New Phytologist 192(1):6-12. http://dx.doi.org/10.1111/ j.1469-8137.2011.03859.x

Holling, C. S., and G. K. Meffe. 1996. Command and control and the pathology of natural resource management. Conservation 
Biology 10(2):328-337. http://dx.doi.org/10.1046/ j.1523-1739.1996.10020328.x

Hulina, J., C. Bocetti, H. Campa III, V. Hull, W. Yang, and J. Liu. 2017. Telecoupling framework for research on migratory species in the Anthropocene. Elementa Science of the Anthropocene 5(5). http://dx.doi.org/10.1525/elementa.184

Intergovernmental Panel on Climate Change (IPCC). $2014 b$. Climate change 2014: impacts, adaptation, and vulnerability. Part A: global and sectoral aspects. Contribution of Working Group II to the Fifth Assessment Report of the Intergovernmental Panel on Climate Change Cambridge University Press, Cambridge, UK.

Intergovernmental Panel on Climate Change (IPCC). $2014 a$. Climate change 2014: synthesis report. Contribution of Working Groups I, II and III to the Fifth Assessment Report of the Intergovernmental Panel on Climate Change. Core Writing Team, R. K. Pachauri, and L. A. Meyer, editors. IPCC, Geneva, Switzerland.

Janssen, M. A., T. Lindahl, and J. J. Murphy. 2015. Advancing the understanding of behavior in social-ecological systems: results from lab and field experiments. Ecology and Society 20 (4):34. http://dx.doi.org/10.5751/es-08097-200434

Leemans, R. 2016. The lessons learned from shifting from globalchange research programmes to transdisciplinary sustainability science. Current Opinion in Environmental Sustainability 19:103-110. http://dx.doi.org/10.1016/j.cosust.2016.01.001

Liu, J., T. Dietz, S. R. Carpenter, M. Alberti, C. Folke, E. Moran, A. N. Pell, P. Deadman, T. Kratz, J. Lubchenco, E. Ostrom, Z. Ouyang, W. Provencher, C. L. Redman, S. H. Schneider, and W. W. Taylor. 2007a. Complexity of coupled human and natural systems. Science 317(5844):1513-1516. http://dx.doi.org/10.1126/ science. 1144004

Liu, J., T. Dietz, S. R. Carpenter, C. Folke, M. Alberti, C. L. Redman, S. H. Schneider, E. Ostrom, A. N. Pell, J. Lubchenco, W. W. Taylor, Z. Ouyang, P. Deadman, T. Kratz, and W. Provencher. 2007b. Coupled human and natural systems. Ambio 36(8):639-649. http://dx.doi.org/10.1579/0044-7447(2007)36[639: CHANS]2.0.CO;2

Liu, J., V. Hull, M. Batistella, R. DeFries, T. Dietz, F. Fu, T. W. Hertel, R. C. Izaurralde, E. F. Lambin, S. Li, L. A. Martinelli, W. J. McConnell, E. F. Moran, R. Naylor, Z. Ouyang, K. R. Polenske, A. Reenberg, G. de Miranda Rocha, C. S. Simmons, P. H. Verburg, P. M. Vitousek, F. Zhang, and C. Zhu. 2013. Framing sustainability in a telecoupled world. Ecology and Society 18 (2):26. http://dx.doi.org/10.5751/es-05873-180226

Liu, J., V. Hull, W. Yang, A. Viña, L. An, N. Carter, X. Chen, W. Liu, Z. Ouyang, and H. Zhang. 2016. Lessons from local studies for global sustainability. Pages 240-252 in J. Liu, V. Hull, W. Yang, A. Viña, X. Chen, Z. Ouyang, and H. Zhang, editors. Pandas and people: coupling human and natural systems for sustainability. First edition. Oxford University Press, Oxford, UK. http://dx.doi. org/10.1093/acprof:oso/9780198703549.003.0018

Liu, J., S. Li, Z. Ouyang, C. Tam, and X. Chen. 2008. Ecological and socioeconomic effects of China's policies for ecosystem services. Proceedings of the National Academy of Sciences of the United States of America 105(28):9477-9482. http://dx.doi. org/10.1073/pnas.0706436105
Liu, J., H. Mooney, V. Hull, S. J. Davis, J. Gaskell, T. Hertel, J. Lubchenco, K. C. Seto, P. Gleick, C. Kremen, and S. Li. 2015. Systems integration for global sustainability. Science 347 (6225):1258832-1258832. http://dx.doi.org/10.1126/science.1258832

Marvier, M., and P. Kareiva. 2014. The evidence and values underlying 'new conservation.' Trends in Ecology and Evolution 29(3):131-132. http://dx.doi.org/10.1016/j.tree.2014.01.005

Michener, W. K., T. J. Baerwald, P. Firth, M. A. Palmer, J. L. Rosenberger, E. A. Sandlin, and H. Zimmerman. 2001. Defining and unraveling biocomplexity. BioScience 51(12):1018-1023. http://dx.doi.org/10.1641/0006-3568(2001)051[1018:DAUB]2.0.CO;2

Millennium Ecosystem Assessment (MEA). 2005. Ecosystems and human well-being: synthesis. Island Press, Washington, D.C., USA.

Mooney, H. 2016. Editorial overview: sustainability science: social-environmental systems (SES) research: how the field has developed and what we have learned for future efforts. Current Opinion in Environmental Sustainability 19:v-xii. http://dx.doi. org/10.1016/j.cosust.2016.05.002

Mooney, H. A., A. Duraiappah, and A. Larigauderie. 2013. Evolution of natural and social science interactions in global change research programs. Proceedings of the National Academy of Sciences of the United States of America 110 Suppl 1:3665-3672. http://dx.doi.org/10.1073/pnas. 1107484110

National Science Foundation of the United States. 2013. Research areas. National Science Foundation, Arlington, Virginia, USA. [online] URL: https://www.nsf.gov/about/research_areas.jsp

National Science Foundation of the United States. 2015. Innovations at the nexus of food, energy, and water systems (INFEWS). National Science Foundation, Arlington, Virginia, USA.

National Science Foundation of the United States (NSF DMUU). 2016. Decision making under uncertainty collaborative groups (DMUU). National Science Foundation, Arlington, Virginia, USA. [online] URL: https://www.nsf.gov/funding/ pgm_summ.jsp?pims_id=503374

Norgaard, R. B. 2010. Ecosystem services: from eye-opening metaphor to complexity blinder. Ecological Economics 69 (6):1219-1227. http://dx.doi.org/10.1016/j.ecolecon.2009.11.009

Parsons, E. C. M., B. Favaro, A. A. Aguirre, A. L. Bauer, L. K. Blight, J. A. Cigliano, M. A. Coleman, I. M. Côté, M. Draheim, S. Fletcher, M. M. Foley, R. Jefferson, M. C. Jones, B. P. Kelaher, C. J. Lundquist, J. B. Mccarthy, A. Nelson, K. Patterson, L. Walsh, A. J. Wright, and W. J. Sutherland. 2014. Seventy-one important questions for the conservation of marine biodiversity. Conservation Biology 28(5):1206-1214. http://dx.doi.org/10.1111/ cobi. 12303

Phalan, B., M. Onial, A. Balmford, and R. E. Green. 2011. Reconciling food production and biodiversity conservation: land sharing and land sparing compared. Science 333(6047):1289-1291. http://dx.doi.org/10.1126/science. 1208742

Pickett, S. T. A., and M. L. Cadenasso. 1995. Landscape ecology: spatial heterogeneity in ecological systems. Science 269 (5222):331-334. http://dx.doi.org/10.1126/science.269.5222.331 
Pickett, S. T. A., M. L. Cadenasso, J. M. Grove, P. M. Groffman, L. E. Band, C. G. Boone, W. R. Burch, C. S. B. Grimmond, J. Hom, J. C. Jenkins, N. L. Law, C. H. Nilon, R. V. Pouyat, K. Szlavecz, P. S. Warren, and M. A. Wilson. 2008. Beyond urban legends: an emerging framework of urban ecology, as illustrated by the Baltimore Ecosystem Study. BioScience 58(2):139. http:// dx.doi.org/10.1641/b580208

Pittman, J., H. Tiessen, and E. Montaña. 2016. The evolution of interdisciplinarity over 20 years of global change research by the IAI. Current Opinion in Environmental Sustainability 19:87-93. http://dx.doi.org/10.1016/j.cosust.2015.12.004

Potschin, M. B., and R. H. Haines-Young. 2011. Ecosystem services: exploring a geographical perspective. Progress in Physical Geography 35(5):575-594. http://dx.doi. org/10.1177/0309133311423172

Pretty, J., W. J. Sutherland, J. Ashby, J. Auburn, D. Baulcombe, M. Bell, J. Bentley, S. Bickersteth, K. Brown, J. Burke, H. Campbell, K. Chen, E. Crowley, I. Crute, D. Dobbelaere, G. Edwards-Jones, F. Funes-Monzote, H. C. J. Godfray, M. Griffon, P. Gypmantisiri, L. Haddad, S. Halavatau, H. Herren, M. Holderness, A.-M. Izac, M. Jones, P. Koohafkan, R. Lal, T. Lang, J. McNeely, A. Mueller, N. Nisbett, A. Noble, P. Pingali, Y. Pinto, R. Rabbinge, N. H. Ravindranath, A. Rola, N. Roling, C. Sage, W. Settle, J. M. Sha, L. Shiming, T. Simons, P. Smith, K. Strzepeck, H. Swaine, E. Terry, T. P. Tomich, C. Toulmin, E. Trigo, S. Twomlow, J. K. Vis, J. Wilson, and S. Pilgrim. 2010. The top 100 questions of importance to the future of global agriculture. International Journal of Agricultural Sustainability 8(4):219-236. http://dx.doi.org/10.3763/ijas.2010.0534

Reid, W. V., and H. A. Mooney. 2016. The Millennium Ecosystem Assessment: testing the limits of interdisciplinary and multi-scale science. Current Opinion in Environmental Sustainability 19:40-46. http://dx.doi.org/10.1016/j.cosust.2015.11.009

Resilience Alliance. 2016. Resilience. [online] URL: http://www. resalliance.org/resilience

Reynolds, J. F., D. M. Stafford Smith, E. F. Lambin, B. L. Turner II, M. Mortimore, S. P. J. Batterbury, T. E. Downing, H. Dowlatabadi, R. J. Fernández, J. E. Herrick, E. Huber-Sannwald, H. Jiang, R. Leemans, T. Lynam, F. T. Maestre, M. Ayarza, and B. Walker. 2007. Global desertification: building a science for dryland development. Science 316(5826):847-851. http://dx.doi. org/10.1126/science.1131634

Rylance, R. 2015. Global funders to focus on interdisciplinarity. Nature 525:313-315. http://dx.doi.org/10.1038/525313a

Schmolke, A., P. Thorbek, D. L. DeAngelis, and V. Grimm. 2010. Ecological models supporting environmental decision making: a strategy for the future. Trends in Ecology and Evolution 25 (8):479-486. http://dx.doi.org/10.1016/j.tree.2010.05.001

Seddon, A. W. R., A. W. Mackay, A. G. Baker, H. J. B. Birks, E. Breman, C. E. Buck, E. C. Ellis, C. A. Froyd, J. L. Gill, L. Gillson, E. A. Johnson, V. J. Jones, S. Juggins, M. Macias-Fauria, K. Mills, J. L. Morris, D. Nogués-Bravo, S. W. Punyasena, T. P. Roland, A. J. Tanentzap, K. J. Willis, M. Aberhan, E. N. van Asperen, W. E. N. Austin, R. W. Battarbee, S. Bhagwat, C. L. Belanger, K. D.
Bennett, H. H. Birks, C. Bronk Ramsey, S. J. Brooks, M. de Bruyn, P. G. Butler, F. M. Chambers, S. J. Clarke, A. L. Davies, J. A. Dearing, T. H. G. Ezard, A. Feurdean, R. J. Flower, P. Gell, S. Hausmann, E. J. Hogan, M. J. Hopkins, E. S. Jeffers, A. A. Korhola, R. Marchant, T. Kiefer, M. Lamentowicz, I. LarocqueTobler, L. López-Merino, L. H. Liow, S. Mcgowan, J. H. Miller, E. Montoya, O. Morton, S. Nogué, C. Onoufriou, L. P. Boush, F. Rodriguez-Sanchez, N. L. Rose, C. D. Sayer, H. E. Shaw, R. Payne, G. Simpson, K. Sohar, N. J. Whitehouse, J. W. Williams, and A. Witkowski. 2014. Looking forward through the past: identification of 50 priority research questions in palaeoecology. Journal of Ecology 102(1):256-267. http://dx.doi. org/10.1111/1365-2745.12195

Seto, K. C., A. Reenberg, C. G. Boone, M. Fragkias, D. Haase, T. Langanke, P. Marcotullio, D. K. Munroe, B. Olah, and D. Simon. 2012. Urban land teleconnections and sustainability. Proceedings of the National Academy of Sciences of the United States of America 109(20):7687-7692. http://dx.doi.org/10.1073/ pnas. 1117622109

Smit, B., and J. Wandel. 2006. Adaptation, adaptive capacity and vulnerability. Global Environmental Change 16(3):282-292. http:// dx.doi.org/10.1016/j.gloenvcha.2006.03.008

Sutherland, W. J., W. M. Adams, R. B. Aronson, R. Aveling, T. M. Blackburn, S. Broad, G. Ceballos, I. M. Côté, R. M. Cowling, G. A. B. Da Fonseca, E. Dinerstein, P. J. Ferraro, E. Fleishman, C. Gascon, M. Hunter, J. Hutton, P. Kareiva, A. Kuria, D. W. Macdonald, K. Mackinnon, F. J. Madgwick, M. B. Mascia, J. McNeely, E. J. Milner-Gulland, S. Moon, C. G. Morley, S. Nelson, D. Osborn, M. Pai, E. C. M. Parsons, L. S. Peck, H. Possingham, S. V Prior, A. S. Pullin, M. R. W. Rands, J. Ranganathan, K. H. Redford, J. P. Rodriguez, F. Seymour, J. Sobel, N. S. Sodhi, A. Stott, K. Vance-Borland, and A. R. Watkinson. 2009. One hundred questions of importance to the conservation of global biological diversity. Conservation Biology 23(3):557-567. http:// dx.doi.org/10.1111/j.1523-1739.2009.01212.x

Sutherland, W. J., S. Bardsley, M. Clout, M. H. Depledge, L. V. Dicks, L. Fellman, E. Fleishman, D. W. Gibbons, B. Keim, F. Lickorish, C. Margerison, K. A. Monk, K. Norris, L. S. Peck, S. V. Prior, J. P. W. Scharlemann, M. D. Spalding, and A. R. Watkinson. 2013. A horizon scan of global conservation issues for 2013. Trends in Ecology and Evolution 28(1):16-22. http://dx. doi.org/10.1016/j.tree.2012.10.022

Sutherland, W. J., R. Aveling, T. M. Brooks, M. Clout, L. V. Dicks, L. Fellman, E. Fleishman, D. W. Gibbons, B. Keim, F. Lickorish, K. A. Monk, D. Mortimer, L. S. Peck, J. Pretty, J. Rockström, J. P. Rodríguez, R. K. Smith, M. D. Spalding, F. H. Tonneijck, and A. R. Watkinson. 2014. A horizon scan of global conservation issues for 2014. Trends in Ecology and Evolution 29(1):15-22. http://dx.doi.org/10.1016/j.tree.2013.11.004

Sutherland, W. J., M. Clout, M. Depledge, L. V. Dicks, J. Dinsdale, A. C. Entwistle, E. Fleishman, D. W. Gibbons, B. Keim, F. A. Lickorish, K. A. Monk, N. Ockendon, L. S. Peck, J. Pretty, J. Rockström, M. D. Spalding, F. H. Tonneijck, and B. C. Wintle. 2015. A horizon scan of global conservation issues for 2015. Trends in Ecology and Evolution 30(1):17-24. http://dx.doi. org/10.1016/j.tree.2014.11.002 
Turner, B. L., II 2010. Vulnerability and resilience: coalescing or paralleling approaches for sustainability science? Global Environmental Change 20(4):570-576. http://dx.doi.org/10.1016/ j.gloenvcha.2010.07.003

Turner, B. L., II, R. E. Kasperson, P. A. Matson, J. J. McCarthy, R. W. Corell, L. Christensen, N. Eckley, J. X. Kasperson, A. Luers, M. L. Martello, C. Polsky, A. Pulsipher, and A. Schiller. $2003 a$. A framework for vulnerability analysis in sustainability science. Proceedings of the National Academy of Sciences of the United States of America 100(14):8074-8079. http://dx.doi.org/10.1073/ pnas. 1231335100

Turner, B. L., II, P. A. Matson, J. J. McCarthy, R. W. Corell, L. Christensen, N. Eckley, G. K. Hovelsrud-Broda, J. X. Kasperson, R. E. Kasperson, A. Luers, M. L. Martello, S. Mathiesen, R. Naylor, C. Polsky, A. Pulsipher, A. Schiller, H. Selin, and N. Tyler. $2003 \mathrm{~b}$. Illustrating the coupled human-environment system for vulnerability analysis: three case studies. Proceedings of the National Academy of Sciences of the United States of America 100(14):8080-8085. http://dx.doi.org/10.1073/pnas.1231334100

United Nations Development Programme (UNDP). 2015. Sustainable development goals. UNDP, New York, New York, USA.

Van Noorden, R. 2015. Interdisciplinary research by the numbers. Nature 525:306-307. http://dx.doi.org/10.1038/525306a

Weber, E. U., and P. C. Stern. 2011. Public understanding of climate change in the United States. American Psychologist 66 (4):315-328. http://dx.doi.org/10.1037/a0023253 


\section{Appendix 1: Question collection survey and consent document.}

Thank you for agreeing to complete the survey below.

Based on your membership in CHANS-Net, you are invited to participate in a research project that seeks to elevate awareness of Coupled Human and Natural Systems (CHANS) research and prioritize future scientific efforts for CHANS research. Examples of CHANS include socialecological systems, coupled human-environmental systems, and population-environment systems. The survey below consists of 10 questions and will take approximately 10 minutes to complete. Survey results will be compiled and analyzed to highlight trends in the key directions for the future of CHANS research. The CHANS community will be notified when the results of the analysis are available.

Regarding privacy and confidentiality of responses, your responses are anonymous and will not be shared with anyone else, in publications, or in presentations. Furthermore, your participation is voluntary. You may refuse to participate in certain questions or discontinue your participation at any time without consequence.

If you have concerns or questions, please contact Dr. Daniel Kramer at the Department of Fisheries and Wildlife at Michigan State University (dbk@msu.edu, +1(517) 432-2199).

If you have questions or concerns about your role and rights as a research participant or would like to register a complaint about this study, you may contact the Michigan State University's Human Research Protection Program (517-355-2180, Fax 517-432-4503, or e-mail irb@msu.edu).

You are providing your voluntary consent to participate in this research by beginning the survey below.

Thank you again for your time and thoughtfulness. 
1. What are the transformative questions to address in order to have the biggest impact on understanding and managing coupled human and natural systems?

\#1:

\#2:

\#3:

2. Have you ever been a Principal Investigator (PI) or co-Principal Investigator (co-PI) on an NSF Coupled Natural and Human Systems (CNHS) grant?

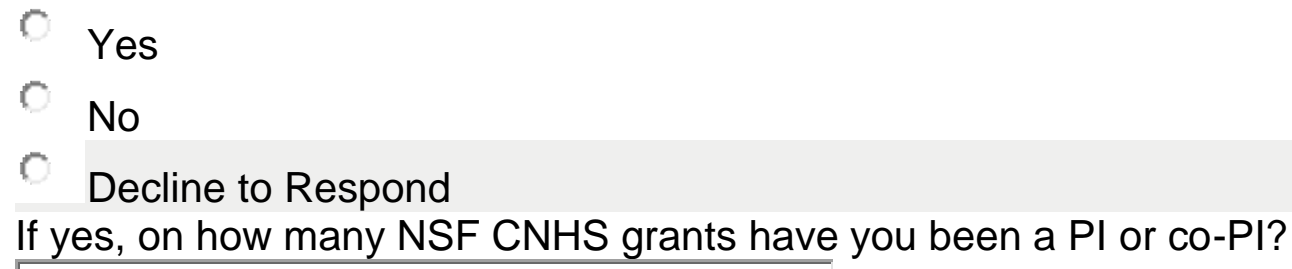

3. What is your primary occupational sector?

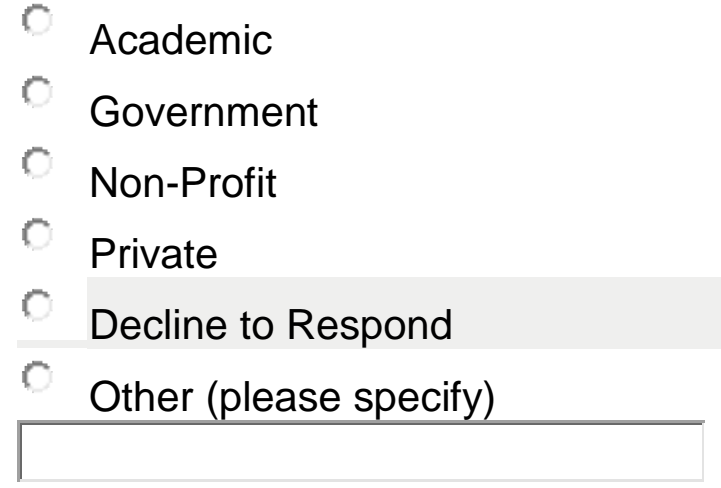

4. Do you consider your work to be strongly inter- or multi-disciplinary (i.e. integration of at least one natural science and one social science discipline)?

$\begin{array}{ll} & \text { Yes } \\ \text { No } \\ \text { Decline to Respond }\end{array}$ 
5. Based on the following categories from NSF-supported disciplines, which of the following do you consider your primary field?

- Chemistry

- Computer and Information Science

- Engineering

- Geosciences

- Mathematical Sciences

- Physics

- Psychology

- Social Sciences

7. In what year were you born?

8. What is your gender?

Male

Female

Decline to Respond

9. What is your primary nationality?

-

Other (please specify)

10. In what country are you primarily employed?

\section{$*$}

Other (please specify) 
Appendix 2: 540 questions and responses resulting from the question collection survey.

1. What steps will result in incorporation of market externalities without causing large negative impacts on significant segments (e.g. low-income) of society?

2. How do power dynamics and differentials within social systems affect $\mathrm{CNH}$ dynamics?

3. How does culture motivate or demotivate humans in protecting their natural environments?

4. Why to people ignore what's in their best interest even when they know?

5. What are the sources of resilience in both social-cultural systems and among nonhuman actors in the ecosystem?

6. How do we account for spatial autocorrelation and distance relationships in these systems?

7. How do we determine the boundaries of coupled human and natural systems as we study them? LCA has some standards - we should too.

8. What role does human decision-making play in CHANS dynamics?

9. How does one promote human awareness of the $\mathrm{CNH}$ basis for human livelihoods?

10. What are the most effective ways to communicate and/or implement interventions in CHANS?

11. How can humans best adapt to anthropogenic climate change?

12. what quantifiable impacts on natural systems do human activities have?

13. Do humans respond similarly to general classes of ecological processes (e.g. linear, non-linear, slow, fast, threshold) despite local context (ecological, political, socioeconomic)? Search for general CHANS principles

14. what are the tipping points, for ecosystems and social systems, under increasing pressure from climate change?

15. What influences (human) behaviour *change*?

16. How are sustainability and peace linked? Can conservation and other sustainability efforts, as well as CHANS research help promote peace, conflict resolution?

17. What is the most effective way to get managers and policy makers involved in coupled systems research?

18. How to balance ever increasing natural resource needs of communities keeping in mind the needs of wildlife?

19. How can social and natural sciences be integrated to best illuminate coupled human and natural systems?

20. How can we link landscape ecology and life cycle assessment to promote sustainable landscapes?

21. How do we effectively link mechanistic and agent-based models in simulating CNHS?

22. what are the right policies for achieving optimal scale of economy relative to the natural systems?

23. How do individual values and governance Systems interact to produce outcomes?

24. How can climate change adaptation and mitigation be integrated?

25. What is the plasticity (ease of change) and elasticity of major human drivers of environmental change? 
26. What kinds of policies or strategies improve the environmental and/or socioeconomic outcomes?

27. How do we break through and begin discussing the role of hard/uncomfortable issues in coupled processes (e.g., privilege, racism, etc.)?

28. How can we systematically consider the tradeoffs between decisions across coupled and human and natural systems?

29. How do natural resource institutions influence the adaptive capacity of coupled systems?

30. How can we learn about ecological boundaries before we cross them, and adjust our human systems to avoid irreparable damage?

31. What types of outreach measures are needed to draw the link between humans and natural systems for non science demographics?

32. How do we create a translational research framework for managing human ecosystems?

33. Can CHANS that are "islands of sustainability" seed up their successes?

34. Which type of studies will be the most efficient, focused, and productive?

35. To what extent should research design and management be different to best address $\mathrm{CNH}$ issues?

36. What are the linkages between ecosystem services and human well-being?

37. What characterizes tipping points in human/social behaviour?

38. What are the best ways to study these dynamic couplings?

39. What effects of changing agricultural trends will have on modern human diet and/or nutrition?

40. How do we truly incorporate iterative process into our decision making process?

41. How can we better use existing data sets to describe human-natural system interactions?

42. What are the interrelated and interacting human institutions that must be created/altered to identify and cope with different coupled-system changes?

43. What level of communication across disciplines is necessary to successfully achieve interdisciplinarity? (i.e., how do we avoid just adding an economist to a project and calling that "human dimensions")

44. How can we develop management tools with incentives to best manage shared goods?

45. How can the proliferation of data access and computational power improve our understanding of CNHs?

46. What areas of human systems have the greatest potential for mitigation of human impacts on natural systems?

47. What essential 'rules' are most important to understand in various complex adaptive systems being managed?

48. Under what conditions do social and ecological disturbances create positive/negative feedback and positive/negative social and ecological consequences?

49. How does scientific information--e.g., predictions, risk assessments, response plans, or scientific study in general--influence people, organizations, and societies in their approach to coupled or potentially coupled systems?

50. What role should citizen stakeholders play in $\mathrm{CNH}$ research? 
51. What are the human consequences of anthropogenic climate change, and how will those human consequences further shape coupled human natural systems?

52. How do humans perceive their place in natural systems? Particularly people who live in developed/industrialized cultures.

53. How is the global economy affecting land-use change at regional and finer scales, and how does this land change impact natural systems?

54. what can we know about the behaviour of systems to new human and physical perturbations?

55. Are people willing to change their behaviors to protect natural systems from degradation?

56. How do economic and institutional factors interact at multiple scales to influence local conditions?

57. How can human incentives be better aligned with their spatially and temporally removed impacts?

58. how does human perception drive system dynamics?

59. How do we measuring resilience in CHANS, and the how then do we develop predictive models of resilience?

60. How do we draw system boundaries in our research for effective input to management?

61. Are members of human systems aware of their systems impacts over natural and climate systems?

62. How can we deal with externalities of human activities?

63. What is the range of "coupling" between humans and nature--e.g., are there any places where there is minimal coupling; what are the places of maximum coupling and how does the closeness of ties impact capacity for management?

64. How can you quantify phase shifts, resilience and thresholds in social-ecological systems?

65. What are the social drivers at multiple scales of coupled complex systems?

66. How can humans best mitigate anthropogenic climate change?

67. Whose interests should take precedence in development particularly in developing countries which still require a lot of natural resources, people or the environment or both?

68. how do we rebuild the connection between humanity and the natural environment in order to foster a protective attitude to sustainability?

69. how can connections to nature of a global urbanizing population be strengthened

70. how do changes in the environment feedback on individuals, groups and institutions?

71. How do different socio-cultural contexts affect $\mathrm{CNH}$ research itself (applying $\mathrm{CNH}$ in other countries etc.).

72. which modeling tools and at what scales are suitable for understanding and forecasting land use change in developing regions?

73. How do we find more resources for research and management?

74. How do short term actions affect the long term behavior of the CHNS?

75. How can we globally find new pathways of development that maintain current quality of life in developed countries and raise quality of life in developing countries without compromising Earth's life supporting capacity? 
76. Under what conditions are changes in natural system conditions most likely to affect human awareness of and response to environmental change?

77. How can we measure and account for ecosystem services in decisions and connect this to policy-making agendas?

78. How do knowledge tools work that support collaboration between those who need to work together to manage coupled human and natural systems?

79. What non-linear feedbacks exist between human civilization and components of the Earth-system?

80. what factors enable motivated people to govern SES effectively?

81. What determines how people in the role of decision-makers value the environment?

82. Are there systematic patterns in coupled interactions that can support the development of a unifying theory of coupled systems?

83. What is the nature of the dynamic couplings in CHANS?

84. How can we more realistically model complex, multi-scale, multi-actor coupled human-natural systems?

85. How do values influence human behavior in regards to natural systems?

86. How are feedbacks manifested between human and natural systems?

87. How can we work better with the media to educate the public about these systems?

88. How do people collaborate to understand the environmental systems they need to engage?

89. How do we co-produce knowledge between scientists, managers and society

90. How can political constraints to sustainable management be overcome?

91. How do people in the system perceive and respond to land use change (either their own action or that imposed upon them from externalities)

92. human consumption has likely already outstripped sustainability. how do we promote the concept of REDUCING global population?

93. What are the points at which ceding decision making about highly technical matters to a professional elite break down?

94. What factors of the human system affect the environmental system?

95. Time lag effects: Why do time lags apply to some aspects of coupled human and natural system dynamics? How so?

96. How does climate variability and water resource accessibility effect population growth and distribution?

97. How can we integrate more realistic human decision making into CHANS models while at the same time controlling for the inevitable increase in complexity that this entails?

98. How do we transfer findings from CHANS studies into recommendations for policy managers?

99. How do we recognize teleconnections and represent them in CHANS models?

100. s there a single, overarching explanation for the biophysical/sociocultural process interactions in CNH's?

101. How to plan for ever increasing human populations around natural areas?

102. How do land use and land cover change influence household and/or community vulnerability and vice versa, especially in marginal environments?

103. How do we evaluate models of environmental change in a no-analogue earth system state? 
104. What kinds of governance systems contribute to improved social and ecological outcomes?

105. How can we better couple / communicate / regulate across disparate and widely spaced geographic regions? e.g., water use within watersheds needs to couple municipalities, industries, resource managers everywhere in the basin, including the coastal zone, but getting farmers to talk to fishermen working 100's of miles away is next to impossible

106. How rapidly can humans adapt to changing ecological circumstances in the current context, and how does that compare to past adaptive behavior?

107. What alternative pathways of development are available that have a lesser impact on ecosystems and the biosphere?

108. What are the feedback structures that inter-relate the coupled human and natural systems?

109. how to better link ecosystem services research to human well-being

110. How much mechanistic knowledge is needed of coupled systems dynamics in order to predict likely responses?

111. Epistemological and philosophical - how much of human action, and the ways that humans couple with natural systems, stems from intrinsic vs extrinsic factors?

Social sciences are way too 'intrinsic' focused. We need more on the big picture and more awareness for how some processes seem to affect very different value systems in similar ways. Preferences and values aren't everything. This is the elephant in the room.

112. Where do individuals obtain information about the natural environment and their impact on it, and how do they evaluate the reliability of that information?

113. How to optimize ecological quality and how this affects human well-being

114. How does human learning at the individual and group level affect the interaction of coupled systems?

115. How do humans perceive and react to changes in climate and the natural environment over short- and long-terms?

116. How to define and stay within planetary boundaries?

117. How can we best translate coupled systems knowledge to inform policy and practice?

118. How can we design natural resource management approaches that reflect and work with biophysical variability (in time \& space)?

119. What pathways of governance can work with complexity, feedbacks, and adaptive management?

120. How do these systems respond to sudden/dramatic external impacts (like rapid climate change)?

121. How do telecouplings (i.e., socioeconomic and environmental interactions among CHANS over distances) evolve?

122. What characterizes sustainable land use systems and how can we transition to such systems?

123. how can we use our knowledge of cities - the ultimate CHANS - to understand and manage other coupled systems?

124. How do systems interact across scales?

125. What are ecological and socio-political consequences of land cover change? 
126. What can be/has been gained from knowledge of coupled natural and human systems?

127. How do you quantify the values humans place on natural resources?

128. How can we best manage and protect fisheries and wildlife in human altered landscapes?

129. How can we utilize our new-found abilities to acquire, store, and process information to manage ecosystems?

130. how \& why \& where are people responding to climate change, including changing their land cover and GHG emissions?

131. What are the environmental and social impacts and underpinnings of a sustainable and just food system?

132. How can we address applications of CHNS theory in policy and practice?

133. How can we effectively treat technological-infrastructural systems within a CHANS framework?

134. What are the main principles governing the interactions between human and natural systems?

135. What factors predispose CHANS to be more or less sustainable, both in absolute and in relative terms?

136. How do we reform global governance (UN work) so that scientists and research carries the day?

137. slow variables vs. fast variables: Which system elements function as underlying, persisting, slow variables vs. fast variables?

138. What are the largest impediments to mitigating climate change?

139. would the mushrooming of sustainability programs at the graduate level produce the critical mass of people who appreciate coupled human and natural systems?

140. What types of science has a real influence on management?

141. How are the forces of globalization and climate change interacting?

142. What urbanization strategies best promote sustainable urban landscapes?

143. On what time scales do coupled human and natural systems operate? Or, more importantly, on what time scales are we able to study coupled human and natural systems?

144. How do we best bring together empirical content from vastly different empirical traditions to parameterize coupled systems models?

145. how and when do humans begin to feel connected to their natural surroundings?

146. How do we better understand linkages between systems?

147. Under what conditions do people exhibit limited or strong ability to respond to the (anticipated or observed) effects of climate change?

148. are existing governance structure, policies and service delivering mechanism effective in addressing marginal places and persons in urban areas especially in the third world economies?

149. How can we best use the reciprocal nature of $\mathrm{CNH}$ systems to support resilience?

150. how can governance systems become resilient in the face of rapidly changing ecological-social systems?

151. How can we transform the human dimension to be more aware of its integration and dependence on natural systems?

152. How do resource users respond to declining resource availability? 
153. How is ecosystem resilience changing with the advent of climate change and changing land use/cover?

154. How is the matrix of land uses related to patterns of biodiversity?

155. Are human adaptation processes similar for a variety of global change drivers (e.g. climate change, globalization) despite local context? Search for general CHANS principles

156. How to co-produce knowledge of CHNS among various stakeholders for learning and action?

157. How do people in the system perceive and respond to climate change (either their own action or that imposed upon them from externalities)

158. How can we manage complex ecological systems?

159. How do we convince society of the value of data? We cannot manage if we have no information.

160. How do we measure externalities and interactions in coupled human-nature systems?

161. How can we identify thresholds and warnings of transitions that lead to degraded benefits to people or difficulties in restoring those benefits?

162. How vulnerable population are adapting to climate change in different parts of the world?

163. What mechanisms facilitate social learning for sustainability

164. The meaning of Good life. Is good life predicated on one negative environmental foot prints?

165. how will climate \& other global env changes (e.g., water availability) affect agricultural systems in different areas of the world?

166. How do the characteristics of coupled human and natural systems shape the tradeoffs between ecosystem sustainability and resilience?

167. Data compatibility: how to reconcile data for different CHANS components when these data are collected at different spatial and temporal scales?

168. how management planners can use basic science most effectively

169. How can we incorporate multiplicity of scales in our models, research design, etc.?

170. How do we radically reduce GHG emissions while at the same time creating just development?

171. How will spatially differential climate change impacts affect local, national and international policy responses?

172. Are tipping points a useful concept? How can we help to monitor and identify them?

173. How are the clear facts of coupled human and natural systems obscured in policy, in management, and in Western cultural orientations?

174. What constitutes evidence of tight coupling in human-natural systems?

175. How to transform cultures to live into being more sustainable social systems.

176. Understanding the impact of extreme events on coupled human and natural systems

177. What is the most successful blend industry and capitalism with protection of natural environments?

178. How can we build science/arts conjoined programs in the public school system with limited budgets? 
179. How to assess trade-offs among ecosystem services quantitatively to optimize ecosystem functioning and human livelihoods

180. What sorts of drivers further mitigation and adaptation to climate change?

181. How do we identify critical linkages btw human and natural systems and how generalizable are these linkages across systems and regions?

182. What is the role of bottom up versus top down policy in the management of these systems?

183. Development of CHANS theory - do we really have guiding theory

184. What is the role of spatial scale in understanding the coupling between natural and human systems?

185. Scale - what aspects of H-E interactions are cross scalar?

186. what drives variability in social and natural processes, and how are they interlinked?

187. How do feedbacks control coupled human and natural systems?

188. Can there be a meeting point between economic development and the environmental protection?

189. What are the feedbacks among sending, receiving, and spillover systems in the telecoupled world?

190. How can we effectively leverage rich place-based studies and "big data" to create a more comprehensive knowledge?

191. How do telecouplings shape socioeconomic and environmental sustainability across local to global levels?

192. Can can we better understand and manage the environmental impacts of the resource and waste streams through which people's needs and wants are met? meeting people's

193. How can we assess social and natural systems in common units?

194. How to foster green growth in a manner that is both sustainable and builds resilience/adaptive capacity?

195. How does measurable and deep uncertainty related to coupled human and natural systems influence human decision making?

196. How to use scientific results in climate to address CHANS research?

197. What types of education and skills are needed by CHANS scientists?

198. How do human responses to change alter the environment?

199. Do network-based hydrologic CNH's behave in fundamentally different ways from patchwork-based terrestrial CNH's?

200. How can coupled-system complexity be reconciled with societal need for a degree of clarity and predictability, and how does this need vary at different social/ecological scales?

201. How do we communicate the complexity of coupled systems to managers and policy makers?

202. What are appropriate and effective methods to bring stakeholders together to address environmental issues.

203. how rapidly are human societies able to adapt to and cope with environmental change and disruption

204. What are the mechanisms and circumstances that create the conditions appropriate for successful collective action? 
205. How to stop forest disappearance due to the expansion of industrial agriculture and urbanization?

206. How do we move beyond ecosystem services to re-conceptualize CNH linkages?

207. How can we best describe and convince politicians to make decisions with a coupled human/natural systems framework?

208. how can we use our knowledge of 'natural' systems to understand cities?

209. How to show that complexities, incentives and uncertainty matters in the coupled human and natural systems?

210. How might we use non-traditional ontologies in interpreting, understanding and managing CHANS?

211. How can we deal with issues of discounting?

212. What are the most appropriate ways of understanding the relationship(s) between humans, other species and the environments we share?

213. How can we accurately measure human response to a CHANS project?

214. How are the human and natural systems coupled?

215. Can the public trust doctrine offer a framework for delivering better social and ecological outcomes?

216. Can regime shifts (i.e. shifts from one basin of attraction to another) be predicted based on system "flickering" (based on recent ecological, economic research) for different domains (i.e. ecological, economic, political, social)? Search for general CHANS principles.

217. What are the effects of exponential economic growth on individual ecosystems and the biosphere as a whole?

218. How do global environmental changes affect the dynamics of regional and local coupled systems, and how to these feed back to higher level processes??

219. what is the most effective way of communicating current scientific knowledge to broader part of society with a particular focus on decision-makers, and resource users?

220. How can people adapt to changing system behavior while still getting what they need from the system?

221. Development of CHANS methods - is there more than just integrative modeling?

222. To what extent is our understanding of hierarchies in CHANS an accurate reflection of what is occurring? Are there other explanations?

223. How to link income streams to various ecosystem services so that better environmental outcomes can be realized?

224. How to build (or manage) sustainable ecosystems that are resilient to change and provide ecosystem services for humans?

225. What are some economical and social factors that prevent sustainable agriculture and permaculture to succeed?

226. What products/outcomes are most useful and relevant in this 'era' of 'wicked problems' and 'post-normal science?'

227. How can we effectively identify both the relevant human and nonhuman actors within systems?

228. What are the perceived and real tradeoffs in valuing specific ecosystem services (for society, environment,...)? 
229. How might we apply non-traditional epistemologies (ways of knowing/methods) to understand CHANS?

230. How can an environmentally sustainable energy system be constructed within existing institutional frameworks?

231. How can resource management practices better integrate ecological resiliency and anticipate disturbance

232. What set of conditions induces an individual human response to environmental change?

233. How to transform the monetary system and the economy so that they don't require growth to avoid collapse and so that they don't continually concentrate wealth and power in few hands?

234. Feedback loops: how do human and natural systems interact?

235. How can science (ecology) embrace novel ecosystems?

236. How sustainable are our current industrial food systems?

237. how can we simulate coupled natural human systems to understand the complex behaviors of these systems?

238. How can we incorporate feedbacks that emerge at multiple temporal and spatial scales into scientific studies?

239. What's the economic trade-offs in multiple-use management of nature resource issue?

240. How can uncertainty be more effectively employed in understanding and managing coupled systems?

241. Why and how do social inequalities emerge, grow, persist, and diminish, and with what consequences?

242. How do coupled systems co-evolve or co-adapt?

243. How can the interaction of social systems and natural life sciences better interact to stop species loss?

244. What factors determine the degree or strength of local coupling or decoupling between the social and ecological portions of CHANS?

245. How to best achieve balance among multiple resources, multiple uses and multiple sectors?

246. How does the spatial configuration of land uses contribute to ecosystem services and sustainability?

247. What is the degree of the success of urban biodiversity conservation in major cities of the world?

248. Do people have an appreciation for their impacts on natural systems?

249. How to best manage CNHS feedbacks for both human needs and the environment's good.

250. How can our improved understanding of neuro-functions of the human brain influence decision sciences in general and our appreciation of cooperative behavior in particular?

251. How can we "unresilience" the bad system dynamics while enhancing the "good" dynamics?

252. What are the appropriate time frames for understanding CHANS and how to determine the necessary time scale? 
253. How is human decision-making likely to change in response to future landscape, environmental and socio-political change?

254. Why do we need interdisciplinarity?

255. What is the extent of the existence of resource curse in areas with abundant natural resources but high rate of poverty?

256. How do different types of ownership of resources (public, private, commons, nullius) affect the viability of CHANS?

257. How does social organization mediate human interaction with the environment, i.e., amplify or attenuate perceptions of risk associated with environmental change

258. What issues need to be investigated from prism of CHANS

259. How do people perceive risk and make decisions around environmental issues with risk and uncertainty?

260. Under what sorts of circumstances does land sharing as opposed to land sparing occur?

261. What other global environmental change besides climate change pose threats to sustainability

262. how do human social networks affect the way humans interact with ecological systems?

263. What leads people to respect natural systems?

264. How can research inform the urban sustainability community to foster creation of resilient cities?

265. What are the key sets of internal system feedback connections, that are most likely to trigger system change, or be affected by external changes?

266. how to improve management in different fields finding nexus between categories now divided

267. how can we reintegrate humans into our conceptualization and management of 'natural' systems?

268. What are the perceptions of landholders/land managers of environmental issues and how do those compare to public perceptions and scientific knowledge?

269. What is the role of variability in system behavior?

270. How can we protect the glaciers, highlands and the local population from opencast mining?

271. How can we apply new information technologies to understand transformations of complex coupled systems and anticipate their consequences?

272. What is the proper scale at which coupled human and natural systems ought to be studied?

273. How do we ensure regulations are flexible and practical but ensure environmental safety?

274. How do ecosystems services/ natural capital and other forms of capital produce human well-being?

275. how can we quantify/incorporate culturally valued resources in SESs?

276. what motivates people to care about the environment?

277. What are the relationships between cultural values, management and natural systems?

278. How can we explore the question of networks between and within CHNS? 
279. How can we formalize and quantify the human behavior at multiple spatial and organizational scales?

280. How best can we represent human built elements of natural systems and human decisions/behavior in coupled process models?

281. How can we provide 9-10 billion people with a decent quality of life and still maintain the ecosystems on which global society depends?

282. How do human-induced changes in global climate affect ecosystem biodiversity and services at finer spatial scales?

283. How can natural processes (i.e. ecosystem services) be integrated into humandominated landscapes?

284. How can we improve knowledge creation with diverse disciplinary scales of importance? -- methodological and epistemological challenges

285. What are appropriate levels (of both human and natural systems) to investigate linkages. I.e. at what level do interaction matter most?

286. What conceptual frameworks provide mechanistic and predictive power without becoming reductionist and exclusionary for other disciplines

287. How far has economic valuation of natural resources helped in protecting natural systems from destruction and over-exploitation?

288. What are the costs and benefits of channeling human and fiscal resources to coupled systems research vs fundamental disciplinary research?

289. How can we design socio-ecological research that is relevant to the social communities affected by ecosystem processes?

290. What new data sets should we be building to improve our modeling of humannatural system dynamics?

291. how to educate public on link of extreme events to long term changes in human natural system

292. How do dynamics at higher or lower scales affect the sustainability/resilience of a given CHANS?

293. what factors do positively contribute to reducing impact of global market system that erodes resilience of social-ecological systems?

294. How does the CHANS community responsibly create and implement a set of coherent, assiduous, transparent, and repeatable research designs and accepted practices to test hypotheses about coupled human natural systems?

295. How can we change the stovepipe attitudes of academia and its stovepipe training of students?

296. How can we rescue natural systems in socially depressed areas of big cities in Latin America as a tool for human development?

297. How can issues of accelerating uncertainty for future projections from coupled human-natural systems be modelled?

298. How do we communicate these issues to the general public?

299. What are the underlying processes or mechanisms for the complexities of coupled human and natural systems?

300. What other factors are most important in changing human behavior?

301. How can conservation of natural systems provide resilience of human systems to impacts of climate change, such as extreme weather and rising sea levels?

302. What are the motivating factors for humans to protect natural systems? 
303. To what extent are $\mathrm{CNH}$ processes culturally, geographically, or subject specific, and to what extent can we find transcendent properties of the ways in which coupled systems evolve?

304. How will the benefits provided by nature and the persistence and distribution of species change in the future?

305. What attitudes, dispositions, and knowledge are needed to further the transition to a just sustainability?

306. What makes a social ecological system resilient?

307. What are the constants in socio-ecological perception and values across race, culture, and economic status?

308. What does "couple" mean?

309. How do interactions among human and natural systems vary across spatial and temporal scales?

310. Are there common patterns of change across CHANs?

311. What are the social and economic challenges to moving forward to a low impact path of development?

312. How can we understand causation in complex coupled systems?

313. How can society better control the spread of invasive species that endanger agricultural and native ecosystems?

314. How do policies influence human-nature interactions?

315. Behavioral - why do people use resources one way in this place but a different way in another place.

316. how can scientists (both natural and social) be better integrated into policy-making, resource management, and decision-making of elected officials and those running governments?

317. How do we account for legacy effects?

318. Can we develop lab- and field-based models that help better understand as well as predict how human decisions influence physical systems and vice-versa?

319. Can we identify patterns of behavior that cut across multiple types of CHANS and at multiple levels of analysis? (I mean whole system behavior, rather than human behavior here.)

320. What are common key indicators of system change (social and ecological) and how can these be better predicted?

321. To what extent might we develop a "global culture" of understanding and managing CHANS?

322. Under what scenarios will drivers of urbanization and land use change promote sustainable city development?

323. What institutional frameworks best facilitate adaptation to environmental change and resources scarcity?

324. What do we address the complex interlinkages between rural livelihoods and natural resource use in the face of climate variability?

325. when and how might environmental (climate), ecosystem, or human population thresholds (catastrophic crashes) occur and how do we forestall them?

326. How to best link small scale (e.g., agent or household based) decisions within larger system wide processes? 
327. How can we design protected areas that are both biologically effective and socially just?

328. How can analysis of currently employed measures of H-E interactions be maximized / improved upon in order to improve observations or change?

329. how to weight the importance of long term consequences into decisions on human impacts on ecosystems?

330. how do human interactions with an ecosystem circulate through ecological networks?

331. How to employ an ecosystem services approach to management from the local to global scale?

332. What are the impacts of globalization on human-nature interactions?

333. What is the role of CHANS researchers in the policy debates that are generated as a function of the community's research?

334. Do people respond to predictive indicators of environmental stress

335. How can we ensure that inter-disciplinary projects that include non-academic stakeholders become the norm rather than the exception (especially in sustainability science)?

336. What learning tools will provide people with the greatest capacity to successfully adapt to global environmental change?

337. How do human activities alter ecological landscape processes?

338. How ongoing and future climate change will be affecting agriculture sector?

339. What theoretical frameworks can be applied to the explanation of coupled system dynamics that scale from micro to macro and span human and biophysical systems

340. How can we design decision-making structures to bring together groups with disparate objectives?

341. To what extent do natural system process affect human decision-making and behavior?

342. How do scientists, managers, and the vast majority of others interact to share knowledge and power over decision making?

343. How persistent is youth education (into adulthood) and how effective is 'spillover' to parents?

344. what is the impact of human-induced land cover change on climate? (need more site studies, data)

345. What are the relationships among environment, population dynamics, settlement structure, and human mobility?

346. How do we couple environmental sustainability with social and economic sustainability?

347. How is environmental change affecting people's long-term capabilities to thrive as a species?

348. How can human civilization withstand threats to it's longevity or existence?

349. What are feedbacks between human impacts and natural system change?

350. What is the expected future of human civilization and life on Earth?

351. What is interdisciplinarity?

352. How many syllabus or curriculum at the undergraduate level include CHANS?

353. Moving beyond the case study in the governance of CHANS 
354. how human per capita population growth rates will change, spatial distribution of change

355. understanding the impact of degradation in upstream parts of river systems on ecosystem services delivery

356. How do these systems grow and change over very long time-spans?

357. If not, can we identify the reasons for difference either across type or across scale?

358. ecology justice and adaptive capacity : how to manage impacts?

359. How local biophysical changes from human interventions influence regional and global biophysical processes - especially with respect to water?

360. How can the existing knowledge of human behavior within multiple social science disciplines serve in answering Q1?

361. Scalar questions - how to link ecological processes, policies, management at multiple scales

362. What can data science increase analysis, (feedback), and response to CHANS processes?

363. How to sample annual systems within long term studies.

364. The scale at which humans are most capable of sustainable interaction with the natural world?

365. how human consumption patterns will change in coming decades

366. How to properly address and study "the interaction term" between human and natural components of CHANS?

367. when communities have never paid for ecosystem services how to get communities to start contributing especially in a context such as India where enforcement is very weak?

368. How to mitigate and adapt to climate change.

369. How to understand context-dependency and place as a driving force

370. How variability in the environment can be understood as an asset in both natural and human systems.

371. Which policy interventions can succeed in altering/maintaining the outcomes noted in previous question?

372. How decision making is coupled across scales

373. Transforming (or retrofitting) existing socio-political systems/institutions that serve as barriers to change (e.g. It seems logical to put a solar panel on every rooftop in the southwestern U.S. and avoid destroying thousands of acres of wildlife habitat yet we haven't seen that happen yet due to political and economic reasons))

374. Is governance up to the task of managing global change

375. Evaluating biodiversity for human needs

376. innovative approaches for promoting adaptation to climate change

377. the interactions among ecosystems and human health, especially in urbanizing areas

378. More equitable distribution of benefits \& burdens of Global Change processes

379. generating political ecology/economy methods that incorporate history, asymmetrical power and access

380. Developing tools to measure various ecological services with economic currencies.

381. How about the social culture of community has been applied on managing the natural resources?

382. Feedbacks between system dynamics and human decision making/management 
383. Natural resource management policies that equally weight social and ecological priorities and outcomes.

384. Social inequality, including between countries, and its role in human-natural system dysfunction

385. Addressing the issues of poverty and sustainable livelihoods on environmental degradation

386. The ability of humans to adapt to a more ecocentric behavior and lifestyle?

387. Political and social development decisions and their impacts on natural systems

388. Including human health issues that are generated by the intersection of human and natural systems

389. Managing perspective: Empowering community-based decisions that satisfy as many stakeholders as possible

390. The biggest question is likely the interrelationship of food use and production energy use and production - and climate change

391. The relationships of settlement types to ecosystem types

392. How can these be integrated to better inform each other to make wise use decisions?

393. Effects of telecoupling or teleconnections between global markets and local SES

394. Links between environment and livelihoods to alleviate poverty.

395. how to properly situate chans research in an institutional/political context

396. We need to better understand feedbacks between human decision-making and the natural resources/environmental factors that these societies depend on.

397. Global market impacts on ecosystems and their management

398. Better understanding the multi-scalar nature of CHANS, particularly the affect of mismatch between social (i.e. governance) and the ecological, as well as the signals that are affecting larger and smaller scales

399. Integrating technological advances to manage and mitigate environmental change.

400. Anticipating and adapting to new and novel conditions in response to climate change and demographic pressures

401. How to integrate across spatial and temporal scales

402. Understanding coupling at the micro social scale and the relationship, if there is one at the macro-scale

403. Peaceful means of sharing declining resources

404. social and cultural impacts - and changes in them - on system interaction

405. understanding the relationship between ecological change and behavioral change

406. use of past systems behavior as a predictor for future systems behaviors

407. Modeling human behavior \& decision-making

408. The 'big equation' is that relating the size and growth of human populations (demography) to resources (ecology and economics) to conservation of species (many fields) - we need more questions focus on this big relationship

409. Population dynamics in ecosystems with heavy human usages

410. Improved (primary) education on CHANS complexity and ways to live with it

411. decision making under uncertainty

412. socio-ecological resilience and its implications for environmental, economic, social trade-offs

413. Moving from individual change to collective action 
414. Human influence on the biogeochemical cycling of toxic trace elements within Earth's System

415. Quantifying the spatio-temporal interactions among human and natural systems

416. Change in human-natural systems relationships across scales.

417. better foundation of decision making linking neurological-behavioral-sociological perspectives

418. Multi-scalar dynamics of resilience and tipping points of SES

419. Arriving at a steady-state economy

420. Best impact: cost ratio uses for government incentive programs to foster improved management

421. GMO safety, confinement, and ecological impact

422. Water. All aspects of security, scarcity, vulnerability and management.

423. Relationships between ecosystem services and function in human dominated systems.

424. Understanding of uncertainty in climate systems and the ways that it translates to decision making on risk for human and natural systems

425. role of ideology in understanding system change

426. Perception of Environmental Change and Response to it

427. Redefining and/or re-understanding "economic growth", green accounting is a start towards this but not enough

428. Changing human behavior to promote ecosystem health

429. How to better represent social systems and processes in CHANS models

430. Anticipatory reflection about systems change across diverse time scales with management in a shockingly narrow timescale

431. incorporating behavior, anticipating tipping points, emergent properties and regime shifts especially for ecosystem function, and social organizations

432. how human population patterns with ongoing changes in water availability

433. Shale gas energy development in interior natural areas and effects on local communities (socioeconomic)

434. Data integration across natural and social science remains a fundamental challenge

435. Moving from proxy variables and simple models of human behavior toward direct measurement

436. Changing natural/urban communities in the face of climate change and how to better prepare for expected changes.

437. Path to a post-capitalist or at least capitalism 2.0 society

438. integrating social science to understand individual and group behaviors and values and how they scale up in coupled human-natural systems

439. feedbacks between variables across systems

440. Maximize prosperity and ecosystem function

441. We need to do more experimental work where we run randomized control trials to examine how different policies can lead to better management of CHANS.

442. Human Perception Towards Natural System

443. generalization of findings from case studies

444. Understanding the vulnerability of coupled human and natural systems to climate change 
445. On the human side, in my opinion there is opportunity for further investigation of how human relationships with the natural world have changed over time and could change in the future. Culture supports the idea that technologically advanced humans like to think that we are able to use technology to control the natural world enough to ensure human survival. However, climate change may show us that we are still or may again become more vulnerable to variability in nature when we have difficulty attaining targets for agricultural crop yields due to erratic climatic variation. Although it hasn't happened yet, I see this likely little injection of humility into public discourse as a potential opportunity to exploit for other benefits for ecosystem management in the future. I am currently working on a philosophical project that includes this issue.

446. how to integrate social and biophysical data (methodological)

447. The factors resulting in robustness vs. evolvability of human systems in the face of climate change

448. Impacts of climate change on major ecosystems and human interactions with them

449. Effective integration of efficient high population density communities within an urban sprawl framework (e.g. Houston)

450. Long and short term socio-economic impacts of contaminated ecosystem mitigation due to Hydraulic fracturing processes

451. defining the linkages between human and natural systems

452. how to value effectively the natural capital facing uncertainty of environmental changes.

453. reciprocal feedback effects between human and natural systems

454. defining the data needed to conduct a CHANS approach

455. Enhancing ecosystem services while reducing negative anthropogenic effects

456. Integrating models for a Global System Science that serves to both Design and technology of biological and socio-technical systems

457. role of technological change and human adaptations in managing CHN systems

458. Prediction of human responses to natural events

459. Scaling up smaller-scale analyses of managed processes in the environment to reflect policy and governance

460. We need to better identify the drivers of human decision-making regarding land use/land cover change and natural resources - only by doing that can we identify better policies for sustainable development/conservation of the environment

461. tradeoff between resolution, model fidelity, scale, and tightness of coupling

462. integrating social and ecological/biophysical data across local to global scales

463. feedbacks between evolving concepts of nature and the rapidly changing earthscape

464. We need a metalogic that allow more effective integration of aspects of the CHANS systems

465. Understanding dynamics and feedbacks between social and ecological sub-systems

466. Improved capacity for adaptation \& transformation (re-organization) in a time of accelerated change

467. What self-organizing and managing parts are necessary

468. improved assessment strategies at appropriate time and space scales

469. Transferable operationalized metrics showing connections between social and ecological systems. 
470. Interplay of local-global governance of SES

471. the similarities, differences and relationships between physical, biological and sociocultural evolution

472. Connectivity of wildlife habitat across the landscape

473. cumulative impacts and their cumulative effects

474. Improved medium \& long term co-viability of ecological and social processes in CHANS

475. tipping points in systems

476. emergent properties in CHANS

477. If both, how can we strike the balance?

478. What is the perceived value of the cost or benefit of management of the major drivers in 1 and 2 ?

479. Cooperation in the Commons

480. Integrate humans in a natural world rather than treated them as 'coupled'

481. defining human well being operationally

482. low level of public concern over the environment

483. lead and lag times in system change

484. unified framework to approach the study of chans

485. How do they recognize each other at all?

486. How do they recognize each other's responses?

487. Are CHANS dynamics lawful?

488. Above questions at LOCAL/REGIONAL scales.

489. Developing a road map to accomplish the first two

490. Adaptations to a changing climate

491. Human valuation of nature

492. What is the most effective way to study them?

493. globalized transformation of ecological risk

494. above question focusing on evolving concepts of human connections to nature

495. all further questions derive from \#1 above.

496. The super-complex interaction between human and nature

497. The human position and responsibility within the Ecosphere?

498. changing lifestyles

499. Analyses that cross boundaries of rural/urban domains

500. And general questions looking across scales and boundaries/edges

501. economic, ecological and social sustainability of systems providing food and water

502. economic development and climate change mitigation

503. thresholds

504. How do we find more resources so that that people are not overwhelmed?

505. It is the reason I did not proceed with the survey after clicking once before.

506. get rid of "coupled" and deal with humans as ecosystem engineers -- there is only one system.

507. complex system interactions

508. Traditional ecological knowledge

509. Adaptation to Environmental Change

510. Human Health

511. management 
512. Community based ecosystem management

513. Wildlife Diseases, zoonotic and not.

514. How about the technology has been applied on managing the natural resources?

515. resilience

516. Local Biggest Never-ending Environmental Issue

517. modeling complex system dynamics

518. Scaling

519. It should have been in the end.

520. Resource Use

521. This will take me a lot more than 10 minutes to complete.

522. evaluation of quality

523. human motivations and behaviors- including human well-being

524. Urban interface with wildlife

525. profit-oriented capitalism production system

526. what are the coupled human-environmental systems? Any specific example?

527. The quantization of human activities

528. Tradeoffs

529. Climate change

530. Growth and shrinking of human population

531. Feedback from one subsystem to another

532. Approaches to sustainability

533. Careful measurements of agricultural systems

534. reducing poverty

535. Scale

536. carrying capacity of the earth

537. feedbacks

538. post-normal science

539. evaluation on impact

540. Discounting 
Appendix 3: 321 questions submitted for evaluation in question evaluation survey and their mean, median, variance, and counts based on a 7category Likert scale. An " $x$ " indicates that the question was included in the final list of top 40 questions.

\begin{tabular}{|c|c|c|c|c|c|c|c|c|c|c|c|c|c|c|}
\hline Question & Category & $\mathrm{N}$ & Mean & Median & Var & $7 \mathrm{~s}$ & $6 s$ & $5 s$ & $4 \mathrm{~s}$ & $3 \mathrm{~s}$ & $2 \mathrm{~s}$ & $1 \mathrm{~s}$ & 0s & $\begin{array}{c}\text { Top } \\
40\end{array}$ \\
\hline $\begin{array}{l}\text { How do policies influence human-nature } \\
\text { interactions? }\end{array}$ & GOVERNANCE & 25 & 6.36 & 6.00 & 0.57 & 12 & 11 & 1 & 1 & 0 & 0 & 0 & 0 & $\mathrm{x}$ \\
\hline $\begin{array}{l}\text { How will human population patterns change with } \\
\text { ongoing changes in availability of water? }\end{array}$ & SOCIETY \& CULTURE & 18 & 6.33 & 6.00 & 0.47 & 8 & 8 & 2 & 0 & 0 & 0 & 0 & 0 & $\mathrm{x}$ \\
\hline $\begin{array}{l}\text { How will climate \& other global environmental } \\
\text { changes (e.g., water availability) affect } \\
\text { agricultural systems in different areas of the } \\
\text { world? }\end{array}$ & LAND USE \& AGRICULTURE & 24 & 6.29 & 6.00 & 0.65 & 11 & 10 & 2 & 1 & 0 & 0 & 0 & 0 & $\mathrm{x}$ \\
\hline $\begin{array}{l}\text { How can social systems and natural life sciences } \\
\text { be integrated to better inform each other to make } \\
\text { wise use decisions? }\end{array}$ & GOVERNANCE & 22 & 6.27 & 6.00 & 0.59 & 10 & 8 & 4 & 0 & 0 & 0 & 0 & 0 & $\mathrm{x}$ \\
\hline $\begin{array}{l}\text { How can water management be improved to } \\
\text { decrease scarcity, increase security, and make the } \\
\text { system less vulnerable? }\end{array}$ & ADAPTATION \& RESILIENCE & 24 & 6.25 & 6.00 & 0.46 & 9 & 12 & 3 & 0 & 0 & 0 & 0 & 0 & $\mathrm{x}$ \\
\hline $\begin{array}{l}\text { How is ecosystem resilience changing with } \\
\text { changes in climate, land use, and land cover? }\end{array}$ & ADAPTATION \& RESILIENCE & 23 & 6.22 & 6.00 & 0.54 & 9 & 10 & 4 & 0 & 0 & 0 & 0 & 0 & $\mathrm{x}$ \\
\hline $\begin{array}{l}\text { How can we control climate change with demands } \\
\text { of increasing food production and increasing } \\
\text { energy use? }\end{array}$ & LAND USE \& AGRICULTURE & 21 & 6.19 & 6.00 & 0.66 & 9 & 7 & 5 & 0 & 0 & 0 & 0 & 0 & $\mathrm{x}$ \\
\hline $\begin{array}{l}\text { How do economic and institutional factors interact } \\
\text { at multiple scales to influence local conditions? }\end{array}$ & $\begin{array}{l}\text { GENERAL PRINCIPLES \& } \\
\text { SYSTEM DYNAMICS }\end{array}$ & 21 & 6.19 & 6.00 & 0.76 & 9 & 8 & 3 & 1 & 0 & 0 & 0 & 0 & $\mathrm{x}$ \\
\hline $\begin{array}{l}\text { How do humans increase their capacity for } \\
\text { adaptation to global environmental change? }\end{array}$ & ADAPTATION \& RESILIENCE & 23 & 6.17 & 6.00 & 0.51 & 8 & 11 & 4 & 0 & 0 & 0 & 0 & 0 & $\mathrm{x}$ \\
\hline $\begin{array}{l}\text { How can we ensure that inter-disciplinary projects } \\
\text { that include non-academic stakeholders become } \\
\text { the norm rather than the exception (especially in } \\
\text { sustainability science)? }\end{array}$ & $\begin{array}{l}\text { EDUCATION \& SCIENCE } \\
\text { COMMUNICATION }\end{array}$ & 20 & 6.15 & 6.00 & 0.77 & 9 & 5 & 6 & 0 & 0 & 0 & 0 & 0 & $\mathrm{x}$ \\
\hline $\begin{array}{l}\text { What other global environmental change besides } \\
\text { climate change pose threats to sustainability? }\end{array}$ & $\begin{array}{l}\text { SUSTAINABILITY \& } \\
\text { DEVELOPMENT }\end{array}$ & 21 & 6.14 & 6.00 & 1.13 & 10 & 6 & 4 & 0 & 1 & 0 & 0 & 0 & $\mathrm{x}$ \\
\hline $\begin{array}{l}\text { What are the human consequences of } \\
\text { anthropogenic climate change, and how will those } \\
\text { human consequences further shape coupled human } \\
\text { and natural systems? }\end{array}$ & CLIMATE CHANGE \& ENERGY & 22 & 6.14 & 6.00 & 0.69 & 8 & 10 & 3 & 1 & 0 & 0 & 0 & 0 & $\mathrm{x}$ \\
\hline $\begin{array}{l}\text { What are the environmental and social impacts } \\
\text { and underpinnings of a sustainable and just food } \\
\text { system? }\end{array}$ & LAND USE \& AGRICULTURE & 22 & 6.14 & 6.00 & 0.98 & 9 & 9 & 3 & 0 & 1 & 0 & 0 & 0 & $\mathrm{x}$ \\
\hline
\end{tabular}


What are the linkages between ecosystem services and human well-being

How can sustainable ecosystems that are resilient to change and provide ecosystem services for humans be built or managed?

How is the global economy affecting land-use change at regional and finer scales, and how does this land change impact natural systems?

How can we best use the reciprocal nature of CHANS systems to support resilience?

What are the social drivers at multiple scales of complex CHANS?

How can communities adaptively (and peacefully) manage common-pool, declining resources?

How can we understand causation in complex coupled systems?

How can scientists best integrate data, methods, and research designs across multiple spatial and temporal scales?

How can we reintegrate humans into our

conceptualization and management of 'natural' systems?

How can we measure and account for ecosystem services in decisions and connect this to policymaking agendas?

What is the role of spatial scale in understanding the coupling between natural and human systems?

What pathways of governance can work with complexity, feedbacks, and adaptive managment?

How can we design natural resource management approaches that reflect and work with biophysical variability (in time \& space)?

Under what conditions do social and ecological disturbances create positive/negative feedback and positive/negative social and ecological consequences?

How can we better represent social systems and processes in CHANS models?

How do changes in the environment feed back on individuals, groups and institutions?
CONSERVATION \& ECOSYSTEM

SERVICES

CONSERVATION \& ECOSYSTEM

SERVICES

LAND USE \& AGRICULTURE

ADAPTATION \& RESILIENCE

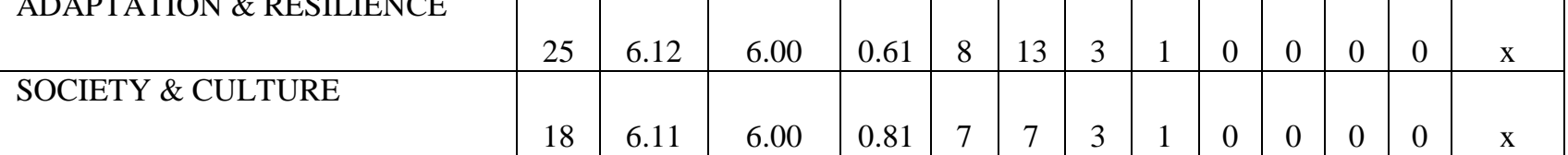

GOVERNANCE

\begin{tabular}{|l|c|c|c|c|c|c|c|c|c|c|c|c|c|} 
& 20 & 6.10 & 6.00 & 1.36 & 8 & 9 & 2 & 0 & 0 & 1 & 0 & 0 & \\
\hline $\begin{array}{l}\text { GENERAL PRINCIPLES \& } \\
\text { SYSTEM DYNAMICS }\end{array}$ & & & & & & & & & & & &
\end{tabular}

SYSTEM DYNAMICS

SCALE

SOCIETY \& CULTURE

\begin{tabular}{|l|l|l|l|l|l|l|l|l|l|l|l|l|l} 
& & & & & & & \\
& 22 & 6.09 & 6.00 & 0.85 & 9 & 7 & 5 & 1 & 0 & 0 & 0 & 0 & $\mathrm{x}$ \\
\hline
\end{tabular}

CONSERVATION \& ECOSYSTEM SERVICES

\begin{tabular}{|l|c|c|c|c|c|c|c|c|c|c|c|c|c|} 
& 23 & 6.09 & 6.00 & 0.45 & 6 & 13 & 4 & 0 & 0 & 0 & 0 & 0 & $\mathrm{x}$ \\
\hline SCALE & 26 & 6.08 & 6.00 & 0.47 & 7 & 14 & 5 & 0 & 0 & 0 & 0 & 0 & $\mathrm{x}$ \\
\hline GOVERNANCE & 26 & 6.08 & 6.00 & 0.71 & 9 & 11 & 5 & 1 & 0 & 0 & 0 & 0 & $\mathrm{x}$ \\
\hline $\begin{array}{l}\text { GOVERNANCE } \\
\text { SYSTEM DYNAMICS }\end{array}$ & 18 & 6.06 & 6.00 & 1.00 & 7 & 7 & 2 & 2 & 0 & 0 & 0 & 0 & $\mathrm{x}$ \\
\hline
\end{tabular}


How can we incorporate behavior, tipping points, emergent properties and regime shifts especially for ecosystem function and social organizations in CHANS models?

How does uncertainty of CHANS affect human decision making?

What characterizes sustainable land use systems and how can we transition to such systems?

\section{How do we address the complex interlinkages}

between rural livelihoods and natural resource use in the face of climate variability?

What are the drivers of human decision-making regarding land use/land cover change and natural resources?

What characterizes and can we predict tipping points or thresholds in CHANS?

What are appropriate and effective methods to bring stakeholders together to address

environmental issues?

How can we best represent human decisions,

behavior, and human-built elements of natural

systems in coupled process models?

How can resource management practices better integrate ecological resiliency and anticipate

disturbance?

How do we couple environmental sustainability with social and economic sustainability?

How can the public be educated on the link

between extreme events and long-term changes in coupled human and natural systems?

What alternative pathways of development are available that have a lesser impact on ecosystems and the biosphere?

How can we design socio-ecological research that is relevant to the social communities affected by ecosystem processes?

How do we integrate social science to understand individual and group behaviors and values and how they scale up in coupled human and natural systems?

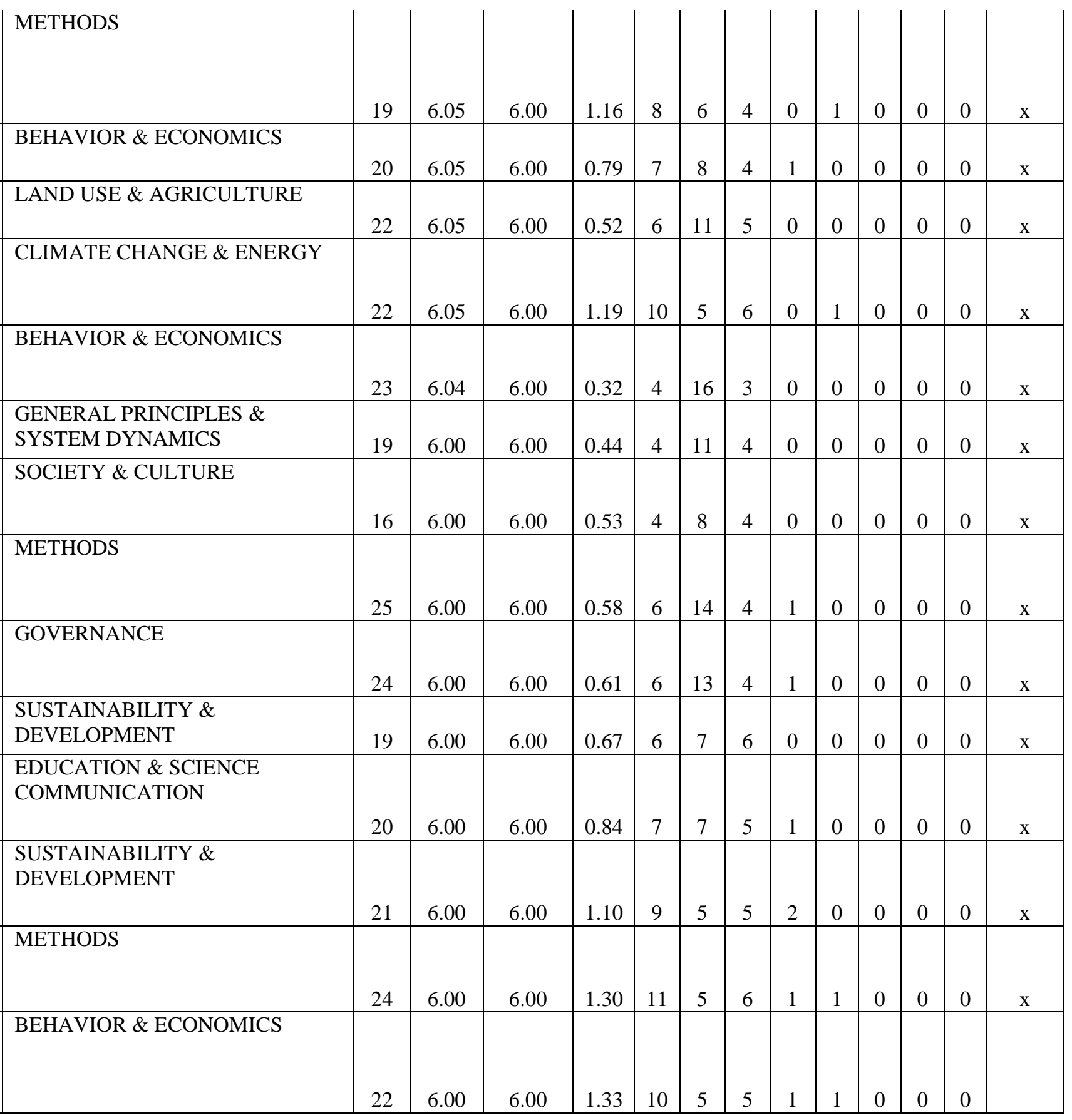


How does society improve medium and long term co-viability of ecological and social processes in CHANS?

What effects will changing agricultural trends have on modern human diet and/or nutrition?

What is the appropriate balance between economic development and environmental protection?

How is environmental change affecting people's capacity and prospects for survival?

What are the relationships between cultural values, management and natural systems?

How do various types and patterns of land uses relate to patterns of biodiversity?

What kinds of governance systems contribute to improved social and ecological outcomes?

\section{What are the perceptions of landholders/land} managers of environmental issues and how do those compare to public perceptions and scientific knowledge?

How do human activities alter ecological

landscape processes?

How can political constraints to sustainable management be overcome?

How do we measure resilience in CHANS, and the how then do we develop predictive models of resilience?

How do human responses to change alter the environment?

How do social and cultural factors affect the management of CHANS?

How can social systems and natural life sciences better interact to stop species loss?

How do global environmental changes affect the dynamics of regional and local coupled systems, and how do these feed back to higher level

processes?

How are the forces of globalization and climate change interacting?

How do CHANS interact across multiple scales?
SUSTAINABILITY \&

DEVELOPMENT

LAND USE \& AGRICULTURE

SUSTAINABILITY \&

DEVELOPMENT

SOCIETY \& CULTURE

SOCIETY \& CULTURE

CONSERVATION \& ECOSYSTEM

SERVICES

GOVERNANCE

SOCIETY \& CULTURE

LAND USE \& AGRICULTURE

GOVERNANCE

METHODS

BEHAVIOR \& ECONOMICS

SOCIETY \& CULTURE

CONSERVATION \& ECOSYSTEM

SERVICES

GENERAL PRINCIPLES \&

SYSTEM DYNAMICS

CLIMATE CHANGE \& ENERGY

GENERAL PRINCIPLES \&

GENERAL PRINCIPLES
SYSTEM DYNAMICS

\begin{tabular}{l|l|l|l|l|l|l|l|l|l|l|l|l|} 
& & & & & & & & & & & & \\
15 & 6.00 & 6.00 & 1.43 & 6 & 6 & 1 & 1 & 1 & 0 & 0 & 0 & \\
24 & 5.96 & 6.00 & 0.91 & 7 & 11 & 5 & 0 & 1 & 0 & 0 & 0 & \\
23 & 5.96 & 6.00 & 0.95 & 8 & 8 & 5 & 2 & 0 & 0 & 0 & 0
\end{tabular}

\begin{tabular}{l|l|l|l|l|l|l|l|l|l|l|l}
22 & 5.95 & 6.00 & 0.81 & 7 & 8 & 6 & 1 & 0 & 0 & 0 & 0
\end{tabular}

\begin{tabular}{l|l|l|l|l|l|l|l|l|l|l|l}
21 & 5.95 & 6.00 & 0.55 & 5 & 10 & 6 & 0 & 0 & 0 & 0 & 0
\end{tabular}

$21 \quad 5.95$

\begin{tabular}{l|l|l|l|l|}
\hline .00 & 1.05 & 6 & 11 & 2 \\
\hline
\end{tabular}

\begin{tabular}{l|l|l|l|l|l|l|}
21 & 5.95 & 6.00 & 1.35 & 7 & 9 & 4
\end{tabular}

\begin{tabular}{l|l|}
\hline & 1 \\
\hline & 0 \\
\hline
\end{tabular}

\begin{tabular}{l|l}
1 & 1 \\
0 & 0
\end{tabular}

\begin{tabular}{|l|l|}
0 & 0 \\
\hline & 1
\end{tabular}

16

$5.94 \quad 6.00$

\begin{tabular}{lll|l|l|l|}
0.60 & 4 & 7 & 5 & 0 \\
\hline
\end{tabular}

0

0

25

\begin{tabular}{|l|l|l|l|l|}
5.92 & 6.00 & 0.91 & 6 & 14 \\
\hline
\end{tabular}

1

23

$23 \quad 5.91$

\begin{tabular}{lllllllllllll}
6.00 & 1.08 & 7 & 10 & 4 & 1 & 1 & 0 & 0 & 0 \\
\hline
\end{tabular}

21

\begin{tabular}{l|l|l} 
& & \\
18 & 5.89 & 6.0
\end{tabular}

\begin{tabular}{|l|lll|l|l|l|l|l|l|l|}
5.89 & 6.00 & 0.81 & 5 & 7 & 5 & 1 & 0 & 0 & 0 & 0 \\
\hline & & & & & & & & &
\end{tabular}

\begin{tabular}{l|l|l|l|l|l|l|l|l|l|l|l}
18 & 5.89 & 6.00 & 0.81 & 4 & 10 & 2 & 2 & 0 & 0 & 0 & 0
\end{tabular}

25

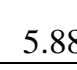

88

\begin{tabular}{l|l|l|l}
\hline .00 & 1.28 & 9 & 8 \\
\hline
\end{tabular}

2

0

How do CHANS interact across multiple scales?

|

\begin{tabular}{|l|l|l|l|l|l|l|l|l|l|l|l|l|}
24 & 5.88 & 6.00 & 0.90 & 6 & 11 & 6 & 0 & 1 & 0 & 0 & 0 & \\
\hline 22 & 5.86 & 6.00 & 1.27 & 6 & 11 & 3 & 0 & 2 & 0 & 0 & 0 & \\
\hline 19 & 5.84 & 6.00 & 0.58 & 4 & 8 & 7 & 0 & 0 & 0 & 0 & 0 & \\
\hline
\end{tabular}


How can we anticipate and adapt to novel conditions in response to climate change and demographic pressures?

How can conservation of natural systems provide resilience of human systems to impacts of climate change, such as extreme weather and rising sea levels?

What is the relationship between ecosystem services and function in human dominated systems?

How can we systematically consider the tradeoffs between decisions across coupled human and natural systems?

How do values influence human behavior in regards to natural systems?

How do feedbacks control coupled human and natural systems?

How do local biophysical changes from human interventions influence regional and global

biophysical processes (especially with respect to water)?

How do people best adapt to climate change?

What is the impact of human-induced land cover change on climate?

How do we account for and understand the role of legacy and cummulative effects in CHANS?

How can climate change adaptation and mitigation be integrated?

How can the interests of people and the environment be balanced in development, particularly in developing countries which still require a lot of natural resources?

How can governance systems become resilient in the face of rapidly changing social-ecological systems?

What urbanization strategies best promote sustainable urban landscapes?

What are some economical and social factors that prevent sustainable agriculture and permaculture from succeeding?

How will spatially differential climate change impacts affect local, national and international policy responses?

\begin{tabular}{|c|c|c|c|c|c|c|c|c|c|c|c|c|}
\hline ADAPTATION \& RESILIENCE & 19 & 5.84 & 6.00 & 0.70 & 3 & 12 & 2 & 2 & 0 & 0 & 0 & 0 \\
\hline CLIMATE CHANGE \& ENERGY & 25 & 5.84 & 6.00 & 1.72 & 9 & 9 & 4 & 1 & 1 & 1 & 0 & 0 \\
\hline $\begin{array}{l}\text { CONSERVATION \& ECOSYSTEM } \\
\text { SERVICES }\end{array}$ & 18 & 5.83 & 6.00 & 0.38 & 2 & 11 & 5 & 0 & 0 & 0 & 0 & 0 \\
\hline METHODS & 24 & 5.83 & 6.00 & 1.19 & 7 & 10 & 4 & 2 & 1 & 0 & 0 & 0 \\
\hline BEHAVIOR \& ECONOMICS & 23 & 5.83 & 6.00 & 0.70 & 5 & 10 & 7 & 1 & 0 & 0 & 0 & 0 \\
\hline $\begin{array}{l}\text { GENERAL PRINCIPLES \& } \\
\text { SYSTEM DYNAMICS }\end{array}$ & 17 & 5.82 & 6.00 & 0.90 & 4 & 8 & 3 & 2 & 0 & 0 & 0 & 0 \\
\hline SCALE & 28 & 5.82 & 6.00 & 1.41 & 9 & 10 & 6 & 2 & 0 & 1 & 0 & 0 \\
\hline ADAPTATION \& RESILIENCE & 22 & 5.82 & 6.00 & 0.82 & 5 & 10 & 5 & 2 & 0 & 0 & 0 & 0 \\
\hline LAND USE \& AGRICULTURE & 16 & 5.81 & 6.00 & 1.36 & 6 & 3 & 6 & 0 & 1 & 0 & 0 & 0 \\
\hline SCALE & 21 & 5.81 & 6.00 & 0.56 & 3 & 12 & 5 & 1 & 0 & 0 & 0 & 0 \\
\hline CLIMATE CHANGE \& ENERGY & 21 & 5.81 & 6.00 & 0.66 & 5 & 7 & 9 & 0 & 0 & 0 & 0 & 0 \\
\hline $\begin{array}{l}\text { SUSTAINABILITY \& } \\
\text { DEVELOPMENT }\end{array}$ & 21 & 5.81 & 6.00 & 1.06 & 6 & 7 & 7 & 0 & 1 & 0 & 0 & 0 \\
\hline GOVERNANCE & 21 & 5.81 & 6.00 & 1.16 & 6 & 8 & 5 & 1 & 1 & 0 & 0 & 0 \\
\hline LAND USE \& AGRICULTURE & 26 & 5.81 & 6.00 & 1.20 & 7 & 11 & 6 & 0 & 2 & 0 & 0 & 0 \\
\hline LAND USE \& AGRICULTURE & 20 & 5.80 & 6.00 & 0.59 & 3 & 11 & 5 & 1 & 0 & 0 & 0 & 0 \\
\hline CLIMATE CHANGE \& ENERGY & 20 & 5.80 & 6.00 & 1.12 & 7 & 4 & 7 & 2 & 0 & 0 & 0 & 0 \\
\hline
\end{tabular}


What determines how people in the role of decision-makers value the environment?

How can we change the stovepipe attitudes of academia and its stovepipe training of students? How does the spatial configuration of land use contribute to ecosystem services and sustainability?

How do human social networks affect the way humans interact with ecological systems?

What are the behavioral explanations for why people use resources one way in one place, but a different way in another place?

What are the linkages between globalization processes and CHANS?

What are the social and economic challenges to moving forward to a low impact path of development?

How can researchers improve assessment strategies at appropriate time and space scales?

What steps will result in the incorporation of market externalities without causing large negative impacts on significant segments (e.g. low-income) of society?

What are the interrelated and interacting human institutions that must be created (or altered) to identify and cope with different coupled-system changes?

Under what conditions do people exhibit a limited or strong ability to respond to the (anticipated or observed) effects of climate change?

What is the scale at which humans are most capable of sustainable interaction with the natural world?

What are the linkages between human populations and natural systems?

How do CHANS dynamics and feedbacks vary across spatial and temporal scales?

How can we learn about ecological boundaries before we cross them, and adjust our human systems to avoid irreparable damage?

How can CHANS feedbacks best be managed for both human needs and the environment's good?

BEHAVIOR \& ECONOMICS

EDUCATION \& SCIENCE

COMMUNICATION

LAND USE \& AGRICULTURE

SOCIETY \& CULTURE

BEHAVIOR \& ECONOMICS

GENERAL PRINCIPLES \&

SYSTEM DYNAMICS

SUSTAINABILITY \&

DEVELOPMENT

SCALE

BEHAVIOR \& ECONOMICS

BEHAVIOR \& ECONOMICS

GOVERNANCE

\begin{tabular}{l|l|l|l|l|l|l|l|l|l|l|l}
20 & 5.70 & 6.00 & 1.17 & 6 & 5 & 6 & 3 & 0 & 0 & 0 & 0
\end{tabular}

\begin{tabular}{l|l|l|l|l|l|l|l|l|l|l|l}
20 & 5.70 & 6.00 & 1.48 & 6 & 5 & 8 & 0 & 0 & 1 & 0 & 0 \\
\hline
\end{tabular}

$23 \quad 5.70$

\begin{tabular}{l|l|l|l|l|l|l|l|l|l}
6.00 & 1.13 & 6 & 7 & 8 & 1 & 1 & 0 & 0 & 0 \\
\hline
\end{tabular}

\begin{tabular}{llllllllllllllll}
23 & 5.70 & 6.00 & 1.58 & 7 & 8 & 4 & 2 & 2 & 0 & 0 & 0 \\
\hline
\end{tabular}

$26 \quad 5.69$

\begin{tabular}{l|l|l}
19 & 5.68 \\
\hline
\end{tabular}

6.00

\begin{tabular}{l|l|l|l|}
0.70 & 4 & 12 & 8
\end{tabular}

\begin{tabular}{ll|l|l|l|} 
& & & & \\
0 & 0 & 0 & 0 \\
\hline
\end{tabular}

\begin{tabular}{|l|l|l|l|l|l|l|l|l|l|l|}
5.68 & 6.00 & 0.89 & 4 & 7 & 6 & 2 & 0 & 0 & 0 & 0 \\
\hline
\end{tabular}

19

\begin{tabular}{l|l|l} 
& & \\
25 & 5.68 & 6.0
\end{tabular}

\begin{tabular}{l|l|l|l|l|l|}
25 & 5.68 & 6.00 & 0.56 & 3 & 12 \\
\hline
\end{tabular}

CLIMATE CHANGE \& ENERGY

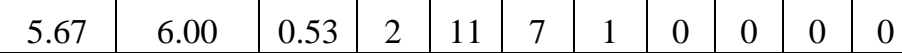

2

SCALE

\begin{tabular}{l|l|l|l|l|l|l|l|l|l|l|l}
24 & 5.67 & 6.00 & 1.01 & 5 & 9 & 8 & 1 & 1 & 0 & 0 & 0
\end{tabular}

SOCIETY \& CULTURE

SCALE

ADAPTATION \& RESILIENCE

\section{GOVERNANCE}

\begin{tabular}{l|l}
20 & 5.65
\end{tabular}

6.00


How can uncertainty be more effectively

employed in understanding and managing coupled systems?

What are ecological and socio-political

consequences of land cover change?

What new data sets should we be building to improve our modeling of human-natural system dynamics?

How will human consumption patterns change in the coming decades?

How does climate change affect ecosystems and biodiversity?

What areas of human systems have the greatest potential for mitigation of human impacts on natural systems?

What policies improve management of CHANS? How do we better understand linkages between systems?

How does culture motivate or demotivate humans in protecting their natural environments?

How can issues of accelerating uncertainty for future projections from coupled human and natural systems be modelled?

How do we quantify the spatio-temporal interactions among human and natural systems?

What are the most effective ways to communicate and/or implement interventions in CHANS?

How do we rebuild the connection between humanity and the natural environment in order to foster a protective attitude to sustainability?

What are the tipping points in CHANS due to climate change?

How can cultures be transformed into more sustainable social systems?

How can we design protected areas that are both

biologically effective and socially just?

What influences human behavioral change towards natural systems?

What is the relationship between poverty, livelihoods and environmental degradation?
GOVERNANCE

LAND USE \& AGRICULTURE

METHODS

SOCIETY \& CULTURE

CLIMATE CHANGE \& ENERGY

SOCIETY \& CULTURE

GOVERNANCE

GENERAL PRINCIPLES \&

SYSTEM DYNAMICS

SOCIETY \& CULTURE

METHODS

METHODS

SCALE

EDUCATION \& SCIENCE

COMMUNICATION

SUSTAINABILITY \&

DEVELOPMENT

CLIMATE CHANGE \& ENERGY

SOCIETY \& CULTURE

CONSERVATION \& ECOSYSTEM

SERVICES

BEHAVIOR \& ECONOMICS

SUSTAINABILITY \&

DEVELOPMENT \begin{tabular}{|l|l|l|l|l|l|l|l|l|l|l|l|l|}
20 & 5.65 & 6.00 & 1.50 & 5 & 8 & 4 & 1 & 2 & 0 & 0 & 0 & \\
17 & 5.65 & 6.00 & 1.12 & 3 & 8 & 4 & 1 & 1 & 0 & 0 & 0 & \\
17 & 5.65 & 6.00 & 1.49 & 5 & 5 & 4 & 2 & 1 & 0 & 0 & 0 & \\
\hline
\end{tabular}

\begin{tabular}{l|l|l|l|l|l|l|l|l|l|l|l}
22 & 5.64 & 6.00 & 1.29 & 6 & 6 & 7 & 2 & 1 & 0 & 0 & 0 \\
\hline
\end{tabular}

\begin{tabular}{l|l|l|l|l|l|l|l|l|l|l|l}
19 & 5.63 & 6.00 & 1.13 & 4 & 8 & 3 & 4 & 0 & 0 & 0 & 0
\end{tabular}

\begin{tabular}{l|l|l|l|l|l|l|l|l|l|l|l}
19 & 5.63 & 6.00 & 1.58 & 5 & 6 & 6 & 1 & 0 & 1 & 0 & 0
\end{tabular}

\begin{tabular}{l|l|l|l|l|l|l|l|l|l|l|l|}
21 & 5.62 & 6.00 & 1.95 & 7 & 6 & 4 & 1 & 3 & 0 & 0 & 0
\end{tabular}

\begin{tabular}{|l|l|l|l|l|l|l|l|l|l|l|l|}
21 & 5.62 & 6.00 & 2.15 & 7 & 7 & 2 & 3 & 1 & 1 & 0 & 0
\end{tabular}

\begin{tabular}{l|l|l|l|l|l|l|l|l|l|l|l}
26 & 5.62 & 6.00 & 0.81 & 4 & 11 & 8 & 3 & 0 & 0 & 0 & 0 \\
\hline
\end{tabular}

\begin{tabular}{|l|l|l|l|l|l|l|l|l|l|l}
5.61 & 6.00 & 0.60 & 2 & 8 & 7 & 1 & 0 & 0 & 0 & 0
\end{tabular}

\begin{tabular}{l|l|l|l|l|l|l|l|l|l|l|l}
18 & 5.61 & 6.00 & 1.19 & 4 & 6 & 6 & 1 & 1 & 0 & 0 & 0 \\
\hline
\end{tabular}

\begin{tabular}{l|l|l|l|l|l|l|l|l|l|l|l}
18 & 5.61 & 6.00 & 1.55 & 4 & 8 & 3 & 1 & 2 & 0 & 0 & 0 \\
\hline
\end{tabular}

\begin{tabular}{|l|l|l|l|l|l|l|l|l|l|l|l}
23 & 5.61 & 6.00 & 1.61 & 6 & 9 & 3 & 3 & 2 & 0 & 0 & 0
\end{tabular}

\begin{tabular}{|l|l|l|l|l|l|l|l|l|l|l|l}
23 & 5.61 & 6.00 & 1.70 & 6 & 8 & 6 & 1 & 1 & 1 & 0 & 0
\end{tabular}

\begin{tabular}{llllllllllllllll|l}
23 & 5.61 & 6.00 & 1.89 & 6 & 8 & 6 & 2 & 0 & 0 & 1 & 0
\end{tabular}

\begin{tabular}{l|l|l|l|l|l|l|l|l|l|l|l|l|}
20 & 5.60 & 6.00 & 1.20 & 5 & 6 & 5 & 4 & 0 & 0 & 0 & 0
\end{tabular}

\begin{tabular}{l|l|l|l|l|l|l|l|l|l|l|l}
20 & 5.60 & 6.00 & 1.20 & 5 & 6 & 5 & 4 & 0 & 0 & 0 & 0 \\
\hline
\end{tabular}

25

$15 \quad 5.60$

\begin{tabular}{l|l|l|l|l|l|l|l|l|l}
6.00 & 1.42 & 6 & 8 & 8 & 2 & 0 & 1 & 0 & 0 \\
6.00 & 1.69 & & & & & & & &
\end{tabular}


How do we measure externalities and interactions in coupled human and natural systems?

How does climate variability and water resource accessibility affect population growth and distribution?

How do scientists best integrate data, methods, and epistomologies from different discipines to best understand CHANS?

How do humans perceive and respond to natural systems?

What drives variability in CHANS and how does variabilty govern system behavior?

How do certain political and social development decisions impact natural systems?

How do we improve cooperation in the commons?

How do scientists best communicate the complexity of CHANS to resource managers, policy makers, and the public?

How do we best manage complex, multi-scaled, multi-objective CHANS?

Under what scenarios will drivers of urbanization and land use change promote sustainable city development?

How do we co-produce knowledge between scientists, managers and society?

How do we convince society of the value of data to support information-driven management? What is the plasticity (ease of change) and elasticity of major human drivers of

environmental change?

What types of outreach measures are needed to draw the link between humans and natural systems for non science demographics?

How can we empower community-based decisions $\quad$ SOCIETY \& CULTURE that satisfy as many stakeholders as possible?

How rapidly can humans adapt to environmental change?

What are the right policies for achieving optimal scale of economy relative to the natural systems? What is the role of bottom-up versus top-down policy in the management of these systems?
METHODS

CLIMATE CHANGE \& ENERGY

METHODS

BHAVIOR \& ECONOMICS

GENERAL PRINCIPLES \&

SYSTEM DYNAMICS

SUSTAINABILITY \&

DEVELOPMENT

GOVERNANCE

EDUCATION \& SCIENCE

COMMUNICATION

GOVERNANCE

LAND USE \& AGRICULTURE

EDUCATION \& SCIENCE

COMMUNICATION

EDUCATION \& SCIENCE

COMMUNICATION

ADAPTATION \& RESILIENCE

EDUCATION \& SCIENCE

COMMUNICATION

ADAPTATION \& RESILIENCE

GOVERNANCE

GOVERNANCE

\begin{tabular}{|c|c|c|c|c|c|c|c|c|c|c|c|}
\hline 20 & 5.60 & 5.50 & 1.73 & 7 & 3 & 7 & 1 & 2 & 0 & 0 & 0 \\
\hline 20 & 5.60 & 6.00 & 2.04 & 7 & 5 & 4 & 1 & 3 & 0 & 0 & 0 \\
\hline 19 & 5.58 & 6.00 & 1.37 & 5 & 5 & 6 & 2 & 1 & 0 & 0 & 0 \\
\hline 21 & 5.57 & 6.00 & 1.16 & 4 & 8 & 6 & 2 & 1 & 0 & 0 & 0 \\
\hline 21 & 5.57 & 6.00 & 1.36 & 4 & 9 & 5 & 1 & 2 & 0 & 0 & 0 \\
\hline 14 & 5.57 & 5.50 & 1.49 & 4 & 3 & 5 & 1 & 1 & 0 & 0 & 0 \\
\hline 23 & 5.57 & 6.00 & 1.44 & 5 & 8 & 7 & 2 & 0 & 1 & 0 & 0 \\
\hline 23 & 5.57 & 6.00 & 2.08 & 7 & 6 & 7 & 1 & 0 & 2 & 0 & 0 \\
\hline 18 & 5.56 & 5.50 & 0.85 & 3 & 6 & 7 & 2 & 0 & 0 & 0 & 0 \\
\hline 18 & 5.56 & 6.00 & 2.03 & 5 & 6 & 4 & 1 & 1 & 1 & 0 & 0 \\
\hline 20 & 5.55 & 6.00 & 1.21 & 2 & 11 & 5 & 1 & 0 & 1 & 0 & 0 \\
\hline 22 & 5.55 & 5.50 & 0.74 & 3 & 8 & 9 & 2 & 0 & 0 & 0 & 0 \\
\hline 22 & 5.55 & 6.00 & 0.83 & 2 & 11 & 7 & 1 & 1 & 0 & 0 & 0 \\
\hline 22 & 5.55 & 6.00 & 1.02 & 4 & 8 & 6 & 4 & 0 & 0 & 0 & 0 \\
\hline 22 & 5.55 & 5.50 & 2.26 & 8 & 3 & 7 & 3 & 0 & 0 & 1 & 0 \\
\hline 24 & 5.54 & 6.00 & 1.30 & 5 & 9 & 5 & 4 & 1 & 0 & 0 & 0 \\
\hline 17 & 5.53 & 6.00 & 1.14 & 2 & 9 & 3 & 2 & 1 & 0 & 0 & 0 \\
\hline 19 & 5.53 & 6.00 & 1.49 & 5 & 5 & 5 & 3 & 1 & 0 & 0 & 0 \\
\hline
\end{tabular}


How do we mobilize individuals for collective action?

How do we break through and begin discussing the role of hard/uncomfortable issues in coupled processes (e.g., privilege, racism, etc.)?

Why and how do social inequalities emerge, grow, persist, and diminish, and with what

consequences?

How can we deal with externalities of human acitvities?

How do we transform (or retrofit) existing sociopolitical systems/institutions that serve as barriers to change?

How do we use technological advances to manage and mitigate environmental change

How do land use and land cover change influence household and/or community vulnerability and vice versa, especially in marginal envrionments?

How and when do humans feel connected to natural systems?

Can we better understand and manage the

environmental impacts of the resource and waste streams through which people's needs and wants are met?

How do different types of ownership of resources (public, private, commons) affect the viability of CHANS?

How best can various disciplines be integrated for effective research on CHANS?

How do short term actions affect the long term behavior of CHANS?

\section{What explains resilience in CHANS?}

How can we design decision-making structures to bring together groups with disparate objectives?

How can we use our knowledge of 'natural' systems to understand cities?

How can we quantify and incorporate culturally valued resources in SES?

What is the most effective way to get managers and policy makers involved in coupled systems research?

\begin{tabular}{|c|c|c|c|c|c|c|c|c|c|c|c|c|}
\hline BEHAVIOR \& ECONOMICS & 19 & 5.53 & 6.00 & 1.93 & 4 & 9 & 2 & 2 & 1 & 1 & 0 & 0 \\
\hline \multirow[t]{2}{*}{ SOCIETY \& CULTURE } & & & & & & & & & & & & \\
\hline & 19 & 5.53 & 6.00 & 2.04 & 3 & 10 & 4 & 0 & 1 & 0 & 1 & 0 \\
\hline $\begin{array}{l}\text { SUSTAINABILITY \& } \\
\text { DEVELOPMENT }\end{array}$ & 21 & 5.52 & 6.00 & 0.56 & 1 & 11 & 7 & 2 & 0 & 0 & 0 & 0 \\
\hline BEHAVIOR \& ECONOMICS & 23 & 5.52 & 6.00 & 1.44 & 6 & 6 & 6 & 4 & 1 & 0 & 0 & 0 \\
\hline GOVERNANCE & 25 & 5.52 & 6.00 & 2.09 & 4 & 15 & 1 & 2 & 2 & 0 & 1 & 0 \\
\hline GOVERNANCE & 24 & 5.50 & 6.00 & 0.96 & 2 & 12 & 8 & 0 & 2 & 0 & 0 & 0 \\
\hline LAND USE \& AGRICULTURE & 18 & 5.50 & 5.50 & 1.09 & 3 & 6 & 7 & 1 & 1 & 0 & 0 & 0 \\
\hline SOCIETY \& CULTURE & 20 & 5.50 & 5.00 & 1.21 & 5 & 3 & 10 & 1 & 1 & 0 & 0 & 0 \\
\hline GOVERNANCE & 22 & 5.50 & 6.00 & 1.60 & 4 & 10 & 4 & 1 & 3 & 0 & 0 & 0 \\
\hline SOCIETY \& CULTURE & 24 & 5.50 & 6.00 & 1.83 & 6 & 8 & 6 & 0 & 4 & 0 & 0 & 0 \\
\hline METHODS & 18 & 5.50 & 6.00 & 2.15 & 5 & 6 & 3 & 2 & 1 & 1 & 0 & 0 \\
\hline $\begin{array}{l}\text { GENERAL PRINCIPLES \& } \\
\text { SYSTEM DYNAMICS }\end{array}$ & 23 & 5.48 & 6.00 & 0.53 & 1 & 11 & 9 & 2 & 0 & 0 & 0 & 0 \\
\hline ADAPTATION \& RESILIENCE & 23 & 5.48 & 6.00 & 1.26 & 3 & 11 & 5 & 2 & 2 & 0 & 0 & 0 \\
\hline GOVERNANCE & 23 & 5.48 & 6.00 & 1.62 & 5 & 7 & 8 & 1 & 1 & 1 & 0 & 0 \\
\hline $\begin{array}{l}\text { GENERAL PRINCIPLES \& } \\
\text { SYSTEM DYNAMICS }\end{array}$ & 21 & 5.48 & 5.00 & 0.86 & 3 & 7 & 8 & 3 & 0 & 0 & 0 & 0 \\
\hline METHODS & 21 & 5.48 & 5.00 & 0.96 & 3 & 7 & 9 & 1 & 1 & 0 & 0 & 0 \\
\hline GOVERNANCE & 21 & 5.48 & 5.00 & 1.06 & 4 & 5 & 10 & 1 & 1 & 0 & 0 & 0 \\
\hline
\end{tabular}


How do you best value natural resources especially when there is great uncertainty regarding environmental change?

How can people adapt to changing system

behavior while still getting what they need from

the system?

If both people and the environment should be

considered in development, how can we strike the balance?

How do we move beyond the case study in the governance of CHANS?

How can we transform the human dimension to be more aware of its integration and dependence on natural systems?

How do natural resource institutions influence the adaptive capacity of coupled systems?

How do we truly incorporate iterative process into our decision making process?

What is and what explains the variability in coupling between human and natural systems?

How can we anticipate system change in a very narrow management time frame?

How do we scale up smaller-scale analyses of managed processes in the enviroment to reflect policy and governance?

How does scientific information--e.g., predictions, risk assessments, response plans, or scientific study in general--influence people, organizations, and societies in their approach to coupled or potentially coupled human and natural systems?

How does human learning at the individual and group level affect the interaction of coupled human and natural systems?

What are the key sets of internal system feedback connections, that are most likely to trigger system change, or be affected by external changes?

How can we develop CHANS theory?
BEHAVIOR \& ECONOMICS

19

ADAPTATION \& RESILIENCE

SUSTAINABILITY \&

DEVELOPMENT

GOVERNANCE

SUSTAINABILITY \&

DEVELOPMENT

ADAPTATION \& RESILIENCE

GOVERNANCE

GOVERNANCE

GENERAL PRINCIPLES \&

SYSTEM DYNAMICS

GOVERNANCE

SCALE

SOCIETY \& CULTURE

19

\begin{tabular}{l|l|l}
19 & 5.47 & 5.00 \\
\hline
\end{tabular} $\begin{array}{lllllllllll}0.49 & 1 & 8 & 9 & 1 & 0 & 0 & 0 & 0\end{array}$

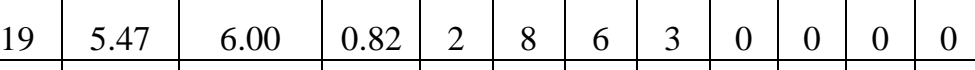
\begin{tabular}{l|l|l|l|l|l|l|l|l|l|l|l}
19 & 5.47 & 6.00 & 2.49 & 6 & 6 & 2 & 2 & 2 & 1 & 0 & 0
\end{tabular}

\begin{tabular}{llllll|l|l|l|l|l|l|l}
26 & 5.46 & 6.00 & 1.38 & 4 & 11 & 7 & 1 & 3 & 0 & 0 & 0 \\
\hline
\end{tabular}

(26

\begin{tabular}{l|l|l|l|l|l|l|l|l|l|l|l|}
26 & 5.46 & 6.00 & 2.34 & 7 & 8 & 6 & 3 & 0 & 1 & 1 & 0 \\
\hline
\end{tabular}

\begin{tabular}{l|l|l|l|l|l|l|l|l|l|l|l}
22 & 5.45 & 6.00 & 1.21 & 2 & 11 & 6 & 2 & 0 & 1 & 0 & 0
\end{tabular}

\begin{tabular}{l|l|l|l|l|l|l|l|l|l|l|l}
20 & 5.45 & 6.00 & 1.52 & 4 & 7 & 5 & 2 & 2 & 0 & 0 & 0
\end{tabular}

\begin{tabular}{|l|l|l|l|l|l|l|l|l|l|l|l|}
5.45 & 6.00 & 1.52 & 4 & 7 & 5 & 2 & 2 & 0 & 0 & 0 & \\
\hline 5.79 & & & & & & & & & & & \\
& & & & & & & & & & &
\end{tabular}

$18 \quad 5.44$

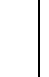

\begin{tabular}{|c|c|c|c|c|c|c|c|c|c|c|c|c|}
\hline & 23 & 5.43 & 6.00 & 1.17 & 2 & 11 & 7 & 2 & 0 & 1 & 0 & 0 \\
\hline \multirow[t]{2}{*}{ BEHAVIOR \& ECONOMIC } & & & & & & & & & & & & \\
\hline & 23 & 5.43 & 6.00 & 1.53 & 4 & 9 & 5 & 4 & 0 & 1 & 0 & 0 \\
\hline \multirow[t]{2}{*}{$\begin{array}{l}\text { GENERAL PRINCIPLES \& } \\
\text { SYSTEM DYNAMICS }\end{array}$} & & & & & & & & & & & & \\
\hline & 23 & 5.43 & 6.00 & 1.53 & 3 & 9 & 9 & 1 & 0 & 0 & 1 & 0 \\
\hline $\begin{array}{l}\text { GENERAL PRINCIPLES \& } \\
\text { SYSTEM DYNAMICS }\end{array}$ & 23 & 5.43 & 6.00 & 1.98 & 5 & 8 & 6 & 2 & 0 & 2 & 0 & 0 \\
\hline
\end{tabular}


How can coupled-system complexity be reconciled with societal need for a degree of clarity and predictability, and how does this need vary at different social/ecological scales?

How will the benefits provided by nature and the persistence and distribution of species change in the future?

What are the long and short term socio-economic impacts of contaminated ecosystem mitigation due to Hydraulic fracturing processes?

How do human interactions with an ecosystem circulate through ecological networks?

How can CHANS methods be developed beyond integrative modeling?

What are the mechanisms and circumstances that create the conditions appropriate for successful collective action?

What essential 'rules' are most important to understand in various complex adaptive systems that are being managed?

How can we link landscape ecology and life cycle assessment to promote sustainable landscapes?

How does upstream degradation affect downriver ecosystem service delivery?

How can we employ an ecosystem services approach to management from the local to global scale?

How are the clear facts of coupled human and

natural systems obscured in policy, in

management, and in Western cultural

orientations?

What issues need to be investigated from the prism of CHANS?

How do we improve connectivity of wildlife habitat across a landscape?

Which modeling tools and what scales are suitable for understanding and forecasting land use change in developing regions?

What has been gained from knowledge of coupled human and natural systems, and what more can be gained?
GENERAL PRINCIPLES \& SYSTEM DYNAMICS

CONSERVATION \& ECOSYSTEM
SERVICES

CLIMATE CHANGE \& ENERGY

GENERAL PRINCIPLES \&

SYSTEM DYNAMICS

METHODS

GOVERNANCE

ADAPTATION \& RESILIENCE

CONSERVATION \& ECOSYSTEM

SERVICES

CONSERVATION \& ECOSYSTEM

SERVICES

SOCIETY \& CULTURE

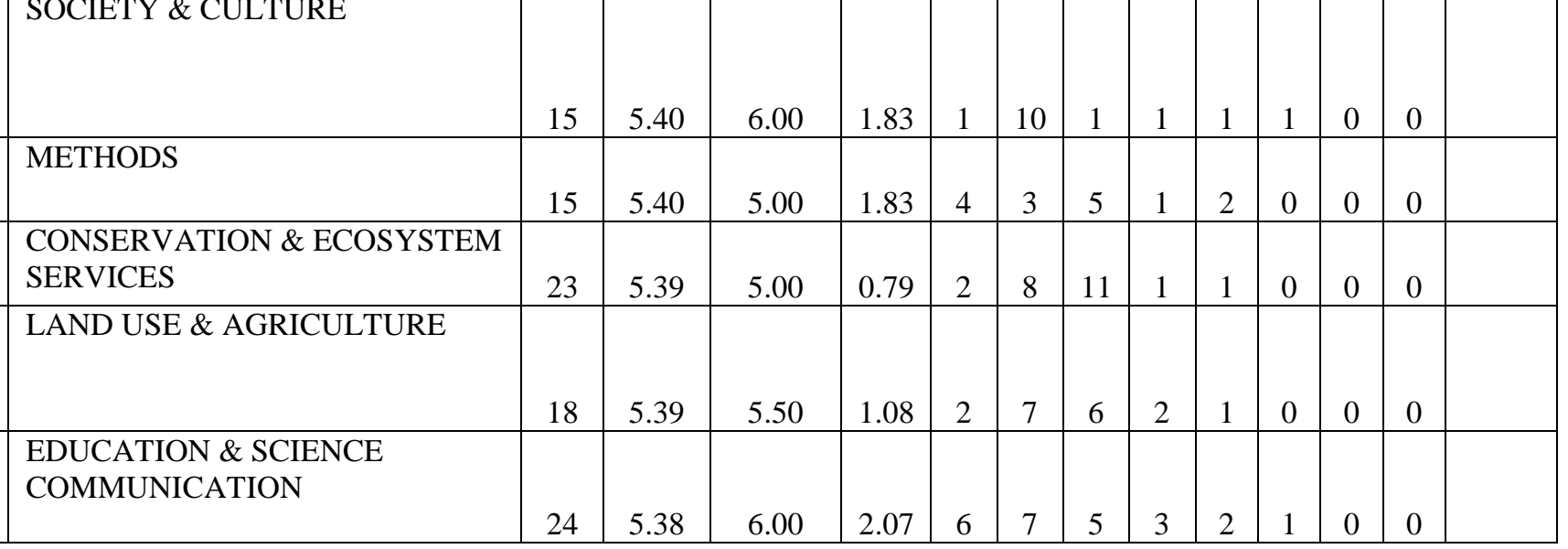


How do we improve primary education on the complexity of CHANS?

What are the best methods for the study of CHANS?

What factors positively contribute to reducing the impact of the global market system that erodes resilience of social-ecological systems?

How sustainable are our current industrial food systems?

How do power dynamics and differentials within social systems affect CHANS dynamics?

What can we know about the behaviour of systems to new human and physical perturbations?

What is the role of technology and human adaptation in managing CHANS systems?

What is the role of CHANS researchers in the policy debates that are generated as a function of the community's research?

What are the relationships among environment, population dynamics, settlement structure, and human mobility?

How much mechanistic knowledge is needed of coupled systems dynamics in order to predict likely responses?

How do we find more resources for research and management?

How can we explore the question of networks between and within CHANS?

How do CHANS evolve?

How can we best model complex, multi-scale, multi-actor CHANS ?

How can income streams be linked to various ecosystem services so that better environmental outcomes can be realized?

Can researchers develop transferable operationalized metrics showing connections between social and ecological systems?

How should we evaluate biodiversity for human needs?
EDUCATION \& SCIENCE COMMUNICATION

METHODS

ADAPTATION \& RESILIENCE

LAND USE \& AGRICULTURE SOCIETY \& CULTURE

GENERAL PRINCIPLES \&

SYSTEM DYNAMICS

SOCIETY \& CULTURE

EDUCATION \& SCIENCE

COMMUNICATION

SOCIETY \& CULTURE

GENERAL PRINCIPLES \&

SYSTEM DYNAMICS

GOVERNANCE

METHODS

GENERAL PRINCIPLES \&

SYSTEM DYNAMICS

METHODS

CONSERVATION \& ECOSYSTEM

SERVICES

GENERAL PRINCIPLES \&

SYSTEM DYNAMICS

CONSERVATION \& ECOSYSTEM

SERVICES \begin{tabular}{l|l|l|l|l|l|l|l|l|l|l|l|}
19 & 5.37 & 6.00 & 1.80 & 4 & 6 & 4 & 4 & 0 & 1 & 0 & 0 \\
\hline
\end{tabular}

\begin{tabular}{l|l|l|l|l|l|l|l|l|l|l|l}
22 & 5.36 & 6.00 & 1.10 & 2 & 10 & 5 & 4 & 1 & 0 & 0 & 0
\end{tabular}

$22 \quad 5.36$

5.00

\begin{tabular}{l|l|l|l|l|l|l|l|l}
1.58 & 4 & 6 & 9 & 1 & 1 & 1 & 0 & 0
\end{tabular}

\begin{tabular}{|l|l|l|l|l|l|l|l|l|l|l|l|l|}
25 & 5.36 & 6.00 & 2.24 & 5 & 9 & 6 & 3 & 0 & 1 & 1 & 0
\end{tabular}

\begin{tabular}{l|l|l|l|l|l|l|l|l|l|l|l}
14 & 5.36 & 5.50 & 1.02 & 1 & 6 & 5 & 1 & 1 & 0 & 0 & 0 \\
\hline
\end{tabular}

17

$5.35 \quad 5.00$

$20 \quad 5.35$

\begin{tabular}{llll|l|l|l|l|l|l|l}
5.00 & 0.56 & 1 & 7 & 10 & 2 & 0 & 0 & 0 & 0
\end{tabular}

$20 \quad 5.35$

6.00

1.71 38

2

2 1

0

23

23

\begin{tabular}{l|l|l|l|l|l|l|l|l|l|l|l}
23 & 5.35 & 5.00 & 2.42 & 6 & 5 & 8 & 2 & 0 & 1 & 1 & 0
\end{tabular}

\begin{tabular}{l|l|l|l|l|l|l|l|l|l|l|l}
18 & 5.33 & 5.00 & 0.71 & 1 & 7 & 7 & 3 & 0 & 0 & 0 & 0 \\
\hline
\end{tabular}

\begin{tabular}{l|l|l|l|l|l|l|l|l|l|l|l}
21 & 5.33 & 6.00 & 1.63 & 3 & 8 & 6 & 2 & 1 & 1 & 0 & 0
\end{tabular}

\begin{tabular}{|l|l|l|l|l|l|l|l|l|l|l|l|}
21 & 5.33 & 5.00 & 1.63 & 4 & 6 & 7 & 1 & 3 & 0 & 0 & 0 \\
\hline
\end{tabular}

\begin{tabular}{l|l|l|l|l|l|l|l|l|l|l|l}
25 & 5.32 & 6.00 & 1.31 & 2 & 11 & 8 & 2 & 1 & 1 & 0 & 0 \\
\hline
\end{tabular}

\begin{tabular}{l|l|l|l|l|l|l|l|l|l|l|l}
25 & 5.32 & 5.00 & 1.73 & 5 & 6 & 10 & 1 & 2 & 1 & 0 & 0
\end{tabular}

\begin{tabular}{l|l|l}
25 & 5.32 & 5.0 \\
\hline
\end{tabular}

\begin{tabular}{|c|c|c|c|c|c|c|c|c|c|c|c|}
\hline 22 & 5.32 & 6.00 & 1.66 & 3 & 9 & 5 & 3 & 1 & 1 & 0 & 0 \\
\hline 19 & 5.32 & 5.00 & 0.56 & 0 & 9 & 7 & 3 & 0 & 0 & 0 & 0 \\
\hline
\end{tabular}


How do we ensure regulations are flexible and practical while also ensuring environmental safety?

What are the perceived and real tradeoffs in valuing specific ecosystem services (for society, environment,...)?

How do we understand context-dependency and place as a driving force?

How can management planners use basic science most effectively?

How will human per capita population growth rates change and what will be the spatial distribution of that change?

What are the most effective ways to model human behavior and decision making?

How can we effectively leverage rich place-based studies and "big data" to create more

comprehensive knowledge?

Which system elements function as underlying, persisting, slow variables vs. fast variables?

How can we accurately measure human response to a CHANS project?

To what extent is our understanding of hierarchies in CHANS an accurate reflection of what is occuring, and what are alternate explanations?

How have human relationships with nature changed over time and how will they change in the future?

How do we operationalize a measure of human well-being?

What is the perceived value of the cost or benefit of management of climate change and land use change?

How can scientific results in climate be used to address CHANS research?

What are the constants in socio-ecological perception and values across race, culture, and economic status?

How can connections to nature of a global urbanizing population be strengthened?

\section{What is the human influence on the}

biogeochemical cycling of toxic trace elements

within Earth's System?
GOVERNANCE

CONSERVATION \& ECOSYSTEM

SERVICES

GENERAL PRINCIPLES \& SYSTEM DYNAMICS

GOVERNANCE

SOCIETY \& CULTURE

16

BEHAVIOR \& ECONOMICS

METHODS

GENERAL PRINCIPLES \&

SYSTEM DYNAMICS

METHODS

SCALE

SOCIETY \& CULTURE

METHODS

BEHAVIOR \& ECONOMICS

CLIMATE CHANGE \& ENERGY

SOCIETY \& CULTURE

SOCIETY \& CULTURE

GENERAL PRINCIPLES \&

SYSTEM DYNAMICS

25 \begin{tabular}{l|l|l|l|l|l|l|l|l|l|l|l}
19 & 5.32 & 5.00 & 1.45 & 3 & 6 & 6 & 2 & 2 & 0 & 0 & 0
\end{tabular}

19

\begin{tabular}{l|l|l|l|l|l|l|l|l|l|l}
5.32 & 6.00 & 1.56 & 3 & 7 & 4 & 3 & 2 & 0 & 0 & 0
\end{tabular}

\begin{tabular}{l|l|l|l|l|l|l|l|l|l|l|l}
19 & 5.32 & 5.00 & 1.89 & 4 & 5 & 6 & 2 & 1 & 1 & 0 & 0 \\
\hline
\end{tabular}

\begin{tabular}{l|l|l|l|l|l|l|l|l|l|l|l}
19 & 5.32 & 6.00 & 2.01 & 2 & 9 & 5 & 1 & 1 & 0 & 1 & 0 \\
\hline
\end{tabular}

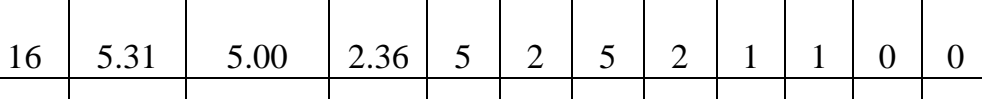

\begin{tabular}{l|l|l|l|l|l|l|l|l|l|l|l}
16 & 5.31 & 6.00 & 3.43 & 4 & 5 & 5 & 0 & 0 & 0 & 2 & 0 \\
\hline
\end{tabular}

\begin{tabular}{|l|l|l|l|l|l|l|l|l|l|l|l}
23 & 5.30 & 6.00 & 3.04 & 6 & 7 & 6 & 0 & 1 & 2 & 1 & 0
\end{tabular}

\begin{tabular}{lllllllllllllllll}
20 & 5.30 & 5.00 & 0.54 & 1 & 6 & 11 & 2 & 0 & 0 & 0 & 0 \\
\hline
\end{tabular}

\begin{tabular}{|l|l|l|l|l|l|l|l|l|l|l|l}
21 & 5.29 & 5.00 & 0.81 & 2 & 5 & 12 & 1 & 1 & 0 & 0 & 0 \\
\hline
\end{tabular}

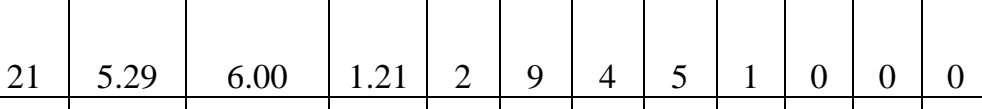

\begin{tabular}{llllll|l|l|l|l|l|l}
28 & 5.29 & 6.00 & 1.84 & 5 & 10 & 5 & 5 & 2 & 1 & 0 & 0
\end{tabular}

\begin{tabular}{|l|l|l|l|l|l|l|l|l|l|l|l}
21 & 5.29 & 5.00 & 2.41 & 6 & 4 & 6 & 1 & 3 & 1 & 0 & 0
\end{tabular}

\begin{tabular}{|l|l|l|l|l|l|l|l|l|l|l}
5.28 & 5.00 & 0.46 & 0 & 10 & 12 & 3 & 0 & 0 & 0 & 0 \\
\hline
\end{tabular}

\begin{tabular}{l|l|l|l|l|l|l|l|l|l|l|l}
18 & 5.28 & 5.50 & 0.80 & 0 & 9 & 6 & 2 & 1 & 0 & 0 & 0
\end{tabular}

\begin{tabular}{l|l|l|l|l|l|l|l|l|l|l|l}
22 & 5.27 & 5.00 & 0.78 & 1 & 8 & 10 & 2 & 1 & 0 & 0 & 0
\end{tabular}

\begin{tabular}{llllllllllllllll}
19 & 5.26 & 5.00 & 1.54 & 3 & 5 & 8 & 0 & 3 & 0 & 0 & 0 \\
\hline
\end{tabular}


What are the costs and benefits of channeling human and fiscal resources to coupled systems research vs fundamental disciplinary research?

How can human incentives be better aligned with their spatially and temporally removed impacts?

Are existing governance structures, policies and service delivering mechanisms effective in addressing marginal places and persons in urban areas, especially in developing economies?

How does one promote human awareness of the CHANS basis for human livelihoods?

How do we move from proxy variables and simple models of human behavior toward direct measurement?

How can forest disappearance due to the expansion of industrial agriculture and urbanization be stopped?

How do we recognize teleconnections and represent them in CHANS models?

How can knowledge of CHANS be co-produced among various stakeholders for learning and action?

How can society better control the spread of invasive species that endanger agricultural and native ecosystems?

How can the ever-increasing natural resource needs of communities be balanced with the needs of wildlife?

How do telecouplings shape socioeconomic and environmental sustainability across local to global levels?

Do people respond to predictive indicators of environmental stress?

How do we integrate humans into the natural world rather than treat them as 'coupled'?

Under what livelihood and environmental conditions do we see an alleviation of poverty?

\section{Do humans respond similarly to general classes of} ecological processes (e.g. linear, non-linear, slow, fast, threshold) despite local context (ecological, political, socio-economic)? Are there general CHANS principles?

\begin{tabular}{|c|c|c|c|c|c|c|c|c|c|c|c|c|}
\hline METHODS & 23 & 5.26 & 5.00 & 1.66 & 4 & 7 & 6 & 3 & 3 & 0 & 0 & 0 \\
\hline BEHAVIOR \& ECONOMICS & 20 & 5.25 & 5.00 & 1.14 & 2 & 6 & 9 & 1 & 2 & 0 & 0 & 0 \\
\hline GOVERNANCE & 24 & 5.25 & 5.50 & 1.59 & 3 & 9 & 6 & 4 & 1 & 1 & 0 & 0 \\
\hline $\begin{array}{l}\text { CONSERVATION \& ECOSYSTEM } \\
\text { SERVICES }\end{array}$ & 20 & 5.25 & 5.50 & 1.78 & 3 & 7 & 5 & 3 & 1 & 1 & 0 & 0 \\
\hline BEHAVIOR \& ECONOMICS & 24 & 5.25 & 5.00 & 2.37 & 5 & 6 & 9 & 1 & 1 & 1 & 1 & 0 \\
\hline LAND USE \& AGRICULTURE & 25 & 5.24 & 6.00 & 1.77 & 4 & 9 & 4 & 6 & 1 & 1 & 0 & 0 \\
\hline METHODS & 17 & 5.24 & 5.00 & 1.19 & 2 & 5 & 6 & 3 & 1 & 0 & 0 & 0 \\
\hline SOCIETY \& CULTURE & 17 & 5.24 & 5.00 & 2.32 & 5 & 3 & 3 & 3 & 3 & 0 & 0 & 0 \\
\hline $\begin{array}{l}\text { CONSERVATION \& ECOSYSTEM } \\
\text { SERVICES }\end{array}$ & 26 & 5.23 & 5.50 & 0.98 & 0 & 13 & 9 & 1 & 3 & 0 & 0 & 0 \\
\hline $\begin{array}{l}\text { CONSERVATION \& ECOSYSTEM } \\
\text { SERVICES }\end{array}$ & 22 & 5.23 & 5.50 & 2.18 & 4 & 7 & 5 & 4 & 1 & 0 & 1 & 0 \\
\hline $\begin{array}{l}\text { GENERAL PRINCIPLES \& } \\
\text { SYSTEM DYNAMICS }\end{array}$ & 18 & 5.22 & 5.00 & 1.24 & 2 & 5 & 8 & 1 & 2 & 0 & 0 & 0 \\
\hline BEHAVIOR \& ECONOMICS & 25 & 5.20 & 5.00 & 0.58 & 1 & 7 & 13 & 4 & 0 & 0 & 0 & 0 \\
\hline SOCIETY \& CULTURE & 20 & 5.20 & 5.50 & 2.48 & 4 & 6 & 5 & 2 & 2 & 0 & 1 & 0 \\
\hline $\begin{array}{l}\text { SUSTAINABILITY \& } \\
\text { DEVELOPMENT }\end{array}$ & 20 & 5.20 & 5.00 & 2.48 & 5 & 4 & 6 & 2 & 1 & 2 & 0 & 0 \\
\hline BEHAVIOR \& ECONOMICS & 116 & 5.19 & 5.00 & 1.89 & 21 & 32 & 30 & 21 & 6 & 5 & 1 & 0 \\
\hline
\end{tabular}


How can research inform the urban sustainability community to foster the creation of resilient cities?

Are there general CHANS principles that tend to produce similar human adaptation processes for a variety of global change drivers (e.g., climate change, globalization) despite local context?

How can the monetary system and the economy be transformed, so that they don't require growth to avoid collapse, and don't continually concentrate wealth and power in few hands?

How can we rescue natural systems in socially depressed areas of big cities in Latin America as a tool for human development?

How much has economic valuation of natural resources helped in protecting natural systems from destruction and over-exploitation?

How do different socio-cultural contexts affect CHANS research itself, for example, when

CHANS research is applied internationally?

How can the existing knowledge of human

behavior within multiple social science disciplines

serve in answering whether lab or field based

models can help us better understand as well as

predict how human decisions influence physical

systems and vice versa?

What tools can measure various ecological

services with economic currencies?

How much of human action, and the ways that

humans couple with natural systems, stems from

intrinsic (e.g., preferences and values) vs. extrinsic factors?

How do we create a translational research framework for managing human ecosystems?

How has culture been integrated to improve community based natural resource management?

How do telecouplings (i.e., socioeconomic and environmental interactions among CHANS over distances) evolve?

Is governance up to the task of managing global change?
EDUCATION \& SCIENCE

COMMUNICATION

ADAPTATION \& RESILIENCE

SUSTAINABILITY \&

DEVELOPMENT

SUSTAINABILITY \&

DEVELOPMENT

BEHAVIOR \& ECONOMICS

SOCIETY \& CULTURE

METHODS

225.

23

$17 \quad 5.18$

\begin{tabular}{|l|l|l|l|l|l|l|l|l|l|l}
5.18 & 5.00 & 1.65 & 1 & 6 & 8 & 1 & 0 & 0 & 1 & 0 \\
\hline
\end{tabular}

\begin{tabular}{llllllllllll|l|l|l|} 
& & & & & & & & & & \\
5.17 & 6.00 & 3.15 & 5 & 8 & 4 & 2 & 2 & 0 & 2 & 0 \\
\hline
\end{tabular}

\begin{tabular}{l|l|l|l|l|l|l|l|l|l|l|l}
20 & 5.15 & 5.00 & 1.19 & 1 & 8 & 6 & 3 & 2 & 0 & 0 & 0
\end{tabular}

SERVICES

BEHAVIOR \& ECONOMICS

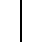

METHODS

\begin{tabular}{|c|c|c|c|c|c|c|c|c|c|c|c|c|}
\hline & 26 & 5.12 & 5.00 & 2.35 & 5 & 7 & 6 & 4 & 3 & 0 & 1 & 0 \\
\hline SOCIETY \& CULTURE & 18 & 5.11 & 5.00 & 1.28 & 2 & 3 & 10 & 2 & 0 & 1 & 0 & 0 \\
\hline $\begin{array}{l}\text { GENERAL PRINCIPLES \& } \\
\text { SYSTEM DYNAMICS }\end{array}$ & 19 & 5.11 & 5.00 & 1.10 & 1 & 6 & 8 & 2 & 2 & 0 & 0 & 0 \\
\hline GOVERNANCE & 19 & 5.11 & 5.00 & 2.77 & 5 & 3 & 5 & 3 & 2 & 0 & 1 & 0 \\
\hline
\end{tabular}


How can an environmentally sustainable energy system be constructed within existing institutional frameworks?

Are their common dynamics and couplings across all CHANS at all scales?

What are the economic trade-offs in multiple-use management of natural resourses?

What are the similarities, differences and relationships between physical, biological and sociocultural evolution?

What is the role of ideology in understanding system change?

What are the linkages between local-global governance of social-ecological systems?

What are the tradeoffs between resolution, model fidelity, scale, and tightness of coupling?

What role should citizen stakeholders play in CHANS research?

How do CHANS researchers determine the most appropriate system boundaries for CHANS for effective research and management?

What are the emergent properties in CHANS?

How can analysis of currently employed measures of human-environment interactions be effectively used, or improved, to improve observations or change?

What is the extent of the existence of a resources curse in areas with abundant natural resources but high rates of poverty?

How should we manage the impacts of improved adapative capacity and ecological justice?

How do we move beyond ecosystem services to re-conceptualize CHANS linkages?

How can we effectively identify both the relevant human and nonhuman actors within systems?

Why do people ignore what is in their best interest even when they know that it is in their best interest?

Can researchers Integrate models for a Global System Science that serves to both design and
CLIMATE CHANGE \& ENERGY

GENERAL PRINCIPLES \&

SYSTEM DYNAMICS

BEHAVIOR \& ECONOMICS

GENERAL PRINCIPLES \&

SYSTEM DYNAMICS

SOCIETY \& CULTURE

GOVERNANCE

METHODS

METHODS

\begin{tabular}{l|l} 
& \\
&
\end{tabular}

SCALE

GENERAL PRINCIPLES \&

SYSTEM DYNAMICS

METHODS

SUSTAINABILITY \&

DEVELOPMENT

GOVERNANCE

CONSERVATION \& ECOSYSTEM

SERVICES

GENERAL PRINCIPLES \&

SYSTEM DYNAMICS

BEHAVIOR \& ECONOMICS

METHODS

\begin{tabular}{|c|c|c|c|c|c|c|c|c|c|c|c|}
\hline 20 & 5.10 & 5.00 & 0.62 & 0 & 6 & 11 & 2 & 1 & 0 & 0 & 0 \\
\hline 20 & 5.10 & 5.00 & 2.52 & 4 & 5 & 6 & 1 & 2 & 2 & 0 & 0 \\
\hline 21 & 5.10 & 5.00 & 0.59 & 0 & 6 & 12 & 2 & 1 & 0 & 0 & 0 \\
\hline 21 & 5.10 & 5.00 & 2.09 & 2 & 7 & 8 & 2 & 0 & 1 & 1 & 0 \\
\hline 2 & 5.09 & 5.00 & 1.42 & 1 & 8 & 9 & 1 & 2 & 1 & 0 & 0 \\
\hline 22 & 5.09 & 5.00 & 2.18 & 3 & 7 & 7 & 1 & 2 & 2 & 0 & 0 \\
\hline 23 & 5.09 & 5.00 & 1.36 & 2 & 6 & 10 & 3 & 1 & 1 & 0 & 0 \\
\hline 17 & 5.06 & 5.00 & 1.93 & 2 & 5 & 6 & 1 & 2 & 1 & 0 & 0 \\
\hline 19 & 5.05 & 5.00 & 1.39 & 0 & 9 & 6 & 0 & 4 & 0 & 0 & 0 \\
\hline 19 & 5.05 & 5.00 & 1.50 & 2 & 4 & 9 & 2 & 1 & 1 & 0 & 0 \\
\hline 20 & 5.05 & 5.50 & 1.52 & 0 & 10 & 5 & 2 & 2 & 1 & 0 & 0 \\
\hline 21 & 5.05 & 5.00 & 1.35 & 2 & 6 & 6 & 5 & 2 & 0 & 0 & 0 \\
\hline 20 & 5.05 & 6.00 & 2.52 & 2 & 10 & 4 & 2 & 2 & 1 & 1 & 0 \\
\hline 22 & 5.05 & 5.00 & 2.90 & 6 & 2 & 8 & 2 & 2 & 1 & 1 & 0 \\
\hline 2 & 5.04 & 5.00 & 2.04 & 3 & 8 & 7 & 3 & 2 & 2 & 0 & 0 \\
\hline 1 & 5.00 & 5.00 & 1.30 & 1 & 6 & 9 & 3 & 1 & 1 & 0 & 0 \\
\hline 26 & 5.00 & 5.00 & 1.36 & 2 & 7 & 9 & 6 & 1 & 1 & 0 & 0 \\
\hline
\end{tabular}


How do we integrate efficient high population density communities within an urban sprawl

framework?

How can we protect the glaciers, highlands and the local population from opencast mining?

How can we build science/arts conjoined

programs in the public school system with limited budgets?

How can science (ecology) embrace novel ecosystems?

To what extent should resarch design and management be different to best address CHANS issues?

How should CHANS be situated in an

institutional/political context?

What are the population dynamics in ecosystems that are heavily impacted by humans?

How can trade-offs among ecosystem services be quantitatively assessed to optimize ecosystem functioning and human livelihoods?

What are the socioeconomic effects on local communities of shale gas energy development in interior natural areas?

What factors enable motivated people to govern social-ecological systems effectively?

How do we reform global governance (UN work) so that scientists and research carries the day?

What factors of the human system affect the environmental system?

How are sustainability and peace linked? Can conservation and other sustainability efforts, as well as CHANS research help promote peace or conflict resolution?

Can the public trust doctrine offer a framework for delivering better social and ecological outcomes?

How do researchers evaluate the data needs of a CHANS approach in inquiry?

\begin{tabular}{|c|c|c|c|c|c|c|c|c|c|c|c|c|}
\hline LAND USE \& AGRICULTURE & 20 & 5.00 & 5.00 & 1.37 & 1 & 7 & 6 & 3 & 3 & 0 & 0 & 0 \\
\hline CLIMATE CHANGE \& ENERGY & 24 & 5.00 & 5.00 & 1.57 & 2 & 7 & 8 & 4 & 2 & 1 & 0 & 0 \\
\hline $\begin{array}{l}\text { EDUCATION \& SCIENCE } \\
\text { COMMUNICATION }\end{array}$ & 21 & 5.00 & 5.00 & 1.60 & 3 & 4 & 7 & 4 & 3 & 0 & 0 & 0 \\
\hline $\begin{array}{l}\text { CONSERVATION \& ECOSYSTEM } \\
\text { SERVICES }\end{array}$ & 17 & 5.00 & 5.00 & 1.63 & 1 & 6 & 5 & 3 & 1 & 1 & 0 & 0 \\
\hline METHODS & 22 & 4.95 & 5.00 & 1.57 & 2 & 5 & 9 & 3 & 2 & 1 & 0 & 0 \\
\hline GOVERNANCE & 19 & 4.95 & 5.00 & 1.16 & 1 & 5 & 7 & 4 & 2 & 0 & 0 & 0 \\
\hline $\begin{array}{l}\text { CONSERVATION \& ECOSYSTEM } \\
\text { SERVICES }\end{array}$ & 19 & 4.95 & 5.00 & 2.39 & 2 & 6 & 6 & 2 & 0 & 3 & 0 & 0 \\
\hline $\begin{array}{l}\text { CONSERVATION \& ECOSYSTEM } \\
\text { SERVICES }\end{array}$ & 18 & 4.94 & 5.00 & 2.41 & 2 & 6 & 5 & 1 & 2 & 2 & 0 & 0 \\
\hline CLIMATE CHANGE \& ENERGY & 24 & 4.92 & 5.00 & 1.56 & 2 & 6 & 8 & 5 & 2 & 1 & 0 & 0 \\
\hline GOVERNANCE & 22 & 4.91 & 5.00 & 1.52 & 1 & 8 & 5 & 4 & 4 & 0 & 0 & 0 \\
\hline GOVERNANCE & 22 & 4.91 & 5.00 & 2.37 & 3 & 7 & 4 & 2 & 5 & 1 & 0 & 0 \\
\hline $\begin{array}{l}\text { GENERAL PRINCIPLES \& } \\
\text { SYSTEM DYNAMICS }\end{array}$ & 20 & 4.90 & 6.00 & 4.52 & 5 & 7 & 1 & 1 & 2 & 2 & 2 & 0 \\
\hline $\begin{array}{l}\text { SUSTAINABILITY \& } \\
\text { DEVELOPMENT }\end{array}$ & & & & & & & & & & & & \\
\hline & 19 & 4.89 & 5.00 & 2.32 & 2 & 4 & 9 & 1 & 1 & 1 & 1 & 0 \\
\hline GOVERNANCE & 26 & 4.88 & 5.00 & 2.51 & 3 & 7 & 8 & 4 & 2 & 0 & 2 & 0 \\
\hline METHODS & 25 & 4.88 & 5.00 & 2.28 & 2 & 9 & 5 & 5 & 2 & 1 & 1 & 0 \\
\hline
\end{tabular}


Can we generate political ecology/economy methods that incorporate history, assymetrical power, and access?

How can we effectively treat technologicalinfrastructural systems within a CHANS framework?

How can recent innovations in data science (i.e. storage, access, processing power) be used to understand CHANS?

How do we evaluate models of environmental change in a no-analogue earth system state?

What are the points at which ceding decision making about highly technical matters to a professional elite break down?

How do we achieve a steady state economy?

How can we best use incentives to manage CHANS?

What self-organizing and managing parts are necessary in CHANS?

What types of education and skills are needed by CHANS scientists?

Are CHANS dynamics lawful (i.e. universal)?

What is the best way to sample annual systems with long-term studies?

How many syllabi or curricula at the undergraduate level include CHANS?

\section{What is the best way to get communities to pay}

for ecosystem services with little history of doing so and where enforcement is weak?

To what extent might we develop a "global culture" of understanding and managing of

\section{CHANS?}

How can non-traditional ontologies and

epistemologies be used to understand and manage CHANS?

What are the feedbacks among sending, receiving, and spillover systems in the telecoupled world?

How do we account for spatial autocorrelation and distance relationships in these systems?

\begin{tabular}{|c|c|c|c|c|c|c|c|c|c|c|c|c|}
\hline METHODS & 19 & 4.84 & 5.00 & 2.25 & 3 & 4 & 5 & 1 & 6 & 0 & 0 & 0 \\
\hline METHODS & 24 & 4.83 & 5.00 & 1.36 & 1 & 6 & 9 & 5 & 2 & 1 & 0 & 0 \\
\hline METHODS & 24 & 4.83 & 5.00 & 1.45 & 1 & 7 & 7 & 6 & 2 & 1 & 0 & 0 \\
\hline METHODS & 21 & 4.81 & 5.00 & 0.76 & 0 & 5 & 8 & 7 & 1 & 0 & 0 & 0 \\
\hline GOVERNANCE & 26 & 4.81 & 5.00 & 1.92 & 0 & 10 & 8 & 5 & 0 & 2 & 1 & 0 \\
\hline $\begin{array}{l}\text { SUSTAINABILITY \& } \\
\text { DEVELOPMENT } \\
\end{array}$ & 20 & 4.80 & 5.00 & 1.96 & 1 & 5 & 8 & 4 & 0 & 1 & 1 & 0 \\
\hline BEHAVIOR \& ECONOMICS & 25 & 4.80 & 5.00 & 2.50 & 1 & 10 & 6 & 3 & 3 & 0 & 2 & 0 \\
\hline ADAPTATION \& RESILIENCE & 24 & 4.79 & 5.00 & 1.30 & 1 & 6 & 7 & 8 & 1 & 1 & 0 & 0 \\
\hline $\begin{array}{l}\text { EDUCATION \& SCIENCE } \\
\text { COMMUNICATION }\end{array}$ & 19 & 4.79 & 5.00 & 2.51 & 1 & 7 & 5 & 2 & 2 & 1 & 1 & 0 \\
\hline $\begin{array}{l}\text { GENERAL PRINCIPLES \& } \\
\text { SYSTEM DYNAMICS }\end{array}$ & 23 & 4.78 & 5.00 & 3.00 & 3 & 6 & 6 & 4 & 1 & 1 & 2 & 0 \\
\hline SCALE & 18 & 4.78 & 5.00 & 1.12 & 1 & 3 & 7 & 5 & 2 & 0 & 0 & 0 \\
\hline $\begin{array}{l}\text { EDUCATION \& SCIENCE } \\
\text { COMMUNICATION }\end{array}$ & 18 & 4.72 & 5.00 & 1.15 & 0 & 3 & 11 & 1 & 2 & 1 & 0 & 0 \\
\hline $\begin{array}{l}\text { CONSERVATION \& ECOSYSTEM } \\
\text { SERVICES }\end{array}$ & 19 & 4.68 & 5.00 & 1.01 & 0 & 3 & 10 & 4 & 1 & 1 & 0 & 0 \\
\hline $\begin{array}{l}\text { EDUCATION \& SCIENCE } \\
\text { COMMUNICATION }\end{array}$ & 18 & 4.67 & 4.00 & 3.41 & 5 & 1 & 2 & 6 & 2 & 1 & 1 & 0 \\
\hline GOVERNANCE & 20 & 4.65 & 4.50 & 1.92 & 2 & 3 & 5 & 8 & 1 & 0 & 1 & 0 \\
\hline $\begin{array}{l}\text { GENERAL PRINCIPLES \& } \\
\text { SYSTEM DYNAMICS }\end{array}$ & 28 & 4.64 & 5.00 & 1.65 & 2 & 4 & 11 & 6 & 3 & 2 & 0 & 0 \\
\hline SCALE & 22 & 4.64 & 5.00 & 1.58 & 0 & 6 & 9 & 1 & 5 & 1 & 0 & 0 \\
\hline
\end{tabular}


How can we use our knowledge of cities - the ultimate CHANS - to understand and manage other coupled systems?

How can we "unresilience" bad system dynamics while enhancing "good" dynamics?

How can we deal with issues of discounting?

Is a good life predicated on negative

environmental footprints?

What types of science has a real influence on management?

How do we effectively link mechanistic and agent-based models in simulating CHANS?

Would the mushrooming of sustainability programs at the graduate level produce the critical mass of people who appreciate coupled human and natural systems?

How persistent is youth education (into adulthood) and how effective is 'spillover' to parents?

What is the relationship of settlement type to ecosystem type?

What are the linkages between evolving concepts of nature and the changing earthscape?

What is the degree of the success of urban biodiversity conservation in major cities of the world?

How do the self-organizing processes of CHANS recognize each other?

What is the most appropriate scale at which to study CHANS?

Under what sorts of circumstances does land sharing as opposed to land sparing occur?

Are GMOs safe for the environment and can GMOs be contained to minimize ecological impact?

What products and outcomes are most useful and relevant in this era of wicked problems and postnormal science?

What are the neurological explanations for behavior in CHANS?

Do network-based hydrologic CHANS behave in fundamentally different ways from patchworkbased terrestrial CHANS?
GENERAL PRINCIPLES \& SYSTEM DYNAMICS

ADAPTATION \& RESILIENCE

BEHAVIOR \& ECONOMICS

SUSTAINABILITY \&

DEVELOPMENT

GOVERNANCE

METHODS

EDUCATION \& SCIENCE

COMMUNICATION

EDUCATION \& SCIENCE

COMMUNICATION

SOCIETY \& CULTURE

GENERAL PRINCIPLES \&

SYSTEM DYNAMICS

CONSERVATION \& ECOSYSTEM

SERVICES

GENERAL PRINCIPLES \&

SYSTEM DYNAMICS

SCALE

LAND USE \& AGRICULTURE

LAND USE \& AGRICULTURE

EDUCATION \& SCIENCE

COMMUNICATION

BEHAVIOR \& ECONOMICS

\section{LAND USE \& AGRICULTURE}

\begin{tabular}{l|l|l|l|l|l|l|l|l|l|l|l|l} 
& & & & & & & & & & & & \\
19 & 4.63 & 5.00 & 1.25 & 0 & 4 & 8 & 4 & 2 & 1 & 0 & 0 & \\
19 & 4.63 & 5.00 & 1.80 & 1 & 4 & 7 & 2 & 4 & 1 & 0 & 0 & \\
21 & 4.62 & 4.00 & 2.25 & 3 & 4 & 3 & 4 & 7 & 0 & 0 & 0 & \\
& & & & & & & & & & & &
\end{tabular}

\begin{tabular}{l|l|l|l|l|l|l|l|l|l|l|l}
18 & 4.61 & 5.00 & 2.13 & 1 & 5 & 5 & 1 & 5 & 1 & 0 & 0
\end{tabular}

\begin{tabular}{llllllllllll|l|l|l}
18 & 4.61 & 5.00 & 4.13 & 3 & 5 & 2 & 4 & 1 & 0 & 3 & 0 \\
\hline
\end{tabular}

21

21

3 \begin{tabular}{l|l|l|l}
3 & 1 & 0 & 0 \\
\hline
\end{tabular}

22

\begin{tabular}{|l|l|l|l|l|l|l|l|l|l|l}
4.55 & 5.00 & 1.59 & 0 & 5 & 8 & 6 & 0 & 3 & 0 & 0 \\
\hline
\end{tabular}

24

$4.54 \quad 5.01$

\begin{tabular}{l|l|l|l|l|l|l|l|l|l|l|l}
19 & 4.53 & 5.00 & 3.26 & 2 & 4 & 7 & 0 & 2 & 3 & 1 & 0
\end{tabular}

\begin{tabular}{l|lllllllllllllll}
18 & 4.50 & 5.00 & 2.50 & 1 & 2 & 10 & 1 & 2 & 0 & 2 & 0 \\
\hline
\end{tabular}

2

22

\begin{tabular}{|l|l|l|l|l|l|l|l|l|l|l|l|}
21 & 4.45 & 4.50 & 2.16 & 2 & 4 & 5 & 3 & 7 & 1 & 0 & 0 \\
\hline & 4.43 & 5.00 & 1.86 & 1 & 2 & 9 & 5 & 2 & 1 & 1 & 0 \\
\hline
\end{tabular}

25

\begin{tabular}{l|l|l|l|l|l|l|l|l|l|l|l}
19 & 4.26 & 4.00 & 1.65 & 0 & 3 & 5 & 8 & 1 & 1 & 1 & 0 \\
\hline
\end{tabular}

\begin{tabular}{l|l|l|l|l|l|l|l|l|l|l|l}
24 & 4.17 & 5.00 & 2.84 & 2 & 2 & 9 & 2 & 5 & 2 & 2 & 0
\end{tabular}

\begin{tabular}{l|l|l|l|l|l|l|l|l|l|l|l|l|l}
19 & 4.05 & 4.00 & 2.27 & 0 & 3 & 5 & 6 & 2 & 1 & 2 & 0
\end{tabular}

\begin{tabular}{|l|l|l|l|l|l|l|l|l|l|l|l}
22 & 4.00 & 4.00 & 2.00 & 0 & 4 & 5 & 3 & 8 & 1 & 1 & 0 \\
\hline
\end{tabular}





\section{Appendix 4: Question evaluation survey and consent document.}

\section{Intro 1 - Survey Information}

Thank you for agreeing to complete the survey below.

In an effort to to elevate awareness of Coupled Human and Natural Systems (CHANS) research and prioritize future scientific efforts for CHANS research, we asked CHANS-Net members in a previous survey: "What are the transformative questions to address in order to have the biggest impact on understanding and managing coupled human and natural systems?"

The following 20 questions were randomly selected from the questions received from CHANSNet members. For each question listed, please indicate how important you think the question is to advancing understanding and management of coupled human and natural systems (CHANS). This survey should take approximately 10 minutes.

Regarding privacy and confidentiality of responses, your individual responses are anonymous and will not be shared with anyone else, in publications, or in presentations. Furthermore, your participation is voluntary. You may refuse to participate in certain questions or discontinue your participation at any time without consequence.

If you have concerns or questions, please contact Dr. Daniel Kramer at the Department of Fisheries and Wildlife at Michigan State University (dbk@msu.edu, +1 (517) 432-2199).

If you have questions or concerns about your role and rights as a research participant or would like to register a complaint about this study, you may contact the Michigan State University's Human Research Protection Program (517-355-2180, Fax 517-432-4503, or email irb@msu.edu).

You are providing your voluntary consent to participate in this research by beginning the survey below.

Thank you again for your time and thoughtfulness. 


\section{CHANS Question Importance}

How can we anticipate and adapt to novel conditions in response to climate change and demographic pressures?

\begin{tabular}{|c|c|c|c|c|c|}
\hline $\begin{array}{l}\text { Not at all } \\
\text { mportant }\end{array}$ & $\begin{array}{c}\text { Very } \\
\text { Unimportant }\end{array}$ & $\begin{array}{l}\text { Somewhat } \\
\text { Unimportant }\end{array}$ & $\begin{array}{c}\text { Neither } \\
\text { Important nor } \\
\text { Unimportant }\end{array}$ & $\begin{array}{l}\text { Somewhat } \\
\text { Important }\end{array}$ & Very Important \\
\hline
\end{tabular}

How is ecosystem resilience changing with changes in climate, land use, and land cover?

\begin{tabular}{|c|c|c|c|c|c|}
\hline $\begin{array}{l}\text { Not at all } \\
\text { Important }\end{array}$ & $\begin{array}{c}\text { Very } \\
\text { Unimportant }\end{array}$ & $\begin{array}{l}\text { Somewhat } \\
\text { Unimportant }\end{array}$ & $\begin{array}{c}\text { Neither } \\
\text { Important nor } \\
\text { Unimportant }\end{array}$ & $\begin{array}{l}\text { Somewhat } \\
\text { Important }\end{array}$ & Very Important \\
\hline
\end{tabular}

How do people best adapt to climate change?

Neither

Not at all Very Somewhat Important nor Somewhat Extremely Important Unimportant Unimportant Unimportant Important Very Important Important

What explains resilience in CHANS?

Neither

Notat all Very Somewhat Important nor Somewhat Extremely Important Unimportant Unimportant Unimportant Important Very Important Important

What essential 'rules' are most important to understand in various complex adaptive systems that being managed?

Neither

Not at all Very Somewhat Important nor Somewhat Extremely Important Unimportant Unimportant Unimportant Important Very Important Important 
Are there general CHANS principles that tend to produce similar human adaptation processes for a variety of global change drivers (e.g., climate change, globalization) despite local context?

\section{Neither}

Not at all Very Somewhat Important nor Somewhat Extremely Important Unimportant Unimportant Unimportant Important Very Important Important

How do natural resource institutions influence the adaptive capacity of coupled systems?

Not at all Very Somewhat Important nor Somewhat Extremely Important Unimportant Unimportant Unimportant Important Very Important Important

How can we learn about ecological boundaries before we cross them, and adjust our human systems to avoid irreparable damage?

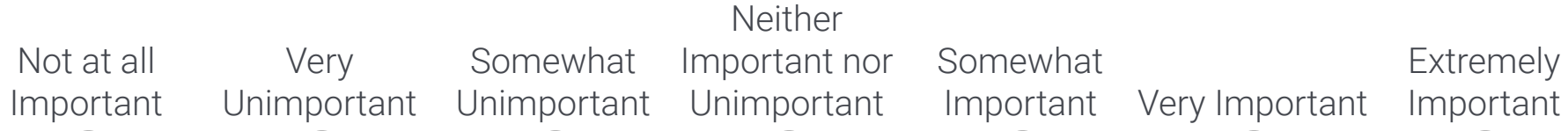

What self-organizing and managing parts are necessary in CHANS?

Neither

Not at all Very Somewhat Important nor Somewhat Extremely Important Unimportant Unimportant Unimportant Important Very Important Important

What factors positively contribute to reducing the impact of the global market system that erodes resilience of social-ecological systems?

Neither

Not at all Very Somewhat Important nor Somewhat Extremely Important Unimportant Unimportant Unimportant Important Very Important Important

What is the plasticity (ease of change) and elasticity of major human drivers of environmental change?

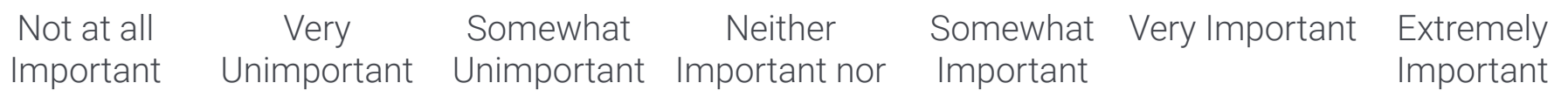


How rapidly can humans adapt to environmental change?

Neither

Not at all Very Somewhat Important nor Somewhat Extremely Important Unimportant Unimportant Unimportant Important Very Important Important

How can we best use the reciprocal nature of CHANS systems to support resilience?

Neither

Not at all Very Somewhat Important nor Somewhat Extremely Important Unimportant Unimportant Unimportant Important Very Important Important

How can people adapt to changing system behavior while still getting what they need from the system?

Not at all Very Somewhat Important nor Somewhat Extremely Important Unimportant Unimportant Unimportant Important Very Important Important

How can we "unresilience" bad system dynamics while enhancing "good" dynamics?

Neither

Not at all Very Somewhat Important nor Somewhat Extremely Important Unimportant Unimportant Unimportant Important Very Important Important

How do humans increase their capacity for adaptation to global environmental change?

Neither

Notat all Very Somewhat Important nor Somewhat Extremely Important Unimportant Unimportant Unimportant Important Very Important Important

How can water management be improved to decrease scarcity, increase security and make the system less vulnerable?

Neither

\begin{tabular}{|c|c|c|c|c|c|}
\hline $\begin{array}{l}\text { Not at all } \\
\text { Important }\end{array}$ & $\begin{array}{c}\text { Very } \\
\text { Unimportant }\end{array}$ & $\begin{array}{l}\text { Somewhat } \\
\text { Unimportant }\end{array}$ & $\begin{array}{l}\text { Important nor } \\
\text { Unimportant }\end{array}$ & $\begin{array}{l}\text { Somewhat } \\
\text { Important }\end{array}$ & Very Important \\
\hline
\end{tabular}


What determines how people in the role of decision-makers value the environment?

Neither

Not at all Very Somewhat Important nor Somewhat Extremely Important Unimportant Unimportant Unimportant Important Very Important Important

How do you best value natural resources especially when there is great uncertainty regarding environmental change?

Neither

Not at all Very Somewhat Important nor Somewhat Extremely Important Unimportant Unimportant Unimportant Important Very Important Important

How much has economic valuation of natural resources helped in protecting natural systems from destruction and over-exploitation?

Neither

Not at all Very Somewhat Important nor Somewhat Extremely Important Unimportant Unimportant Unimportant Important Very Important Important

Do humans respond similarly to general classes of ecological processes (e.g. linear, non-linear, slow, fast, threshold) despite local context (ecological, political, socio-economic)? Are there general CHANS principles?

Neither

Not at all Very Somewhat Important nor Somewhat Extremely important Unimportant Unimportant Unimportant Important Very Important Important

What are the economic trade-offs in multiple-use management of natural resources?

Neither

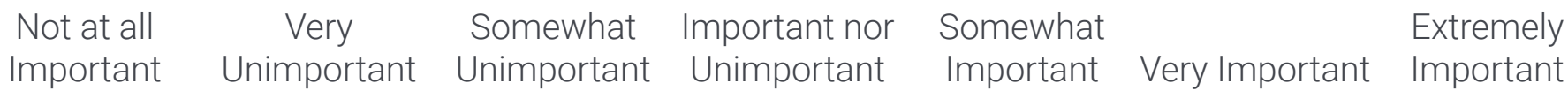

How can we best use incentives to manage CHANS?

Not at all Very Somewhat Neither Somewhat Very Important Extremely 
Important Unimportant Unimportant Important nor Important

Important

Unimportant

How can we deal with externalities of human activities?

Not at all

$\begin{array}{ccc}\text { Very } & \text { Soither } \\ \text { Unimportant } & \text { Unimportant } & \text { Important nor } \\ \end{array}$

Somewhat

Important Unimportant Unimportant Unimportant Important Very Important Important

How can the importance of long-term consequences be weighed into decisions on human impacts on ecosystems?

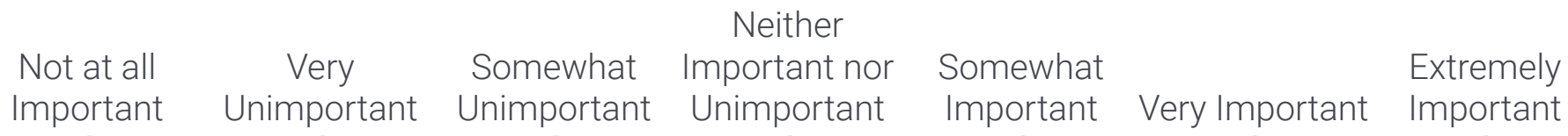

How do we mobilize individuals for collective action?

$\begin{array}{ccccc}\text { Not at all } & \text { Very } & \text { Somewhat } & \text { Neither } & \\ \text { Important nor } & \text { Somewhat } & \text { Extremely } \\ \text { Important } & \text { Unimportant } & \text { Unimportant } & \text { Unimportant } & \text { Important }\end{array}$

What is the perceived value of the cost or benefit of management of climate change and land use change?

Neither

Not at all Very Somewhat Important nor Somewhat Extremely Important Unimportant Unimportant Unimportant Important Very Important Important

What are the drivers of human decision-making regarding land use/land cover change and natural resources?

Neither

Not at all Very Somewhat Important nor Somewhat Extremely Important Unimportant Unimportant Unimportant Important Very Important Important

How do we move from proxy variables and simple models of human behavior toward direct measurement? 
Neither

Not at all Very Somewhat Important nor Somewhat Extremely Important Unimportant Unimportant Unimportant Important Very Important Important

How do we integrate social science to understand individual and group behaviors and values and how they scale up in coupled human-natural systems?

Neither

Not at all Very Somewhat Important nor Somewhat Extremely Important Unimportant Unimportant Unimportant Important Very Important Important

What steps will result in incorporation of market externalities without causing large negative impacts on significant segments (e.g. low-income) of society?

Neither

Not at all Very Somewhat Important nor Somewhat Extremely Important Unimportant Unimportant Unimportant Important Very Important Important

Why do people ignore what's in their best interest even when they know that it is in their best interest?

Not at all Very Somewhat Important nor Somewhat Extremely Important Unimportant Unimportant Unimportant Important Very Important Important

What influences human behavioral change towards natural systems?

Neither

Not at all Very Somewhat Important nor Somewhat Extremely Important Unimportant Unimportant Unimportant Important Very Important Important

How do humans perceive and respond to natural systems?

Neither

Not at all Very Somewhat Important nor Somewhat Extremely Important Unimportant Unimportant Unimportant Important Very Important Important 
How can human incentives be better aligned with their spatially and temporally removed impacts?

Neither

Notat all Very Somewhat Important nor Somewhat Extremely Important Unimportant Unimportant Unimportant Important Very Important Important

What are the most effective ways to model human behavior and decision making?

Neither

Not at all Very Somewhat Important nor Somewhat Extremely Important Unimportant Unimportant Unimportant Important Very Important Important

How do values influence human behavior in regards to natural systems?

Neither

Not at all Very Somewhat Important nor Somewhat Extremely Important Unimportant Unimportant Unimportant Important Very Important Important

How much of human action, and the ways that humans couple with natural systems, stems from intrinsic (e.g., preferences and values) vs. extrinsic factors?

Neither

Not at all Very Somewhat Important nor Somewhat Extremely Important Unimportant Unimportant Unimportant Important Very Important Important

Where do individuals obtain information about the natural environment and their impact on it, and how do they evaluate the reliability of that information?

Neither

Not at all Very Somewhat Important nor Somewhat Extremely Important Unimportant Unimportant Unimportant Important Very Important Important

How does human learning at the individual and group level affect the interaction of coupled human and natural systems?

Neither

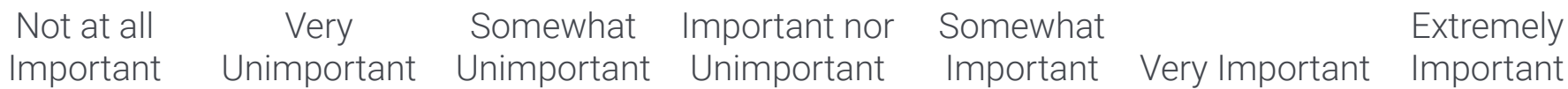


How does uncertainty of CHANS affect human decision making?

Neither

Not at all Very Somewhat Important nor Somewhat Important Unimportant Unimportant Unimportant Important Very Important Important

How do human responses to change alter the environment?

Neither

Not at all Very Somewhat Important nor Somewhat Extremely Important Unimportant Unimportant Unimportant Important Very Important Important

How can we deal with issues of discounting?

Neither

Not at all Very Somewhat Important nor Somewhat Extremely Important Unimportant Unimportant Unimportant Important Very Important Important

What are the neurological explanations for behavior in CHANS?

Neither

Not at all Very Somewhat Important nor Somewhat Extremely Important Unimportant Unimportant Unimportant Important Very Important Important

What are the behavioral explanations for why people use resources one way in one place, but a different way in another place?

Neither

Notatall Very Somewhat Important nor Somewhat Extremely Important Unimportant Unimportant Unimportant Important Very Important Important

Do people respond to predictive indicators of environmental stress?

Neither

Not at all Very Somewhat Important nor Somewhat Extremely Important Unimportant Unimportant Unimportant Important Very Important Important 
What are the tipping points in CHANS due to climate change?

Neither

Not at all

Very

Somewhat Important nor

Somewhat

Important Unimportant Unimportant Unimportant Important Very Important Important

Extremely

Under what conditions do people exhibit limited or strong ability to respond to the (anticipated or observed) effects of climate change?

Neither

Not at all Very Somewhat Important nor Somewhat Extremely Important Unimportant Unimportant Unimportant Important Very Important Important

How can conservation of natural systems provide resilience of human systems to impacts of climate change, such as extreme weather and rising sea levels?

Neither

Not at all Very Somewhat Important nor Somewhat Extremely

Important Unimportant Unimportant Unimportant Important Very Important Important

How does climate change affect ecosystems and biodiversity?

$\begin{array}{ccccc}\text { Not at all } & \text { Very } & \text { Somewhat } & \text { Neither } & \\ \text { Important nor } & \text { Somewhat } & \text { Extremely } \\ \text { Important } & \text { Unimportant } & \text { Unimportant } & \text { Unimportant } & \text { Important }\end{array}$

How do humans best mitigate climate change?

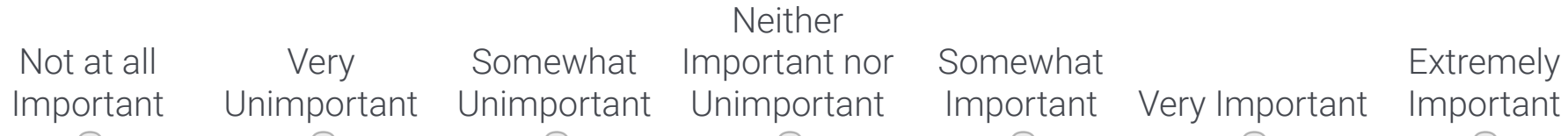

How will spatially differential climate change impacts affect local, national and international policy responses?

Neither

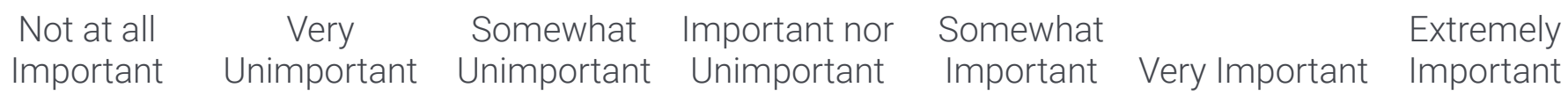


What are the human consequences of anthropogenic climate change, and how will those human consequences further shape coupled human natural systems?

Neither

Notatall Very Somewhat Important nor Somewhat Extremely Important Unimportant Unimportant Unimportant Important Very Important Important

What are the socioeconomic effects on local communities of shale gas energy development in interior natural areas?

Neither

Notat all Very Somewhat Important nor Somewhat Extremely Important Unimportant Unimportant Unimportant Important Very Important Important

What are the long and short term socio-economic impacts of contaminated ecosystem mitigation due to Hydraulic fracturing processes?

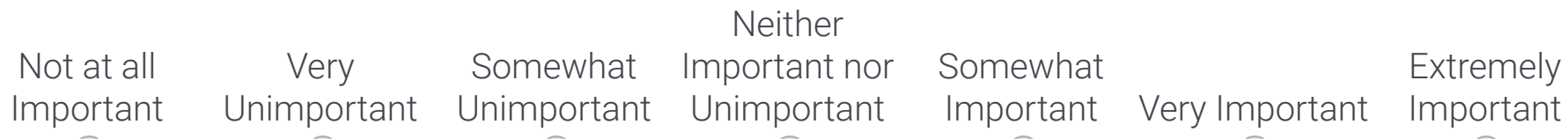

How does climate variability and water resource accessibility affect population growth and distribution?

Neither

Not at all Very Somewhat Important nor Somewhat Extremely Important Unimportant Unimportant Unimportant Important Very Important Important

How are the forces of globalization and climate change interacting?

Neither

Not at all Very Somewhat Important nor Somewhat Extremely Important Unimportant Unimportant Unimportant Important Very Important Important

How do we address the complex interlinkages between rural livelihoods and natural resource use in the face of climate variability?

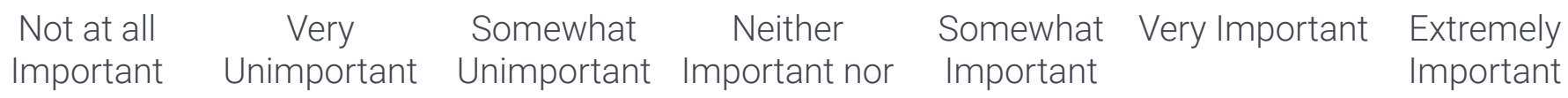


How can an environmentally sustainable energy system be constructed within existing institutional frameworks?

\section{Neither}

Not at all Very Somewhat Important nor Somewhat Extremely Important Unimportant Unimportant Unimportant Important Very Important Important

How can climate change adaptation and mitigation be integrated?

Not at all Very Somewhat Important nor Somewhat Extremely Important Unimportant Unimportant Unimportant Important Very Important Important

How can scientific results in climate be used to address CHANS research?

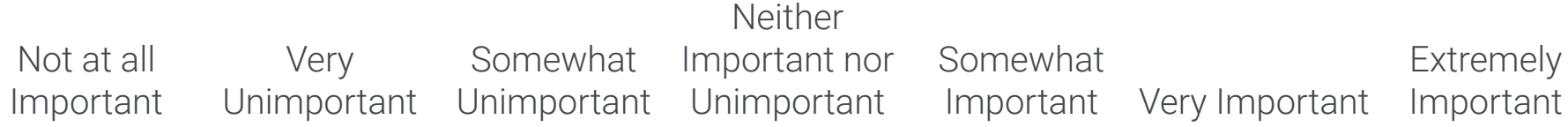

How can we protect the glaciers, highlands and the local population from opencast mining?

\begin{tabular}{|c|c|c|c|c|c|}
\hline $\begin{array}{l}\text { Not at all } \\
\text { Important }\end{array}$ & $\begin{array}{c}\text { Very } \\
\text { Unimportant }\end{array}$ & $\begin{array}{l}\text { Somewhat } \\
\text { Unimportant }\end{array}$ & $\begin{array}{c}\text { Neither } \\
\text { Important nor } \\
\text { Unimportant }\end{array}$ & $\begin{array}{l}\text { Somewhat } \\
\text { Important }\end{array}$ & rtant \\
\hline
\end{tabular}

How can sustainable ecosystems that are resilient to change and provide ecosystem services for humans be built or managed?

Neither

Not at all Very Somewhat Important nor Somewhat Extremely Important Unimportant Unimportant Unimportant Important Very Important Important

What is the best way to get communities to pay for ecosystem services with little history of doing so and where enforcement is weak?

Not at all Very Somewhat Neither Somewhat Very Important Extremely 
Important Unimportant Unimportant Important nor Important

Important Unimportant

How does one promote human awareness of the CHANS basis for human livelihoods?

Not at all

Important

Very Somewhat Important

$\begin{array}{ccc}\text { Uery } & \text { Somewhat } & \text { Important nor } \\ \text { Unimportant } & \text { Unimportant } & \text { Unimportant }\end{array}$

Somewhat

Important Very Important Important

How can we measure and account for ecosystem services in decisions and connect this to policy-making agendas?

\begin{tabular}{|c|c|c|c|c|c|}
\hline Not at all & $\begin{array}{c}\text { Very } \\
\text { Unimportant }\end{array}$ & $\begin{array}{l}\text { Somewhat } \\
\text { Unimnortant }\end{array}$ & $\begin{array}{c}\text { Neither } \\
\text { Important nor } \\
\text { Unimportant }\end{array}$ & Somewhat & erv Important \\
\hline
\end{tabular}

What are the population dynamics in ecosystems that are heavily impacted by humans?

\begin{tabular}{|c|c|c|c|c|c|}
\hline $\begin{array}{l}\text { Not at all } \\
\text { mportant }\end{array}$ & $\begin{array}{c}\text { Very } \\
\text { Unimportant }\end{array}$ & $\begin{array}{l}\text { Somewhat } \\
\text { Unimportant }\end{array}$ & $\begin{array}{c}\text { Neither } \\
\text { Important nor } \\
\text { Unimportant }\end{array}$ & $\begin{array}{l}\text { Somewhat } \\
\text { Important }\end{array}$ & Very Important \\
\hline
\end{tabular}

How can natural processes (i.e. ecosystem services) be integrated into human-dominated landscapes?

Neither

Notatall Very Somewhat Important nor Somewhat Extremely Important Unimportant Unimportant Unimportant Important Very Important Important

How do various types and patterns of land uses relate to patterns of biodiversity?

Neither

Notat all Very Somewhat Important nor Somewhat Extremely Important Unimportant Unimportant Unimportant Important Very Important Important

What tools can measure various ecological services with economic currencies?

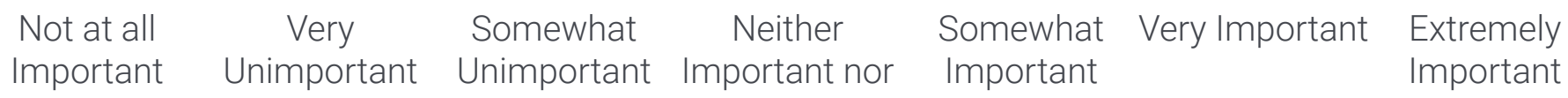


How can the ever-increasing natural resource needs of communities be balanced with the needs of wildlife?

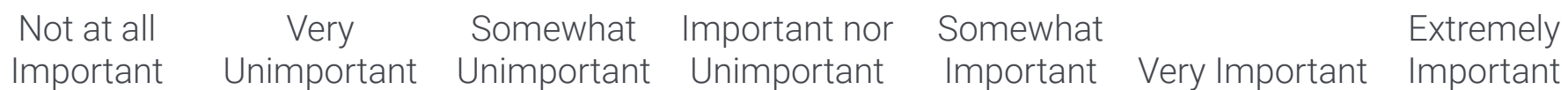

What are the linkages between ecosystem services and human well-being?

Neither

Not at all Very Somewhat Important nor Somewhat Extremely Important Unimportant Unimportant Unimportant Important Very Important Important

How can we enhance ecosystem services while reducing negative anthropogenic effects?

Not at all Very Somewhat Important nor Somewhat Extremely Important Unimportant Unimportant Unimportant Important Very Important Important

How do we improve connectivity of wildlife habitat across the landscape?

\begin{tabular}{|c|c|c|c|c|c|}
\hline $\begin{array}{l}\text { Not at all } \\
\text { Important }\end{array}$ & $\begin{array}{c}\text { Very } \\
\text { Unimportant }\end{array}$ & $\begin{array}{l}\text { Somewhat } \\
\text { Unimportant }\end{array}$ & $\begin{array}{c}\text { Neither } \\
\text { Important nor } \\
\text { Unimportant }\end{array}$ & $\begin{array}{l}\text { Somewhat } \\
\text { Important }\end{array}$ & rtant \\
\hline
\end{tabular}

How can social systems and natural life sciences better interact to stop species loss?

Neither

Notat all Very Somewhat Important nor Somewhat Extremely Important Unimportant Unimportant Unimportant Important Very Important Important

What is the degree of the success of urban biodiversity conservation in major cities of the world?

Neither

Notatall Very Somewhat Important nor Somewhat Extremely Important Unimportant Unimportant Unimportant Important Very Important Important 
How will the benefits provided by nature and the persistence and distribution of species change in the future?

Neither

Not at all Very Somewhat Important nor Somewhat Extremely Important Unimportant Unimportant Unimportant Important Very Important Important

How can society better control the spread of invasive species that endanger agricultural and native ecosystems?

Not at all Very Somewhat Important nor Somewhat Extremely Important Unimportant Unimportant Unimportant Important Very Important Important

How can we design protected areas that are both biologically effective and socially just?

$\begin{array}{cccccc}\text { Not at all } & \text { Very } & \text { Somewhat } & \text { Important nor } & \text { Somewhat } & \text { Extremely } \\ \text { Important } & \text { Unimportant } & \text { Unimportant } & \text { Unimportant } & \text { Important } & \text { Very Important } \\ \text { Important }\end{array}$

How should we evaluate biodiversity for human needs?

\begin{tabular}{|c|c|c|c|c|c|}
\hline $\begin{array}{l}\text { Not at all } \\
\text { Important }\end{array}$ & $\begin{array}{c}\text { Very } \\
\text { Unimportant }\end{array}$ & $\begin{array}{l}\text { Somewhat } \\
\text { Unimportant }\end{array}$ & $\begin{array}{c}\text { Neither } \\
\text { Important nor } \\
\text { Unimportant }\end{array}$ & $\begin{array}{l}\text { Somewhat } \\
\text { Important }\end{array}$ & rtant \\
\hline
\end{tabular}

How does upstream degradation affect downriver ecosystem services delivery?

Neither

Not at all Very Somewhat Important nor Somewhat Extremely Important Unimportant Unimportant Unimportant Important Very Important Important

What is the relationship between ecosystem services and function in human dominated systems?

Not at all Very Somewhat Neither Somewhat Very Important Extremely Important Unimportant Unimportant Important nor Important Important 
How can trade-offs among ecosystem services be quantitatively assessed to optimize ecosystem functioning and human livelihoods?

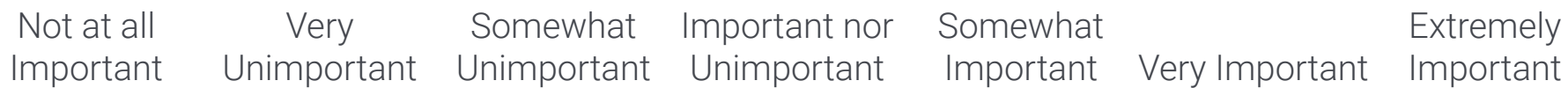

How do we move beyond ecosystem services to re-conceptualize CHANS linkages?

Not at all Very Somewhat Important nor Somewhat Extremely Important Unimportant Unimportant Unimportant Important Very Important Important

How can income streams be linked to various ecosystem services so that better environmental outcomes can be realized?

Neither

Not at all Very Somewhat Important nor Somewhat Extremely Important Unimportant Unimportant Unimportant Important Very Important Important

What are the perceived and real tradeoffs in valuing specific ecosystem services (for society, environment etc.)?

Neither

Not at all Very Somewhat Important nor Somewhat Extremely Important Unimportant Unimportant Unimportant Important Very Important Important

How can we employ an ecosystem services approach to management from the local to global scale?

Neither

Not at all Very Somewhat Important nor Somewhat Extremely Important Unimportant Unimportant Unimportant Important Very Important Important

How can science (ecology) embrace novel ecosystems? 
Not at all

Very

Somewhat

Neither

Somewhat

Unimportant

Unimportant

Important nor

Unimportant

Extremely

Important

How can research inform the urban sustainability community to foster creation of resilient cities?

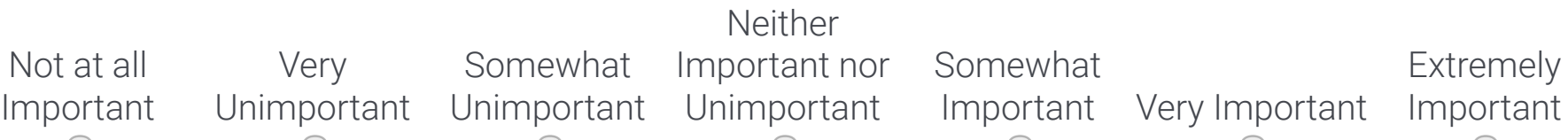

What types of outreach measures are needed to draw the link between humans and natural systems for non science demographics?

Neither

Not at all Very Somewhat Important nor Somewhat Extremely Important Unimportant Unimportant Unimportant Important Very Important Important

What has been gained from knowledge of coupled natural and human systems, and what more can be gained?

Neither

Notatall Very Somewhat Important nor Somewhat Extremely Important Unimportant Unimportant Unimportant Important Very Important Important

What is the role of CHANS researchers in the policy debates that are generated as a function of the community's research?

Not at all Very Somewhat Important nor Somewhat Extremely Important Unimportant Unimportant Unimportant Important Very Important Important

What are the most effective ways to communicate and/or implement interventions in CHANS?

Neither

$\begin{array}{cccccc}\text { Not at all } & \text { Very } & \text { Somewhat } & \text { Important nor } & \text { Somewhat } & \text { Extremely } \\ \text { Important } & \text { Unimportant } & \text { Unimportant } & \text { Unimportant } & \text { Important } & \text { Very Important } \\ \text { Important }\end{array}$ 
How do we co-produce knowledge between scientists, managers and society?

Neither

Not at all Very Somewhat Important nor Somewhat Extremely Important Unimportant Unimportant Unimportant Important Very Important Important

How do we convince society of the value of data to support information-driven management?

Neither

Not at all Very Somewhat Important nor Somewhat Extremely Important Unimportant Unimportant Unimportant Important Very Important Important

How do scientists best communicate the complexity of CHANS to resource managers, policy makers, and the public?

Not at all Very Somewhat Important nor Somewhat Extremely Important Unimportant Unimportant Unimportant Important Very Important Important

How do we improve primary education on the complexity of CHANS?

Not at all Very Somewhat Important nor Somewhat Extremely Important Unimportant Unimportant Unimportant Important Very Important Important

Will the mushrooming of sustainability programs at the graduate level produce a critical mass of people who appreciate coupled human and natural systems?

Neither

Notat all Very Somewhat Important nor Somewhat Extremely Important Unimportant Unimportant Unimportant Important Very Important Important

What mechanisms facilitate social learning for sustainability?

Neither

Not at all Very Somewhat Important nor Somewhat Extremely Important Unimportant Unimportant Unimportant Important Very Important Important 
How can we build science/arts conjoined programs in the public school system with limited budgets?

Neither

Notat all Very Somewhat Important nor Somewhat Extremely Important Unimportant Unimportant Unimportant Important Very Important Important

What types of education and skills are needed by CHANS scientists?

Neither

Not at all Very Somewhat Important nor Somewhat Extremely Important Unimportant Unimportant Unimportant Important Very Important Important

How can the public be educated on the link between extreme events and long-term changes in coupled human-natural systems?

Not at all Very Somewhat Important nor Somewhat Extremely Important Unimportant Unimportant Unimportant Important Very Important Important

How can we change the stovepipe attitudes of academia and its stovepipe training of students?

Neither

Not at all Very Somewhat Important nor Somewhat Extremely Important Unimportant Unimportant Unimportant Important Very Important Important

How many syllabi or curricula at the undergraduate level include CHANS?

Neither

Notatall Very Somewhat Important nor Somewhat Extremely Important Unimportant Unimportant Unimportant Important Very Important Important

To what extent might we develop a "global culture" of understanding and managing CHANS?

Neither

Notat all Very Somewhat Important nor Somewhat Extremely Important Unimportant Unimportant Unimportant Important Very Important Important 
How persistent is youth education (into adulthood) and how effective is 'spillover' to parents?

Neither

Not at all Very Somewhat Important nor Somewhat Extremely Important Unimportant Unimportant Unimportant Important Very Important Important

What products and outcomes are most useful and relevant in this era of wicked problems and post-normal science?

Neither

Not at all Very Somewhat Important nor Somewhat Extremely Important Unimportant Unimportant Unimportant Important Very Important Important

What characterizes tipping points or thresholds in CHANS and can we predict them?

Not at all Very Somewhat Important nor Somewhat Extremely Important Unimportant Unimportant Unimportant Important Very Important Important

How do CHANS evolve?

Neither

Not at all Very Somewhat Important nor Somewhat Extremely Important Unimportant Unimportant Unimportant Important Very Important Important

What are the feedbacks between human decision making and natural system processes?

$\begin{array}{cccccc}\text { Notatall } & \text { Very } & \text { Somewhat } & \text { Neither } & & \\ \text { Important } & \text { Unimportant } & \text { Unimportant } & \text { Unimportant } & \text { Somewhat } & \text { Important } \\ \text { Very Important } & \text { Important }\end{array}$

How much mechanistic knowledge is needed of coupled systems dynamics in order to predict likely responses?

Neither

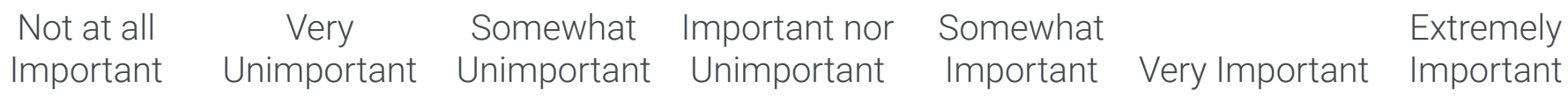


How do economic and institutional factors interact at multiple scales to influence local conditions?

Neither

Not at all Very Somewhat Important nor Somewhat Extremely Important Unimportant Unimportant Unimportant Important Very Important Important

Are there common dynamics and couplings across all CHANS at all scales?

Neither

Not at all Very Somewhat Important nor Somewhat Extremely Important Unimportant Unimportant Unimportant Important Very Important Important

How do CHANS interact across multiple scales?

Not at all Very Somewhat Important nor Somewhat Extremely Important Unimportant Unimportant Unimportant Important Very Important Important

Can researchers develop transferable operationalized metrics showing connections between social and ecological systems?

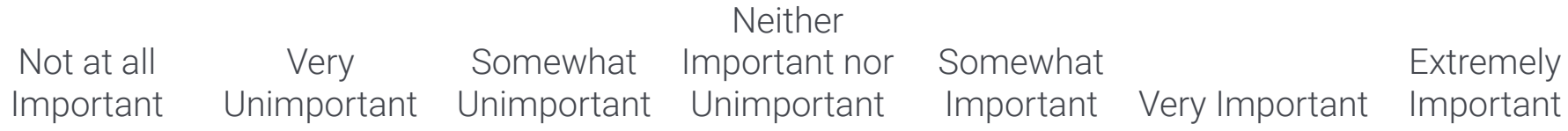

How can coupled-system complexity be reconciled with societal need for a degree of clarity and predictability, and how does this need vary at different social/ecological scales?

Neither

Not at all Very Somewhat Important nor Somewhat Extremely Important Unimportant Unimportant Unimportant Important Very Important Important

How do short term actions affect the long term behavior of the CHANS?

Neither

Notat all Very Somewhat Important nor Somewhat Extremely Important Unimportant Unimportant Unimportant Important Very Important Important 
How do changes in the environment feedback on individuals, groups and institutions?

Neither

Not at all Very Somewhat Important nor Somewhat Extremely Important Unimportant Unimportant Unimportant Important Very Important Important

What factors of the human system affect the environmental system?

Neither

Not at all Very Somewhat Important nor Somewhat Extremely Important Unimportant Unimportant Unimportant Important Very Important Important

Under what conditions do social and ecological disturbances create positive/negative feedback and positive/negative social and ecological consequences?

Not at all Very Somewhat Important nor Somewhat Extremely Important Unimportant Unimportant Unimportant Important Very Important Important

What can we know about how new human and physical perturbations affect the behaviour of systems?

Not at all Very Somewhat Important nor Somewhat Extremely Important Unimportant Unimportant Unimportant Important Very Important Important

What is and what explains the variability in coupling between human and natural systems?

Neither

Not at all Very Somewhat Important nor Somewhat Extremely

Important Unimportant Unimportant Unimportant Important Very Important Important

What are the feedbacks between CHANS?

Neither

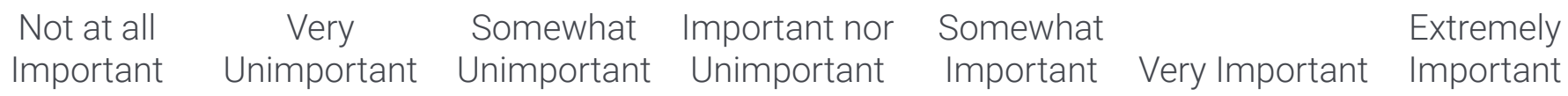


How do we use past systems behavior as a predictor for future systems behaviors?

Neither

Not at all Very Somewhat Important nor Somewhat Extremely Important Unimportant Unimportant Unimportant Important Very Important Important

What is the human influence on the biogeochemical cycling of toxic trace elements within Earth's System?

Neither

Not at all Very Somewhat Important nor Somewhat Extremely Important Unimportant Unimportant Unimportant Important Very Important Important

How do CHANS respond to external perturbations?

Not at all Very Somewhat Important nor Somewhat Extremely Important Unimportant Unimportant Unimportant Important Very Important Important

How do telecouplings (i.e., socioeconomic and environmental interactions among CHANS over distances) evolve?

Notat all Very Somewhat Important nor Somewhat Extremely Important Unimportant Unimportant Unimportant Important Very Important Important

Which system elements function as underlying, persisting, slow variables vs. fast variables?

Neither

Notat all Very Somewhat Important nor Somewhat Extremely Important Unimportant Unimportant Unimportant Important Very Important Important

What are the similarities, differences and relationships between physical, biological and sociocultural evolution?

Neither

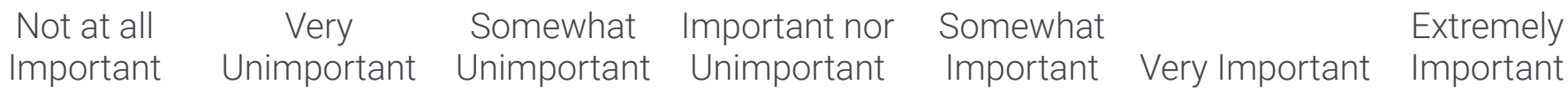


How can we develop CHANS theory?

Neither

Not at all

Very

Somewhat Important nor

Somewhat Unimportant Unimportant Unimportant

Important

Extremely

Importan
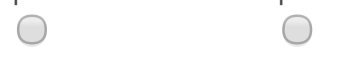

Very Important

Important

How do we understand context-dependency and place as a driving force?

Neither

Not at all

Very

Somewhat Important nor

Somewhat

Extremely

Important

Unimportant

Unimportant Unimportant

Important

Very Important

Important

What are the emergent properties in CHANS?

Neither

Not at all Very Somewhat Important nor Somewhat Extremely

Important Unimportant Unimportant Unimportant Important Very Important Important

What drives variability in CHANS and how does variability govern system behavior?

Neither

Not at all Very Somewhat Important nor Somewhat Extremely

Important Unimportant Unimportant Unimportant Important Very Important Important

How do feedbacks control CHANS?

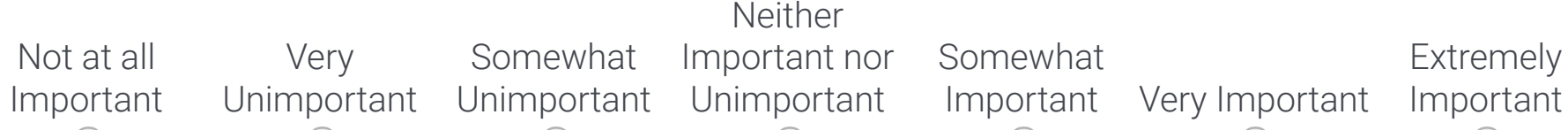

What are the feedbacks among sending, receiving, and spillover systems in the telecoupled world?

Neither

Not at all Very Somewhat Important nor Somewhat Extremely

Important Unimportant Unimportant Unimportant Important Very Important Important 
How do telecouplings shape socioeconomic and environmental sustainability across local to global levels?

Neither

Notat all Very Somewhat Important nor Somewhat Extremely Important Unimportant Unimportant Unimportant Important Very Important Important

How do global environmental changes affect the dynamics of regional and local coupled systems, and how do these feed back to higher level processes?

Neither

Notat all Very Somewhat Important nor Somewhat Extremely Important Unimportant Unimportant Unimportant Important Very Important Important

What are the key sets of internal system feedback connections, that are most likely to trigger system change, or be affected by external changes?

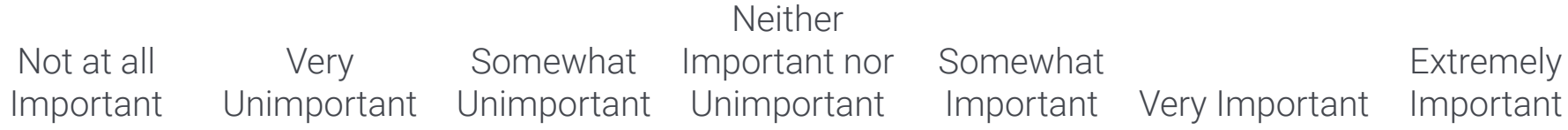

What are the linkages between evolving concepts of nature and the changing earthscape?

Neither

Not at all Very Somewhat Important nor Somewhat Extremely Important Unimportant Unimportant Unimportant Important Very Important Important

How do the self-organizing processes of CHANS recognize each other?

Neither

Not at all Very Somewhat Important nor Somewhat Extremely Important Unimportant Unimportant Unimportant Important Very Important Important

How do human interactions with an ecosystem circulate through ecological networks?

Neither

Notat all Very Somewhat Important nor Somewhat Extremely Important Unimportant Unimportant Unimportant Important Very Important Important 
Are CHANS dynamics lawful (i.e. universal)?

$\begin{array}{ccccc}\text { Not at all } & \text { Very } & \text { Somewhat } & \text { Neither } & \\ \text { Important nor } & \text { Somewhat } & \text { Extremely } \\ \text { Important } & \text { Unimportant } & \text { Unimportant } & \text { Unimportant } & \text { Important }\end{array}$

How can we use our knowledge of cities - the ultimate CHANS - to understand and manage other coupled systems?

Neither

Not at all Very Somewhat Important nor Somewhat Extremely Important Unimportant Unimportant Unimportant Important Very Important Important

How can we use our knowledge of 'natural' systems to understand cities?

Not at all Very Somewhat Important nor Somewhat Extremely Important Unimportant Unimportant Unimportant Important Very Important Important

What quantifiable impacts on natural systems do human activities have?

Not at all Very Somewhat Important nor Somewhat Extremely Important Unimportant Unimportant Unimportant Important Very Important Important

What are the linkages between globalization processes and CHANS?

\begin{tabular}{|c|c|c|c|c|c|}
\hline $\begin{array}{l}\text { Not at all } \\
\text { Important }\end{array}$ & $\begin{array}{c}\text { Very } \\
\text { Unimportant }\end{array}$ & $\begin{array}{l}\text { Somewhat } \\
\text { Unimportant }\end{array}$ & $\begin{array}{c}\text { Neither } \\
\text { Important nor } \\
\text { Unimportant }\end{array}$ & $\begin{array}{l}\text { Somewhat } \\
\text { Important }\end{array}$ & rtant \\
\hline
\end{tabular}

How do we better understand linkages between systems?

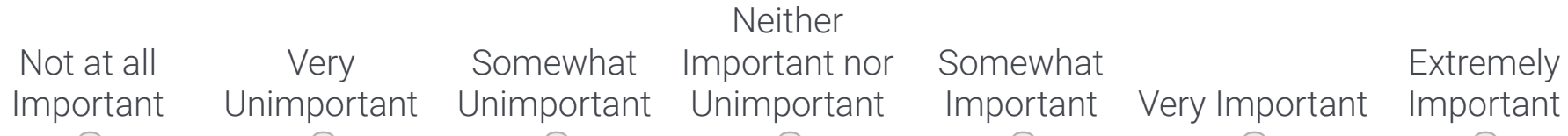


How can we effectively identify both the relevant human and nonhuman actors within systems?

Neither

Notat all Very Somewhat Important nor Somewhat Extremely Important Unimportant Unimportant Unimportant Important Very Important Important

How can we understand causation in complex coupled systems?

Neither

Not at all Very Somewhat Important nor Somewhat Extremely Important Unimportant Unimportant Unimportant Important Very Important Important

How should we manage the impacts of improved adapative capacity and ecological justice?

Notat all Very Somewhat Important nor Somewhat Extremely Important Unimportant Unimportant Unimportant Important Very Important Important

What pathways of governance can work with complexity, feedbacks, and adaptive managment?

\begin{tabular}{|c|c|c|c|c|c|}
\hline $\begin{array}{l}\text { Not at all } \\
\text { mportant }\end{array}$ & $\begin{array}{c}\text { Very } \\
\text { Unimportant }\end{array}$ & $\begin{array}{l}\text { Somewhat } \\
\text { Unimportant }\end{array}$ & $\begin{array}{c}\text { Neither } \\
\text { Important nor } \\
\text { Unimportant }\end{array}$ & $\begin{array}{l}\text { Somewhat } \\
\text { Important }\end{array}$ & Very Important \\
\hline
\end{tabular}

How can governance systems become resilient in the face of rapidly changing ecologicalsocial systems?

Neither

Not at all Very Somewhat Important nor Somewhat Extremely Important Unimportant Unimportant Unimportant Important Very Important Important

How can resource management practices better integrate ecological resiliency and anticipate disturbance?

Neither

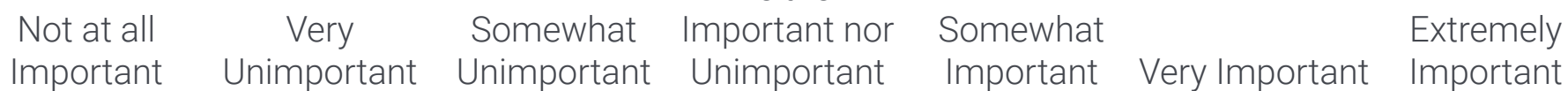


What institutional frameworks best facilitate adaptation to environmental change and resource scarcity?

Neither

Notatall Very Somewhat Important nor Somewhat Extremely Important Unimportant Unimportant Unimportant Important Very Important Important

How can social systems and natural life sciences be integrated to better inform each other to make wise use decisions?

Neither

Notat all Very Somewhat Important nor Somewhat Extremely Important Unimportant Unimportant Unimportant Important Very Important Important

How do we move beyond the case study in the governance of CHANS?

Not at all Very Somewhat Important nor Somewhat Extremely Important Unimportant Unimportant Unimportant Important Very Important Important

How do individual values and governance systems interact to produce outcomes?

Neither

Not at all Very Somewhat Important nor Somewhat Extremely Important Unimportant Unimportant Unimportant Important Very Important Important

What factors enable motivated people to govern CHANS effectively?

Neither

Not at all Very Somewhat Important nor Somewhat Extremely Important Unimportant Unimportant Unimportant Important Very Important Important

How can uncertainty be more effectively employed in understanding and managing coupled systems?

Not at all

Very Somewhat Neither Somewhat Very Important

Important Unimportant Unimportant Important nor Important

Extremely Important 
How do we best manage complex, multi-scaled, multi-objective CHANS?

Neither

Not at all Very Somewhat Important nor Somewhat Extremely Important Unimportant Unimportant Unimportant Important Very Important Important

How can we design natural resource management approaches that reflect and work with biophysical variability (in time \& space)?

Neither

Not at all Very Somewhat Important nor Somewhat Extremely Important Unimportant Unimportant Unimportant Important Very Important Important

What are the linkages between local and global governance of CHANS?

Not at all Very Somewhat Important nor Somewhat Extremely Important Unimportant Unimportant Unimportant Important Very Important Important

How can we anticipate system change in a very narrow management time frame?

\begin{tabular}{|c|c|c|c|c|c|}
\hline $\begin{array}{l}\text { Not at all } \\
\text { Important }\end{array}$ & $\begin{array}{c}\text { Very } \\
\text { Unimportant }\end{array}$ & $\begin{array}{l}\text { Somewhat } \\
\text { Unimportant }\end{array}$ & $\begin{array}{c}\text { Neither } \\
\text { Important nor } \\
\text { Unimportant }\end{array}$ & $\begin{array}{l}\text { Somewhat } \\
\text { Important }\end{array}$ & Very Important \\
\hline
\end{tabular}

How do we improve cooperation in the commons?

Neither

Notat all Very Somewhat Important nor Somewhat Extremely Important Unimportant Unimportant Unimportant Important Very Important Important

What are the mechanisms and circumstances that create the conditions appropriate for successful collective action?

Neither

\begin{tabular}{|c|c|c|c|c|c|}
\hline $\begin{array}{l}\text { Not at all } \\
\text { Important }\end{array}$ & $\begin{array}{c}\text { Very } \\
\text { Unimportant }\end{array}$ & $\begin{array}{l}\text { Somewhat } \\
\text { Unimportant }\end{array}$ & $\begin{array}{l}\text { Important nor } \\
\text { Unimportant }\end{array}$ & $\begin{array}{l}\text { Somewhat } \\
\text { Important }\end{array}$ & Very Important \\
\hline
\end{tabular}


What are the right policies for achieving optimal scale of economy relative to the natural systems?

Neither

Notatall Very Somewhat Important nor Somewhat Extremely Important Unimportant Unimportant Unimportant Important Very Important Important

How can CHANS feedbacks best be managed for both human needs and the good of the environment?

Not at all Very Somewhat Important nor Somewhat Extremely Important Unimportant Unimportant Unimportant Important Very Important Important

What is the most effective way to get managers and policy makers involved in coupled systems research?

\begin{tabular}{|c|c|c|c|c|c|}
\hline $\begin{array}{l}\text { Not at all } \\
\text { mportant }\end{array}$ & $\begin{array}{c}\text { Very } \\
\text { Unimportant }\end{array}$ & $\begin{array}{l}\text { Somewhat } \\
\text { Unimportant }\end{array}$ & $\begin{array}{c}\text { Neither } \\
\text { Important nor } \\
\text { Unimportant }\end{array}$ & $\begin{array}{l}\text { Somewhat } \\
\text { Important }\end{array}$ & Very Important \\
\hline
\end{tabular}

How do we truly incorporate iterative processes into our decision making process?

Neither

Not at all Very Somewhat Important nor Somewhat Extremely Important Unimportant Unimportant Unimportant Important Very Important Important

What are the interrelated and interacting human institutions that must be created (or altered) to identify and cope with different coupled system changes?

Neither

Not at all Very Somewhat Important nor Somewhat Extremely Important Unimportant Unimportant Unimportant Important Very Important Important

How do we transform (or retrofit) existing socio-political systems/institutions that serve as barriers to change? 
Neither

Not at all Very Somewhat Important nor Somewhat Extremely Important Unimportant Unimportant Unimportant Important Very Important Important

How should CHANS be situated in an institutional/political context?

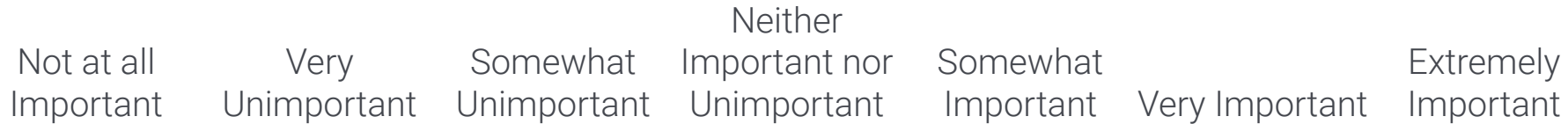

How do we use technological advances to manage and mitigate environmental change?

Neither

Not at all Very Somewhat Important nor Somewhat Extremely Important Unimportant Unimportant Unimportant Important Very Important Important

How can communities adaptively (and peacefully) manage common-pool, declining resources?

Neither

Notat all Very Somewhat Important nor Somewhat Extremely Important Unimportant Unimportant Unimportant Important Very Important Important

How can political constraints to sustainable management be overcome?

Neither

Notat all Very Somewhat Important nor Somewhat Extremely Important Unimportant Unimportant Unimportant Important Very Important Important

What are the points at which ceding decision making about highly technical matters to a professional elite break down?

Neither

Not at all Very Somewhat Important nor Somewhat Extremely Important Unimportant Unimportant Unimportant Important Very Important Important

What kinds of governance systems contribute to improved social and ecological outcomes?

Not at all Very Somewhat Neither Somewhat Very Important Extremely 
Important Unimportant Unimportant Important nor Important

Important Unimportant

How do we reform global governance (UN work) so that scientists and research carries the day?

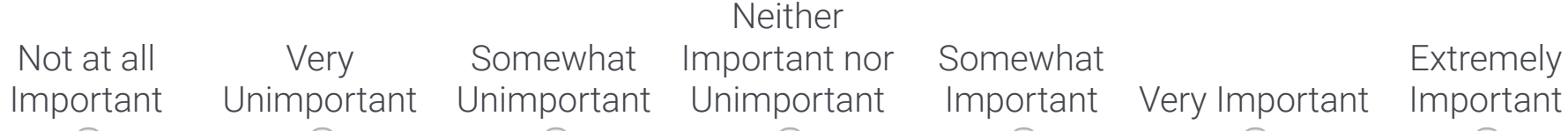

What types of science have a real influence on management?

\begin{tabular}{|c|c|c|c|c|c|}
\hline $\begin{array}{l}\text { Not at all } \\
\text { Important }\end{array}$ & $\begin{array}{c}\text { Very } \\
\text { Unimportant }\end{array}$ & $\begin{array}{l}\text { Somewhat } \\
\text { Unimportant }\end{array}$ & $\begin{array}{c}\text { Neither } \\
\text { Important nor } \\
\text { Unimportant }\end{array}$ & $\begin{array}{l}\text { Somewhat } \\
\text { Important }\end{array}$ & ortant \\
\hline
\end{tabular}

Are existing governance structures, policies and service delivery mechanisms effective in addressing marginal places and persons in urban areas, especially in developing economies?

Neither

Notatall Very Somewhat Important nor Somewhat Extremely Important Unimportant Unimportant Unimportant Important Very Important Important

How can management planners use basic science most effectively?

Neither

Not at all Very Somewhat Important nor Somewhat Extremely Important Unimportant Unimportant Unimportant Important Very Important Important

What is the role of bottom-up versus top-down policy in the management of CHANS?

Neither

Notatall Very Somewhat Important nor Somewhat Extremely Important Unimportant Unimportant Unimportant Important Very Important Important

Can can we better understand and manage the environmental impacts of the resource and waste streams through which people's needs and wants are met? 
Not at all Very Somewhat Neither Somewhat Very Important Extremely Important Unimportant Unimportant Important nor Important Important Unimportant

Can the public trust doctrine offer a framework for delivering better social and ecological outcomes?

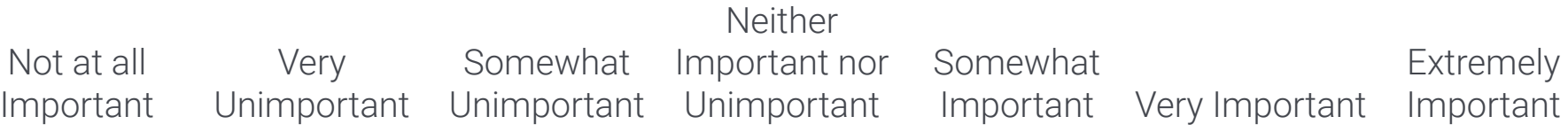

What policies improve management of CHANS?

Neither

Not at all Very Somewhat Important nor Somewhat Extremely Important Unimportant Unimportant Unimportant Important Very Important Important

Is governance up to the task of managing global change?

Neither

Not at all Very Somewhat Important nor Somewhat Extremely Important Unimportant Unimportant Unimportant Important Very Important Important

How do we ensure regulations are flexible and practical but ensure environmental safety?

Neither

Not at all Very Somewhat Important nor Somewhat Extremely Important Unimportant Unimportant Unimportant Important Very Important Important

How do policies influence human-nature interactions?

Neither

Not at all Very Somewhat Important nor Somewhat Extremely Important Unimportant Unimportant Unimportant Important Very Important Important

How can we design decision-making structures to bring together groups with disparate objectives?

Not at all Very Somewhat Neither Somewhat Very Important Extremely 
Important Unimportant Unimportant Important nor Important

Important

Unimportant

How do we find more resources for research and management?

Not at all Very Somewhat Important nor Somewhat Extremely Important Unimportant Unimportant Unimportant Important Very Important Important

How can non-traditional ontologies and epistemologies be used to understand and manage CHANS?

\begin{tabular}{|c|c|c|c|c|c|}
\hline $\begin{array}{l}\text { Not at all } \\
\text { Important }\end{array}$ & $\begin{array}{c}\text { Very } \\
\text { Unimportant }\end{array}$ & $\begin{array}{l}\text { Somewhat } \\
\text { Unimportant }\end{array}$ & $\begin{array}{c}\text { Neither } \\
\text { Important nor } \\
\text { Unimportant }\end{array}$ & $\begin{array}{l}\text { Somewhat } \\
\text { Important }\end{array}$ & erv Important \\
\hline
\end{tabular}

How can we control climate change with demands of increasing food production and increasing energy use?

Neither

Notatall Very Somewhat Important nor Somewhat Extremely Important Unimportant Unimportant Unimportant Important Very Important Important

How will climate \& other global environmental changes (e.g., water availability) affect agricultural systems in different areas of the world?

Neither

Not at all Very Somewhat Important nor Somewhat Extremely Important Unimportant Unimportant Unimportant Important Very Important Important

How will ongoing and future climate change affect the agriculture sector?

Neither

Not at all Very Somewhat Important nor Somewhat Extremely Important Unimportant Unimportant Unimportant Important Very Important Important

What is the impact of human-induced land cover change on climate? 
Not at all Very Somewhat Neither Somewhat Very Important Extremely Important Unimportant Unimportant Important nor Important Important Unimportant

How can forest disappearance due to the expansion of industrial agriculture and urbanization be stopped?

$\begin{array}{ccccc}\text { Not at all } & \text { Very } & \text { Somewhat } & \text { Neither } & \\ \text { Important nor } & \text { Somewhat } & \text { Extremely } \\ \text { Important } & \text { Unimportant } & \text { Unimportant } & \text { Unimportant } & \text { Important }\end{array}$

How can we link landscape ecology and life cycle assessment to promote sustainable landscapes?

Neither

Not at all Very Somewhat Important nor Somewhat Extremely Important Unimportant Unimportant Unimportant Important Very Important Important

How does the spatial configuration of land uses contribute to ecosystem services and sustainability?

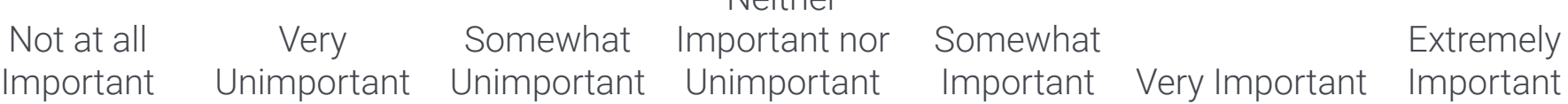

Do network-based hydrologic CHANS behave in fundamentally different ways from patchworkbased terrestrial CHANS?

Not at all Very Somewhat Important nor Somewhat Extremely Important Unimportant Unimportant Unimportant Important Very Important Important

Which modeling tools are suitable for understanding and forecasting land use change in developing regions, and at what scales?

Neither

Not at all Very Somewhat Important nor Somewhat Extremely Important Unimportant Unimportant Unimportant Important Very Important Important 
How is the global economy affecting land-use change at regional and finer scales, and how does this impact natural systems?

Neither

Notat all Very Somewhat Important nor Somewhat Extremely Important Unimportant Unimportant Unimportant Important Very Important Important

Under what scenarios will drivers of urbanization and land use change promote sustainable city development?

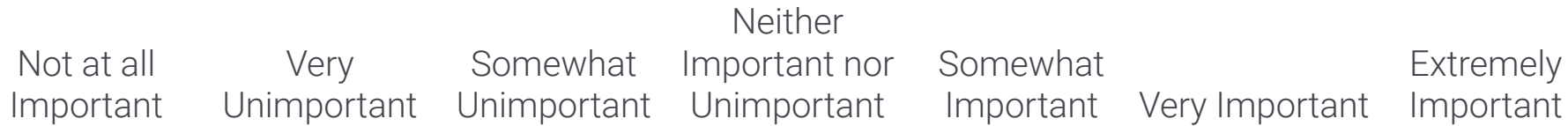

What effects will changing agricultural trends have on modern human diet and/or nutrition?

Not at all Very Somewhat Important nor Somewhat Extremely Important Unimportant Unimportant Unimportant Important Very Important Important

Are GMOs safe for the environment and can GMOs be contained to minimize ecological impact?

\begin{tabular}{|c|c|c|c|c|c|}
\hline Not at all & $\begin{array}{c}\text { Very } \\
\text { Unimportant }\end{array}$ & $\begin{array}{l}\text { Somewhat } \\
\text { Unimportant }\end{array}$ & $\begin{array}{c}\text { Neither } \\
\text { Important nor } \\
\text { Unimportant }\end{array}$ & Somewhat & erv Important \\
\hline
\end{tabular}

What are the environmental and social impacts and underpinnings of a sustainable and just food system?

Neither

Not at all Very Somewhat Important nor Somewhat Extremely Important Unimportant Unimportant Unimportant Important Very Important Important

What are some economical and social factors that prevent sustainable agriculture and permaculture from succeeding?

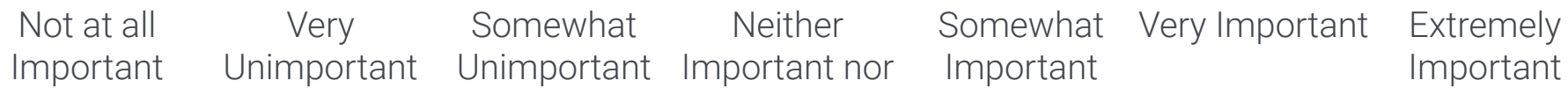


How sustainable are our current industrial food systems?

Neither

Not at all Very Somewhat Important nor Somewhat Extremely Important Unimportant Unimportant Unimportant Important Very Important Important

How do land use and land cover change influence household and/or community vulnerability and vice versa, especially in marginal environments?

Neither

Not at all Very Somewhat Important nor Somewhat Extremely Important Unimportant Unimportant Unimportant Important Very Important Important

What characterizes sustainable land use systems and how can we transition to such systems?

Not at all Very Somewhat Important nor Somewhat Extremely Important Unimportant Unimportant Unimportant Important Very Important Important

What are ecological and socio-political consequences of land cover change?

Neither

Not at all Very Somewhat Important nor Somewhat Extremely Important Unimportant Unimportant Unimportant Important Very Important Important

Under what sorts of circumstances does land sharing as opposed to land sparing occur?

Neither

Not at all Very Somewhat Important nor Somewhat Extremely Important Unimportant Unimportant Unimportant Important Very Important Important

How do human activities alter ecological landscape processes?

Neither

Notat all Very Somewhat Important nor Somewhat Extremely Important Unimportant Unimportant Unimportant Important Very Important Important 
What urbanization strategies best promote sustainable urban landscapes?

Neither

Not at all Very Somewhat Important nor Somewhat Extremely Important Unimportant Unimportant Unimportant Important Very Important Important

How do we integrate efficient high population density communities within an urban sprawl framework?

Neither

Not at all Very Somewhat Important nor Somewhat Extremely Important Unimportant Unimportant Unimportant Important Very Important Important

How do we measure resilience in CHANS, and how do we develop predictive models of resilience?

Not at all Very Somewhat Important nor Somewhat Extremely Important Unimportant Unimportant Unimportant Important Very Important Important

How can we incorporate behavior, tipping points, emergent properties and regime shifts especially for ecosystem function and social organizations in CHANS models?

\begin{tabular}{|c|c|c|c|c|}
\hline & & & & \\
\hline & $\begin{array}{c}\text { Very } \\
\text { Unimportant }\end{array}$ & $\begin{array}{l}\text { Somewhat } \\
\text { Unimportant }\end{array}$ & $\begin{array}{l}\text { Important nor } \\
\text { Unimportant }\end{array}$ & $\begin{array}{l}\text { Somewh } \\
\text { Importar }\end{array}$ \\
\hline
\end{tabular}

How can we systematically consider the tradeoffs between decisions across coupled and human and natural systems?

Neither

Not at all Very Somewhat Important nor Somewhat Extremely Important Unimportant Unimportant Unimportant Important Very Important Important

How can the existing knowledge of human behavior within multiple social science disciplines serve in answering whether lab or field based models can help us better understand as well as 
predict how human decisions influence physical systems and vice versa?

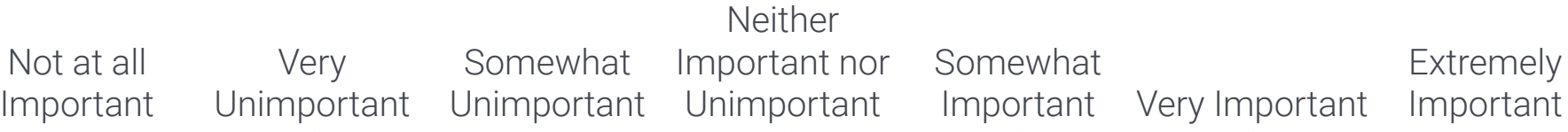

What role should citizen stakeholders play in CHANS research?

Not at all Very Somewhat Important nor Somewhat Extremely Important Unimportant Unimportant Unimportant Important Very Important Important

How can we effectively treat technological-infrastructural systems within a CHANS framework?

How can recent innovations in data science (i.e. storage, access, processing power) be used to understand CHANS?

Neither

Not at all Very Somewhat Important nor Somewhat Extremely Important Unimportant Unimportant Unimportant Important Very Important Important

To what extent should resarch design and management be different to best address CHANS issues?

Neither

Not at all Very Somewhat Important nor Somewhat Extremely Important Unimportant Unimportant Unimportant Important Very Important Important

How can we best model complex, multi-scale, multi-actor CHANS?

Neither

Not at all Very Somewhat Important nor Somewhat Extremely Important Unimportant Unimportant Unimportant Important Very Important Important 
What are the costs and benefits of channeling human and fiscal resources to coupled systems research vs fundamental disciplinary research?

Neither

Not at all Very Somewhat Important nor Somewhat Extremely Important Unimportant Unimportant Unimportant Important Very Important Important

Can we generate political ecology/economy methods that incorporate history, assymetrical power, and access?

Neither

Not at all Very Somewhat Important nor Somewhat Extremely Important Unimportant Unimportant Unimportant Important Very Important Important

How best can various disciplines be integrated for effective research on CHANS?

Neither

Not at all Very Somewhat Important nor Somewhat Extremely Important Unimportant Unimportant Unimportant Important Very Important Important

How do we effectively link mechanistic and agent-based models in simulating CHANS?

Notat all Very Somewhat Important nor Somewhat Extremely Important Unimportant Unimportant Unimportant Important Very Important Important

How do we create a translational research framework for managing human ecosystems?

Neither

Not at all Very Somewhat Important nor Somewhat Extremely Important Unimportant Unimportant Unimportant Important Very Important Important

What are the best methods for the study of CHANS?

Neither

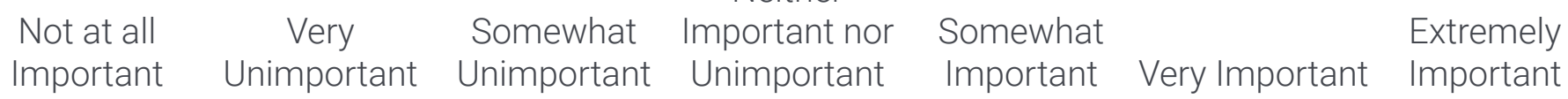


How do scientists best integrate data, methods, and epistomologies from different discipines to best understand CHANS?

Neither

Not at all Very Somewhat Important nor Somewhat Extremely Important Unimportant Unimportant Unimportant Important Very Important Important

How do we recognize teleconnections and represent them in CHANS models?

Neither

Not at all Very Somewhat Important nor Somewhat Extremely Important Unimportant Unimportant Unimportant Important Very Important Important

How do we evaluate models of environmental change in a no-analogue earth system state?

Not at all Very Somewhat Important nor Somewhat Extremely Important Unimportant Unimportant Unimportant Important Very Important Important

How do we measure externalities and interactions in CHANS?

Not at all Very Somewhat Important nor Somewhat Extremely Important Unimportant Unimportant Unimportant Important Very Important Important

How can we effectively leverage rich place-based studies and "big data" to create more comprehensive knowledge?

$\begin{array}{ccccc}\text { Not at all } & \text { Very } & \text { Somewhat } & \text { Neither } & \\ \text { Important nor } & \text { Somewhat } & \text { Extremely } \\ \text { Important } & \text { Unimportant } & \text { Unimportant } & \text { Unimportant } & \text { Important }\end{array}$

How can we better represent social systems and processes in CHANS models?

Neither

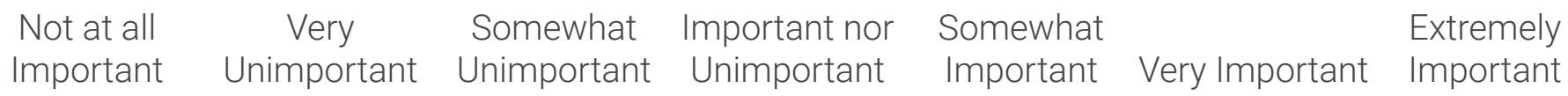


Neither

Not at all Very Somewhat Important nor Somewhat Extremely Important Unimportant Unimportant Unimportant Important Very Important Important

How can we design socio-ecological research that is relevant to the social communities affected by ecosystem processes?

Not at all Very Somewhat Important nor Somewhat Extremely Important Unimportant Unimportant Unimportant Important Very Important Important

What new data sets should we be building to improve our modeling of human-natural system dynamics?

Neither

Not at all Very Somewhat Important nor Somewhat Extremely Important Unimportant Unimportant Unimportant Important Very Important Important

How can issues of accelerating uncertainty for future projections from coupled human-natural systems be modelled?

Neither

Notatall Very Somewhat Important nor Somewhat Extremely Important Unimportant Unimportant Unimportant Important Very Important Important

How do researchers evalute the data needs of a CHANS approach in inquiry?

Neither

Not at all Very Somewhat Important nor Somewhat Extremely Important Unimportant Unimportant Unimportant Important Very Important Important

How can analysis of currently employed measures of human-environment interactions be effectively used, or improved, to improve observations of change?

Neither

Not at all Very Somewhat Important nor Somewhat Extremely Important Unimportant Unimportant Unimportant Important Very Important Important 
Can researchers integrate models for a Global System Science that serves to both design and create technology for biological and socio-technical systems?

Neither

Not at all Very Somewhat Important nor Somewhat Extremely Important Unimportant Unimportant Unimportant Important Very Important Important

How can we ensure that inter-disciplinary projects that include non-academic stakeholders become the norm rather than the exception (especially in sustainability science)?

Not at all Very Somewhat Important nor Somewhat Extremely Important Unimportant Unimportant Unimportant Important Very Important Important

What are the tradeoffs between resolution, model fidelity, scale, and tightness of coupling?

Not at all Very Somewhat Important nor Somewhat Extremely Important Unimportant Unimportant Unimportant Important Very Important Important

How is decision makiing coupled across scales?

\begin{tabular}{|c|c|c|c|c|c|}
\hline $\begin{array}{l}\text { Not at all } \\
\text { Important }\end{array}$ & $\begin{array}{c}\text { Very } \\
\text { Unimportant }\end{array}$ & $\begin{array}{l}\text { Somewhat } \\
\text { Unimportant }\end{array}$ & $\begin{array}{c}\text { Neither } \\
\text { Important nor } \\
\text { Unimportant }\end{array}$ & $\begin{array}{l}\text { Somewhat } \\
\text { Important }\end{array}$ & rtant \\
\hline
\end{tabular}

How do we account for and understand the role of legacy and cummulative effects in CHANS?

Neither

Not at all Very Somewhat Important nor Somewhat Extremely Important Unimportant Unimportant Unimportant Important Very Important Important

How do we quantify the spatio-temporal interactions among human and natural systems?

Neither

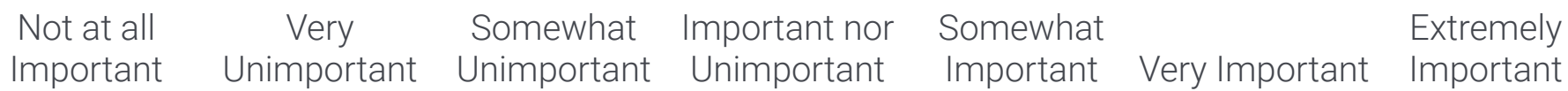


How do we account for spatial autocorrelation and distance relationships in these systems?

Neither

Not at all Very Somewhat Important nor Somewhat Extremely Important Unimportant Unimportant Unimportant Important Very Important Important

How do CHANS researchers determine the most appropriate system boundaries for CHANS for effective research and management?

Neither

Not at all Very Somewhat Important nor Somewhat Extremely Important Unimportant Unimportant Unimportant Important Very Important Important

What is the best way to sample annual systems with long-term studies?

Not at all Very Somewhat Important nor Somewhat Extremely Important Unimportant Unimportant Unimportant Important Very Important Important

What is the scale at which humans are most capable of sustainable interaction with the natural world?

Not at all Very Somewhat Important nor Somewhat Extremely Important Unimportant Unimportant Unimportant Important Very Important Important

How can researchers improve assessment strategies at appropriate time and space scales?

Neither

Notat all Very Somewhat Important nor Somewhat Extremely Important Unimportant Unimportant Unimportant Important Very Important Important

What is the most appropriate scale at which to study CHANS?

Neither

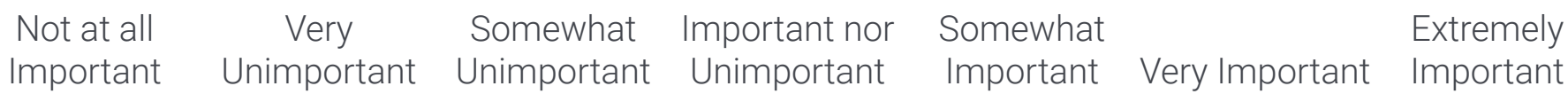


How can scientists best integrate data, methods, and research designs across multiple spatial and temporal scales?

Neither

Not at all Very Somewhat Important nor Somewhat Extremely Important Unimportant Unimportant Unimportant Important Very Important Important

What is the role of spatial scale in understanding the coupling between natural and human systems?

\section{Neither}

Not at all Very Somewhat Important nor Somewhat Extremely Important Unimportant Unimportant Unimportant Important Very Important Important

How do CHANS dynamics and feedbacks vary across spatial and temporal scales?

Neither

Not at all Very Somewhat Important nor Somewhat Extremely Important Unimportant Unimportant Unimportant Important Very Important Important

To what extent is our understanding of hierarchies in CHANS an accurate reflection of what is occuring, and what are alternate explanations?

Neither

Not at all Very Somewhat Important nor Somewhat Extremely Important Unimportant Unimportant Unimportant Important Very Important Important

How do we scale up smaller-scale analyses of managed processes in the enviroment to reflect policy and governance?

Neither

Not at all Very Somewhat Important nor Somewhat Extremely Important Unimportant Unimportant Unimportant Important Very Important Important

How do local biophysical changes from human interventions influence regional and global biophysical processes - especially with respect to water?

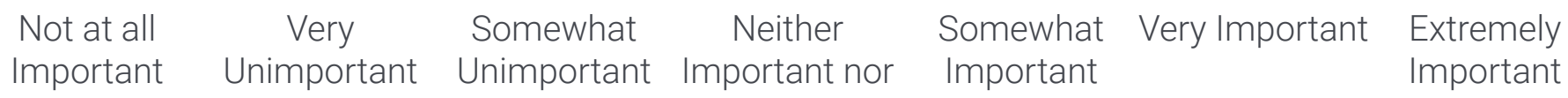


What is the role of technology and human adaptation in managing CHANS systems?

Neither

Not at all Very Somewhat Important nor Somewhat Extremely Important Unimportant Unimportant Unimportant Important Very Important Important

How does culture motivate or demotivate humans in protecting their natural environments?

Not at all Very Somewhat Important nor Somewhat Extremely Important Unimportant Unimportant Unimportant Important Very Important Important

What are the social drivers at multiple scales of coupled complex systems?

Neither

Not at all Very Somewhat Important nor Somewhat Extremely Important Unimportant Unimportant Unimportant Important Very Important Important

How do human social networks affect the way humans interact with ecological systems?

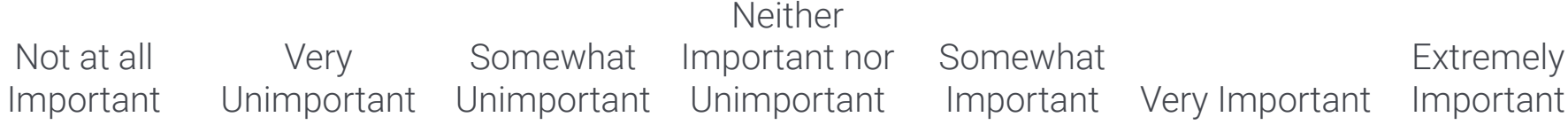

How can knowledge of CHANS be co-produced among various stakeholders for learning and action?

Neither

Notat all Very Somewhat Important nor Somewhat Extremely Important Unimportant Unimportant Unimportant Important Very Important Important

What is the role of ideology in understanding system change?

Neither

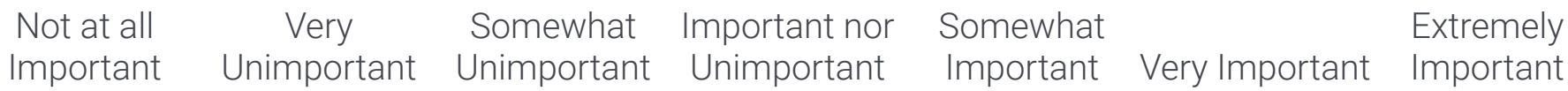


What are the constants in socio-ecological perception and values across race, culture, and economic status?

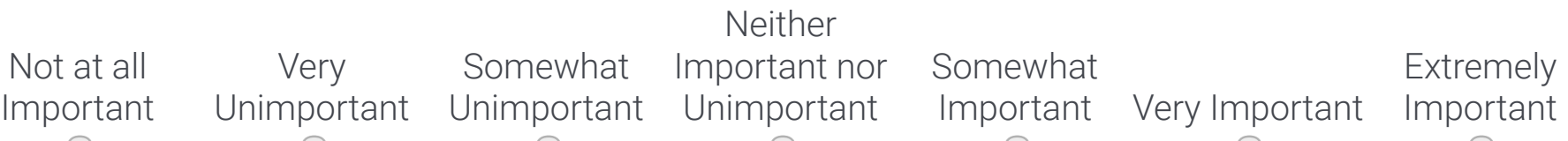

How are the clear facts of coupled human and natural systems obscured in policy, in management, and in Western cultural orientations?

Neither

Not at all Very Somewhat Important nor Somewhat Extremely Important Unimportant Unimportant Unimportant Important Very Important Important

How does scientific information--e.g., predictions, risk assessments, response plans, or scientific study in general--influence people, organizations, and societies in their approach to coupled or potentially coupled systems?

\begin{tabular}{|c|c|c|c|c|c|}
\hline $\begin{array}{l}\text { Not at all } \\
\text { Important }\end{array}$ & $\begin{array}{c}\text { Very } \\
\text { Unimportant }\end{array}$ & $\begin{array}{l}\text { Somewhat } \\
\text { Unimportant }\end{array}$ & $\begin{array}{c}\text { Neither } \\
\text { Important nor } \\
\text { Unimportant }\end{array}$ & $\begin{array}{l}\text { Somewhat } \\
\text { Important }\end{array}$ & Very Important \\
\hline
\end{tabular}

How can we reintegrate humans into our conceptualization and management of 'natural' systems?

Neither

Not at all Very Somewhat Important nor Somewhat Extremely Important Unimportant Unimportant Unimportant Important Very Important Important

How can connections to nature of a global urbanizing population be strengthened?

Neither

Notat all Very Somewhat Important nor Somewhat Extremely Important Unimportant Unimportant Unimportant Important Very Important Important

How can cultures be transformed into more sustainable social systems?

Not at all Very Somewhat Neither Somewhat Very Important Extremely 
Important Unimportant Unimportant Important nor Important

Important Unimportant

How do different socio-cultural contexts affect CHANS research itself, for example, when CHANS research is applied internationally?

Not at alt Nery

Not at all Very Somewhat Important nor Somewhat Extremely Important Unimportant Unimportant Unimportant Important Very Important Important

How do we integrate humans in the natural world rather than treat them as 'coupled'?

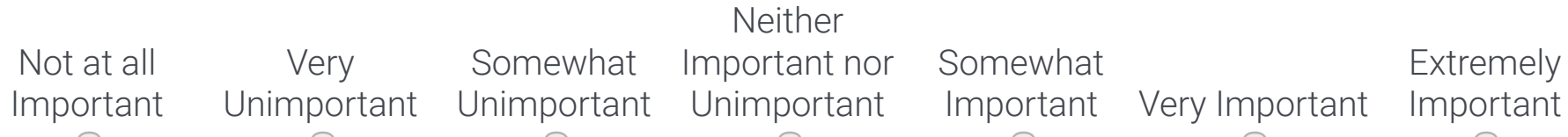

What areas of human systems have the greatest potential for mitigation of human impacts on natural systems?

Neither

Not at all Very Somewhat Important nor Somewhat Extremely Important Unimportant Unimportant Unimportant Important Very Important Important

What are the linkages between human population and natural systems?

Neither

Notatall Very Somewhat Important nor Somewhat Extremely Important Unimportant Unimportant Unimportant Important Very Important Important

How and when do humans feel connected to natural systems?

Neither

Notat all Very Somewhat Important nor Somewhat Extremely Important Unimportant Unimportant Unimportant Important Very Important Important

How have human relationships with nature changed over time and how will they change in the future? 
Not at all Very Somewhat Neither Somewhat Very Important Extremely Important Unimportant Unimportant Important nor Important Important Unimportant

How do power dynamics and differentials within social systems affect CHANS dynamics?

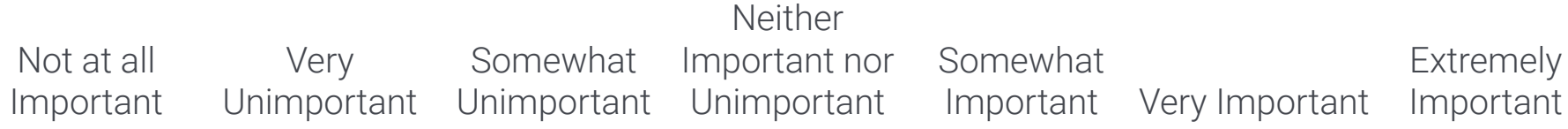

How will human per capita population growth rates change and what will be the spatial distribution of that change?

Neither

Not at all Very Somewhat Important nor Somewhat Extremely Important Unimportant Unimportant Unimportant Important Very Important Important

How has culture been integrated to improve community based natural resource management?

Neither

Not at all Very Somewhat Important nor Somewhat Extremely Important Unimportant Unimportant Unimportant Important Very Important Important

How do we break through and begin discussing the role of hard/uncomfortable issues in coupled processes (e.g., privilege, racism, etc.)?

Neither

Not at all Very Somewhat Important nor Somewhat Extremely Important Unimportant Unimportant Unimportant Important Very Important Important

How can we empower community-based decisions that satisfy as many stakeholders as possible?

Neither

Not at all Very Somewhat Important nor Somewhat Extremely Important Unimportant Unimportant Unimportant Important Very Important Important

What is the relationship between settlement type and ecosystem type? 
Neither

Not at all Very Somewhat Important nor Somewhat Extremely Important Unimportant Unimportant Unimportant Important Very Important Important

How do social and cultural factors affect the management of CHANS?

Neither

Not at all Very Somewhat Important nor Somewhat Extremely Important Unimportant Unimportant Unimportant Important Very Important Important

How is environmental change affecting people's capacity and prospects for survival?

Neither

Not at all Very Somewhat Important nor Somewhat Extremely Important Unimportant Unimportant Unimportant Important Very Important Important

How will human consumption patterns change in the coming decades?

Neither

Not at all Very Somewhat Important nor Somewhat Extremely Important Unimportant Unimportant Unimportant Important Very Important Important

What are appropriate and effective methods to bring stakeholders together to address environmental issues?

Not at all Very Somewhat Important nor Somewhat Extremely Important Unimportant Unimportant Unimportant Important Very Important Important

How do different types of ownership of resources (public, private, commons, nullius) affect the viability of CHANS?

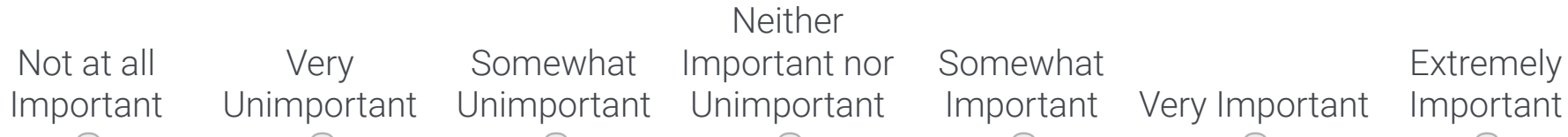

How does social organization mediate human interaction with the environment, i.e., amplify or attenuate perceptions of risk associated with environmental change? 


\section{Not at all Neither}

Not at all Very Somewhat Important nor Somewhat Extremely Important Unimportant Unimportant Unimportant Important Very Important Important

What are the perceptions of landholders/land managers of environmental issues and how do those compare to public perceptions and scientific knowledge?

$\begin{array}{ccccc}\text { Not at all } & \text { Very } & \text { Somewhat } & \text { Neither } & \\ \text { Important nor } & \text { Somewhat } & \text { Extremely } \\ \text { Important } & \text { Unimportant } & \text { Unimportant } & \text { Unimportant } & \text { Important }\end{array}$

What are the relationships between cultural values, management and natural systems?

$\begin{array}{ccccc}\text { Not at all } & \text { Very } & \text { Somewhat } & \text { Neither } & \\ \text { Important nor } & \text { Somewhat } & \text { Extremely } \\ \text { Important } & \text { Unimportant } & \text { Unimportant } & \text { Unimportant } & \text { Important }\end{array}$

What are the relationships among environment, population dynamics, settlement structure, and human mobility?

\begin{tabular}{|c|c|c|c|c|c|c|}
\hline & & & (5) & & & \\
\hline $\begin{array}{l}\text { Not at all } \\
\text { Important }\end{array}$ & $\begin{array}{c}\text { Very } \\
\text { Unimportant }\end{array}$ & $\begin{array}{c}\text { Somewhat } \\
\text { Unimportant }\end{array}$ & $\begin{array}{l}\text { Important nor } \\
\text { Unimportant }\end{array}$ & $\begin{array}{l}\text { Somewhat } \\
\text { Important }\end{array}$ & Very Important & $\begin{array}{l}\text { Extremely } \\
\text { Important }\end{array}$ \\
\hline
\end{tabular}

How will human population patterns change with ongoing changes in availability of water?

Neither

Not at all Very Somewhat Important nor Somewhat Extremely Important Unimportant Unimportant Unimportant Important Very Important Important

How do certain political and social development decisions impact natural systems?

Neither

Not at all Very Somewhat Important nor Somewhat Extremely Important Unimportant Unimportant Unimportant Important Very Important Important

If both people and the environment should be considered in development, how can we strike the balance? 
Neither

Not at all Very Somewhat Important nor Somewhat Extremely Important Unimportant Unimportant Unimportant Important Very Important Important

What attitudes, dispositions, and knowledge are needed to further the transition to a just sustainability?

Neither

Not at all Very Somewhat Important nor Somewhat Extremely Important Unimportant Unimportant Unimportant Important Very Important Important

What are the linkages between inequality and CHANS processes?

Neither

Not at all Very Somewhat Important nor Somewhat Extremely Important Unimportant Unimportant Unimportant Important Very Important Important

Why and how do social inequalities emerge, grow, persist, and diminish, and with what consequences?

Not at all Very Somewhat Important nor Somewhat Extremely Important Unimportant Unimportant Unimportant Important Very Important Important

What factors predispose CHANS to be more or less sustainable, both in absolute and in relative terms?

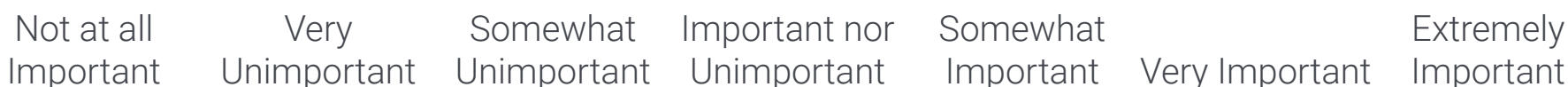

What is the extent of the existence of a resources curse in areas with abundant natural resources but high rates of poverty?

Neither

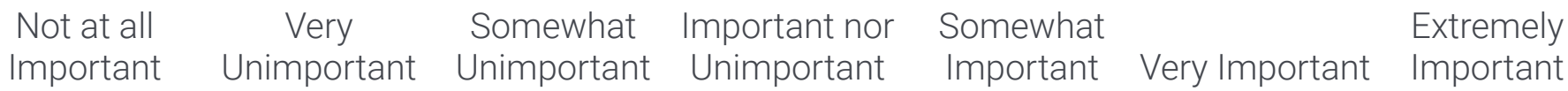


What is the relationship between poverty, livelihoods and environmental degradation?

Neither

Not at all Very Somewhat Important nor Somewhat Extremely Important Unimportant Unimportant Unimportant Important Very Important Important

How does society improve medium and long term co-viability of ecological and social processes in CHANS?

Neither

Not at all Very Somewhat Important nor Somewhat Extremely Important Unimportant Unimportant Unimportant Important Very Important Important

How can the monetary system and the economy be transformed, so that they don't require growth to avoid collapse, and don't continually concentrate wealth and power in few hands?

Not at all Very Somewhat Important nor Somewhat Extremely Important Unimportant Unimportant Unimportant Important Very Important Important

How do we achieve a steady state economy?

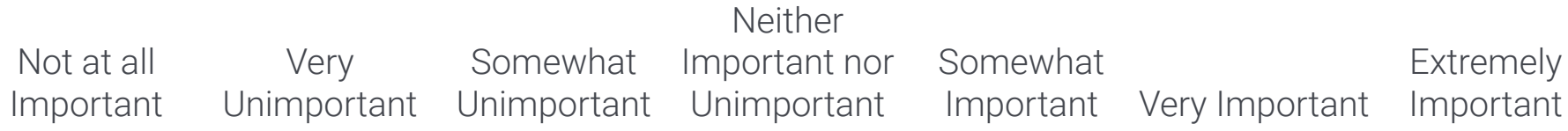

How can we rescue natural systems in socially depressed areas of big cities in Latin America as a tool for human development?

Neither

Not at all Very Somewhat Important nor Somewhat Extremely Important Unimportant Unimportant Unimportant Important Very Important Important

What other global environmental change besides climate change pose threats to sustainability?

Neither

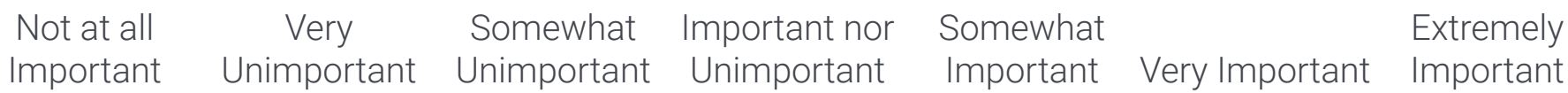


How are sustainability and peace linked? Can conservation and other sustainability efforts, as well as CHANS research help promote peace or conflict resolution?

Neither

Not at all Very Somewhat Important nor Somewhat Extremely Important Unimportant Unimportant Unimportant Important Very Important Important

Under what livelihood and environmental conditions do we see an alleviation of poverty?

Not at all Very Somewhat Important nor Somewhat Extremely Important Unimportant Unimportant Unimportant Important Very Important Important

How can the interests of people and the environment be balanced in development, particularly in developing countries which still require a lot of natural resources?

Neither

Not at all Very Somewhat Important nor Somewhat Extremely Important Unimportant Unimportant Unimportant Important Very Important Important

How do we rebuild the connection between humanity and the natural environment in order to foster a protective attitude towards sustainability?

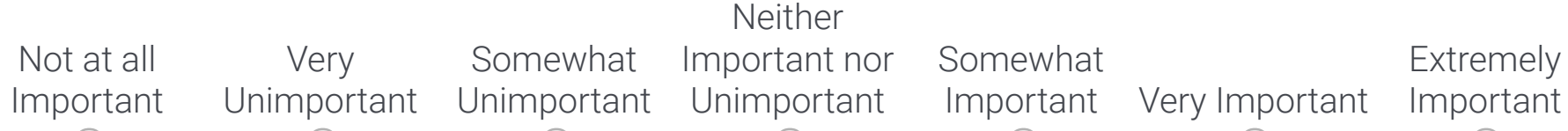

What alternative pathways of development are available that have a lesser impact on ecosystems and the biosphere?

Neither

Not at all Very Somewhat Important nor Somewhat Extremely Important Unimportant Unimportant Unimportant Important Very Important Important

What is the appropriate balance between economic development and environmental protection? 
Neither

Not at all Very Somewhat Important nor Somewhat Extremely Important Unimportant Unimportant Unimportant Important Very Important Important

How can we transform the human dimension to be more aware of its integration and dependence on natural systems?

$\begin{array}{ccccc}\text { Not at all } & \text { Very } & \text { Somewhat } & \text { Neither } & \\ \text { Important nor } & \text { Somewhat } & \text { Extremely } \\ \text { Important } & \text { Unimportant } & \text { Unimportant } & \text { Unimportant } & \text { Important }\end{array}$

Is a good life predicated on negative environmental footprints?

Neither

Not at all Very Somewhat Important nor Somewhat Extremely Important Unimportant Unimportant Unimportant Important Very Important Important

What are the social and economic challenges to moving forward to a low impact path of development?

Neither

Not at all Very Somewhat Important nor Somewhat Extremely Important Unimportant Unimportant Unimportant Important Very Important Important

How do we couple environmental sustainability with social and economic sustainability?

Not at all Very Somewhat Important nor Somewhat Extremely Important Unimportant Unimportant Unimportant Important Very Important Important

\section{Respondent Information}

Have you ever been a Principal Investigator (PI) or co-Principal Investigator (co-PI) on an NSF Coupled Natural and Human Systems (CNHS) grant?

\section{Yes}

No 
Decline to Respond

Page 3 of 4

On how many NSF CNHS grants have you been a PI or co-PI? (enter number)

What is your primary occupational sector?

Academic

Government

Non-Profit

Private

Decline to Respond

Other (please specify)

Do you consider your work to be strongly inter- or multi-disciplinary (i.e. integration of at least one natural science and one social science discipline)?
Yes
No
Decline to Repond

Based on the following categories from NSF-supported disciplines, which of the following do you consider your primary field?

Chemistry

Computer and Information Science

Engineering

Geosciences

Mathematical Sciences 
Physics

Psychology

Social Sciences

Life Sciences

In what year were you born?

What is your gender identity?

Male

$\bigcirc$ Female

Decline to Respond

What country do you consider your primary nationality?

\section{$\boldsymbol{\nabla}$}

In which country are you primarily employed? 
MICHIGAN STATE

U N I V E R S I T Y

May 13, 2013

To: $\quad$ Daniel Kramer 370 N. Case Hall

East Lansing, Michigan 48825

Re: $\quad$ IRB\# x13-433e Category: Exempt 1.2

Approval Date: May 13, 2013

Title: $\quad$ Future Directions of Coupled Human and Natural Systems Research

The Institutional Review Board has completed their review of your project. I am pleased to advise you that your project has been deemed as exempt in accordance with federal regulations.

The IRB has found that your research project meets the criteria for exempt status and the criteria for the protection of human subjects in exempt research. Under our exempt policy the Principal Investigator assumes the responsibilities for the protection of human subjects in this project as outlined in the assurance letter and exempt educational material. The IRB office has received your signed assurance for exempt research. A copy of this signed agreement is appended for your information and records.

Renewals: Exempt protocols do not need to be renewed. If the project is completed, please submit an Application for Permanent Closure.

Revisions: Exempt protocols do not require revisions. However, if changes are made to a protocol that may no longer meet the exempt criteria, a new initial application will be required.

Problems: If issues should arise during the conduct of the research, such as unanticipated problems, adverse events, or any problem that may increase the risk to the human subjects and change the category of review, notify the IRB office promptly. Any complaints from participants regarding the risk and benefits of the project must be reported to the IRB.

Follow-up: If your exempt project is not completed and closed after three years, the IRB office will contact you regarding the status of the project and to verify that no changes have occurred that may affect exempt status.

Please use the IRB number listed above on any forms submitted which relate to this project, or on any correspondence with the IRB office.

Good luck in your research. If we can be of further assistance, please contact us at 517-355-2180 or via email at IRB@msu.edu. Thank you for your cooperation.

Sincerely,<smiles>CC1CC1C=C1CC1</smiles>

Harry McGee, MPH

SIRB Chair 